\title{
Hemodynamic and hemostatic effects of erythropoietin therapy
}

Citation for published version (APA):

Wirtz, J. J. J. M. (1993). Hemodynamic and hemostatic effects of erythropoietin therapy. [Doctoral Thesis, Maastricht University]. Datawyse / Universitaire Pers Maastricht. https://doi.org/10.26481/dis.19931126jw

Document status and date:

Published: 01/01/1993

DOI:

10.26481/dis.19931126jw

Document Version:

Publisher's PDF, also known as Version of record

\section{Please check the document version of this publication:}

- A submitted manuscript is the version of the article upon submission and before peer-review. There can be important differences between the submitted version and the official published version of record.

People interested in the research are advised to contact the author for the final version of the publication, or visit the DOI to the publisher's website.

- The final author version and the galley proof are versions of the publication after peer review.

- The final published version features the final layout of the paper including the volume, issue and page numbers.

Link to publication

\footnotetext{
General rights rights.

- You may freely distribute the URL identifying the publication in the public portal. please follow below link for the End User Agreement:

www.umlib.nl/taverne-license

Take down policy

If you believe that this document breaches copyright please contact us at:

repository@maastrichtuniversity.nl

providing details and we will investigate your claim.
}

Copyright and moral rights for the publications made accessible in the public portal are retained by the authors and/or other copyright owners and it is a condition of accessing publications that users recognise and abide by the legal requirements associated with these

- Users may download and print one copy of any publication from the public portal for the purpose of private study or research.

- You may not further distribute the material or use it for any profit-making activity or commercial gain

If the publication is distributed under the terms of Article $25 \mathrm{fa}$ of the Dutch Copyright Act, indicated by the "Taverne" license above, 
Hemodynamic and hemostatic effects of erythropoietin therapy 


\section{CIP-DATA KONINKLIJKE BIBLIOTHEEK DEN HAAG}

Wirtz, Joris Jeroen Johannes Maria

Hemodynamic and hemostatic effects of erythropoietin therapy / Joris Jeroen Johannes Maria Wirz. - Maastricht

: Universitaire Pers Maastricht. - Ill.

Thesis Maastricht. - With ref. - With summary in Dutch.

ISBN 90-5278-111-7

NUGI 742

Subject headings: hemodynamics / hemostatics /

erythropoietin.

C 1993 No parts of this book may be reproduced in any form, by print, photoprint, microfilm or any other means, without written permission from the author and the respective editors of the journals in which the various articles appeared in print.

Produktion: Datawyse I Universitaire Pers Masstricht

The studies in this thesis were made possible by financial support of Cilag (Belgium) and printing of this thesis was financially supported by the Dutch Kidney Foundation, Bayer B.V. and Gambro B.V. 


\section{HEMODYNAMIC AND HEMOSTATIC EFFECTS OF ERYTHROPOIETIN THERAPY}

\section{PROEFSCHRIFT}

ter verkrijging van de graad van doctor aan de Rijksuniversiteit Limburg te Maastricht, op gezag van de Rector Magnificus, Prof.dr. H. Philipsen, volgens het besluit van het College van Dekanen, in het openbaar te verdedigen op vrijdag 26 november 1993 om 14.00 uur

door

Joris Jeroen Johannes Maria Wirtz

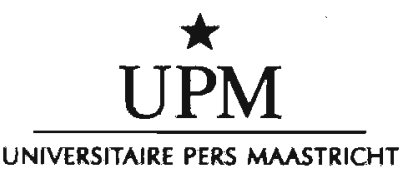




\section{Promotor:}

Prof.dr. J.P. van Hooff

\section{Co-promotor:}

Dr. K.M.L. Leunissen

\section{Beoordelingscommissie:}

Prof.dr. R.S. Reneman (voorzitter)

Dr. K. Hamulyak

Prof.dr, P.J.E.H.M. Kitslaar

Prof.dr. K.M. Koch (Hannover, Germany)

Prof.dr. Q. Maggiore (Florence, Italy) 


\section{Contents}

CHAPTER I . . . . . . . . . . . . . . . . . 7

Introduction to the study:

Recombinant human erythropoietin in hemodialysis patients

CHAPTER II . . . . . . . . . . . . . . . . . . . 21

Recombinant human erythropoietin and its effects on macro- and microcirculation during normovolemia

CHAPTER III ............................. 35

The longterm effects of recombinant human erythropoietin on macro- and microcirculation in chronic hemodialysis patients

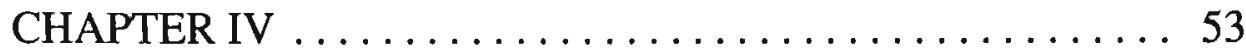

Influence of hematocrit level on plasma volume preservation and on hemodynamics during dialysis

CHAPTER V . . . . . . . . . . . . . . . . . . . . . . . . 67

Recombinant human erythropoietin and dialysis fistula function

CHAPTER VI . . . . . . . . . . . . . . . . . . . 79

The effects of recombinant human erythropoietin on hemostasis and fibrinolysis in hemodialysis patients 
CHAPTER VII........................... 91

Summary and conclusions

CHAPTER VIII $\ldots \ldots \ldots \ldots \ldots \ldots \ldots \ldots \ldots \ldots \ldots . \ldots 7$

Samenvatting

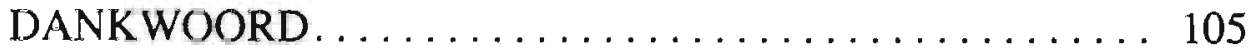

CURRICULUM VITAE . . . . . . . . . . . . . . . . . 109 


\section{CHAPTER T \\ Introduction to the study}

In part published in:

K.M.L Leunissen, J.J.J.M Wirtz, W.H.M van Kuijk, J.P van Hooff.

Recombinant human erythropoietin: Benefits for the heart and physical performance; in: Bauer C.H.R., Koch K., Scigalla P., Wieczorek L. (eds): Erythropoietin, Molecular Physiology and Clinical Application, New York, Marcel Dekker, 1993, P 107-127 


\section{Introduction}

Patients with end stage renal failure generally have anemia. This anemia has a great impact on physical capacity, general well being and cognitive and sexual functions, thus limiting the quality of life. Before the wide therapeutical application of erythropoietin, more than $50 \%$ of those patients needed periodically red cell transfusions for relieving the symptoms of anemia [1]. However, a transfusion gives relieve for a short period only and has certain risks such as transmission of infections, iron overload, the induction of lymfocytotoxic antibodies and erythroid suppression [2]. Therefore, therapeutical alternatives for correcting this anemia were imperative. Attempts with androgens and cobalt and optimalization of dialysis procedures were either not effective enough or created inacceptable side effects.

\section{The anemia of chronic renal failure}

The association between anemia with chronic renal disease and renal failure has been described for the first time by Richard Bright in 1836. It is a normocytic and normochromic anemia with a hypoproliferative bone marrow. The mechanisms responsible for the anemia of renal disease are: (1) decreased marrow stimulation, (2) decreased marrow response, and (3) decreased red cell survival.

(1) Decreased marrow stimulation

Decreased marrow stimulation is the most important cause of anemia in renal disease. Erythropoietin (Epo), which stimulates marrow red cell production, is produced by the peritubular capillary endothelial cells and interstitial fibroblasts of the kidney [3-4]. Its production depends on the availability of oxygen to the kidney and the registration by a not yet defined oxygen sensoring mechanism in the kidney itself [5].

Renal insufficiency is leading to a decreased erythropoietin production, blunting the normal feedback between erythropoiesis and erythropoietin production. There are other factors as well that blunt the response of the marrow to Epo in uremics, such as altered oxygen sensoring [6], the increase in red cell 2, 3-DPG levels with a right shift on the hemoglobin - oxygen dissociation curve and subsequently increased oxygen delivery to the oxygen sensor [7], direct inhibition of the erythropoietin immunoreactivity [8] and retention of inhibitors of erythropoietin. 
(2) Decreased marrow response

A decreased marrow response for erythropoietin might be due to the presence of uremic inhibitors [9-10]: candidates are polyamines [11], parathyroid hormone [12], ribonuclease [13] and prostaglandins [14].

Several other factors can give a decreased response such as iron deficiency, decreased iron utilization due to inflammatory iron block [15], aluminium toxicity [16], folate deficiency [17], and secondary hyperparathyroidism [18].

\section{(3) Decreased red cell survival}

The decrease of red cell survival during renal failure and dialysis is due to blood loss by frequent venapunctures, to blood loss associated with the dialysis procedure itself and surgery. The latter is amplificated by the increased uremic bleeding tendency. A decreased red cell survival may also be due to intravascular hemolysis of dysfunctioning red cells in the uremic environment as well as hemolysis secondary to improper dialysis techniques, resulting in oncotic, thermal and mechanical injury of the red cells.

\section{History and development of erythropoietin}

In 1906, Paul Carnot hypothesized that erythropoiesis was regulated by humoral factors [19]. Jacobson detected the central role of the kidney in erythropoiesis [20]. Erythropoietin was extracted and purified by Goldwasser and coworkers from the plasma of uremic sheep [21-23]. Many years later, it was demonstrated that erythropoietin rich plasma of uremic sheep could correct renal anemia of uremic sheep [24]. From that moment on it was attempted to purify erythropoietin from the urine of anemic patients. For this purification, huge amounts of urine were necessary to obtain small amounts of erythropoietin.

The amino-acid sequence of erythropoietin was partially determined by Miyake et al [25] and the cloning of the gene coding for human erythropoietin successfully undertaken by Jacobs et al [26] and Lin et al [27].

Since the successful insertion of the gene for human erythropoietin in a mammalial cell line, large amounts of recombinant human erythropoietin (ReHuEpo) became widely available for therapeutical application. 


\section{Beneficial effects}

ReHuEpo corrects anemia in patients with end stage renal disease and in patients maintained on dialysis [28-32]. A dose dependent increase in hemoglobin concentration and an improved well being and physical fitness of the patients were found [33-38]. Treatment with ReHuEpo ameliorated exercise capacity and endurance. The duration of exercise, the maximum oxygen consumption, oxygen uptake and anaerobic threshold improved [35, 39]. Analysis of pulmonary function tests and ergospirometry demonstrated that improved oxygen transport in the blood and changes of the anaerobic threshold and heart rate appeared to be main causes of improvement. Respiratory mechanisms and gas exchange remained unaltered [39].

Also, muscle energy metabolism, i.e. the rate of recovery of phosphocreatinin as a function of oxydative phosphorylation, improved during treatment with ReHuEpo [40].

Furthermore, improvements have been reported in brain and cognitive function [41-44], as well as in endocrine and sexual function [45-46], protein metabolism [47-48] and primary hemostasis [49-50].

\section{Side effects}

During treatment with ReHuEpo for renal anemia, side effects have been encountered of which the clinical most important are:

(1) Hypertension.

If hypertension develops it occurs mainly during the induction phase of treatment with ReHuEpo when the red cell mass increases [29-30, 32, 51-54], especially in case of preexistent hypertension [51] and in case of a steep increase of hematocrit.

When hematocrit rises, vasodilation due to hypoxia decreases, and the responsivity of the peripheral vascular smooth muscle cells to vasoconstrictor stimuli might recover [55]. Furthermore, due to the elevated red blood cell mass, blood viscosity will increase. All these factors may lead to an increase of blood pressure. Patients with hypertension have a diminished compliance of the vascular bed due to structural as well as functional changes [56-57], and treatment with ReHuEpo might result in an exaggerated rise in peripheral vascular resistance. Other factors, which could play a role, are an inadequate reduction of the elevated cardiac output of chronic anemia [57-63], but also an 
incorrect estimation of dialysis dry weight. When dialysis dry weight is incorrectly estimated, volume contraction as well as fluid overload might lead to an increase of blood pressure.

\section{(2) Seizures}

Seizures occur in about $4 \%$ of the patients treated with ReHuepo [28-29, 32]. These seizures might be caused by a critical reduction in cerebral perfusion during treatment with ReHuEpo, by thrombo-embolism or by development of hypertension.

\section{(3) Clotting}

An increased incidence of clotting of the vascular access $[30,32,53,64-66]$ but also of other vasculature has been reported during ReHuEpo therapy. This clotting tendency can be explained by an increased blood viscosity, changes in the hemostatic as well as in the fibrinolytic system but also hemodynamic factors may contribute, especially in case of preexistent vasculopathy.

\section{Hemodynamic response to chronic anemia}

In patients with chronic anemia a hyperkinetic circulation is observed, characterized by a high cardiac output. Furthermore, tissue extraction of oxygen is increased [58-59]. This hyperkinetic circulation is caused by several factors. Blood viscosity is reduced leading to a decrease of the resistance to blood flow in the peripheral vessels, while the venous retum is increased and thereby cardiac output [67-68]. A diminished transport of oxygen causes vasodilatation of the small vessels, leading to an increase of venous return and cardiac output. The decreased arterial pressure in chronic anemia is related to a generalized vasodilatation of the arterial system, whereas on the other hand venoconstriction will maintain central blood volume and venous pressure [58]. So, one of the major effects of anemia is a greatly increased workload on the heart with an increase of myocardial oxygen consumption [69].

In anemic hemodialysis patients, stroke work index as well as left ventricular work indices are increased [69]. Left ventricular end-diastolic pressure is generally elevated. Myocardial mass is increased and will result in an increased myocardial oxygen demand. When those oxygen requirements are not met because of the reduced erythrocyte mass, myocardial failure could ensue.

Chronic anemia not only induces functional changes of the cardiovascular system, but structural changes as well. The increased venous return will lead to increased left ventricular dimensions, especially of the end diastolic left ventricular diameter [70]. Furthermore, there is a significant relation between anemia and left ventricular hypertrophy, indicating that anemia contributes to 
the development of left ventricular hypertrophy in patients with end stage renal disease [71]. Moreover, Florenzano et al found some evidence for the existence of a non-catecholamine positive inotropic factor in the serum of chronic anemic patients [72]. It is likely that the development of hypertrophy allows tissue oxygen needs to be met by increasing stroke volume, while normalizing systolic wall stress.

Microvascular changes have been described in skin biopsies of hemodialysis patients, such as thickening of the basement membrane, endothelial activation and chronic inflammatory cell infiltration with participation of mast cells [7375]. Intravital microscopy of the finger nailfold of hypertensive dialysis patients revealed a reduction of the number of capillaries and an increased percentage of abnormal tortuous capillaries as compared to non-hypertensive dialysis patients and controls.

The cause of the observed pathological microvascularity in hemodialysis patients seems to be multifactorial: hypertension, uremic toxins and anemia may all be responsible. After successful kidney transplantation complete normalisation of the microcirculation has been observed [75].

\section{Hemodynamic effects of the correction of anemia by blood transfusion}

The effect of a gradual correction of chronic anemia was studied by Duke et al [58]. Significant decreases in heart rate, stroke index and cardiac index and an increase in systemic vascular resistance were the most significant findings, while rapid red blood cell transfusions resulted in a rise of cardiac output, venous pressure and blood volume [76]. Neff et al [77] studied the hemodynamic effects of serial red blood cell transfusion before and during a 6-12 week treatment period. Cardiac index decreased, reaching a normal level at a hematocrit of $30 \%$. Diastolic blood pressure rose progressively $( \pm 20 \mathrm{mmHg}$ ) and the vascular resistance increased by $80 \%$, when the hematocrit increased from 20 to $40 \%$. An inverse correlation between cardiac index and hematocrit $(r=-0.76 ; p<0.01)$ and a positive correlation between peripheral vascular resistance and hematocrit ( $r=0.675 ; p<0.01$ ) was observed.

Hematocrit is an important determinant of blood viscosity. The increasing cardiac output, when hematocrit decreases, is related to an increase in venous return and a decrease in outflow impedance. Murray et al [67] studied the effects of changes in whole blood viscosity on hemodynamic responses in acute normovolemic anemia, plotting mean cardiac output against mean hematocrit ratios obtained during control periods and after isovolemic exchange with dextran solutions of three different molecular weights. It turned out that recipients of low molecular weight dextran had a higher cardiac output than those receiving high molecular weight dextran at comparable levels of anemia. These results sug- 
gested that a reduction in outflow impedance in anemic patients is probably largely determined by changes in whole blood viscosity. The increase of whole blood viscosity during the correction of chronic anemia [78-79] is in part responsible for the increase of the peripheral vascular resistance, especially in the presence of preexistent microvascular abnormalities.

\section{Aim of the study}

The aim of the present study was to evaluate the effects of the increased hematocrit due to ReHuEpo therapy on the circulation of normovolemic chronic hemodialysed patients.

In chapter I, data are presented of the effects of treatment with ReHuEpo during the correction phase of hematocrit ( \pm 4 months) on blood volume, plasma volume, red blood cell volume, macrocirculation (mean arterial pressure, heart rate, cardiac index, stroke index, systemic vascular resistance), peripheral oxygenation and skin microcirculatory flow (by transcutaneous oxymetry) in chronically hemodialysed and normovolemic renal failure patients.

In chapter II, the effects of treatment with ReHuEpo at long term ( \pm 14 months), after reaching and maintaining the target hematocrit, are presented concerning fluid status, macrocirculation, cardiac functional and structural parameters. Moreover, data are given on the long term morphological adaptations of the pathological capillary loops in the distal row of the finger nailfolds. The functional and structural aspects and their possible (patho-)physiological significance are subsequently discussed.

In chapter III, the data are given on the study to the effects of the increased hematocrit during treatment with ReHuEpo on dialysis fluid handling and plasma volume preservation in chronic renal failure patients maintained on hemodialysis under standardized conditions. The results are presented on dialytic changes in plasma oncotic pressure, osmolality and hematocrit, but also on the changes in hemodynamic and cardial function (mean arterial pressure, cardiac output, stroke volume, left ventricular end diastolic and end systolic diameters, fractional fiber shortening) and humoral substances known to be involved in dialytic hemodynamic regulation and stability (plasma adrenaline and noradrenaline, atrial natriuretic factor).

In chapter IV the data of direct and indirect dialysis fistula function analysis (by Duplex doppler ultrasonar scanning and spectral analysis) are given before and after treatment with ReHuEpo. Moreover, the effects on venous pressure in the 
extracorporeal dialysis circuit and the heparin need during dialysis, macrocirculatory indices, rheological parameters and indices of primary hemostasis are studied.

Multiregression analysis is subsequently used to interrelate potential risk factors for shunt thrombosis as independent variables with the fistula flow parameters as dependent factors.

In chapter $\mathrm{V}$ the results are presented of the measurements of the effects of treatment with ReHuEpo on indices of primary hemostasis (platelet count, bleeding time, spontaneous and ADP induced platelet aggregation) but also on other hemostatic (antithrombin III, protein-C antigen and activity, total and free protein-S antigens) and fibrinolytic parameters (tissue plasminogen activator antigen, plasminogen activity, plasminogen activator inhibitor activity). 


\section{References}

1. Crowley JP, Nealey TA, Metzger J, Pono L, Chazan JA. Transfusion and long-term hemodialysis. Arch Int Med 1987: 147: 1925-1928.

2. Eschbach JW, Adamson JW, Cook JD. Disorders of red blood cell production in uremia. Arch Int Med 1970; 126: 812-815.

3. Kurtz A, Eckhardt KU, Neumann R. Site of erythropoietin formation. Contrib Nephrol 1989; 76: 14-23.

4. Koury MJ, Koury ST, Bondurant MC, Graber SE. Correlation of the molecular and anatomical aspects of renal erythropoietin production. Contrib Nephrol 1989; 76:24-32.

5. Eckhardt KU, Kurtz A, Scholz, H, Bauer C. Regulation of erythropoietin formation in vivo. Contrib Nephrol 1989; 76: 33-38.

6. Pavlovic-Kentera V, Clemans GK, Djukanovic L, Biljanovic-Pacinovic L. Erythropoietin and anemia in chronic renal failure. Exp Hematol 1987; 15: 785-789.

7. Torrence J, Jacobs P, Restrepo A, Eschbach J, Lenfant C. Intra-erythrocytic adaptation to anemia. NEJM 1970; $283: 165-169$.

8. McGonigle RJS, Boineau FG, Beckman BS, Ohene-Frempay K, Lewy JE. Erythropoietin and inhibitors of in vitro erythropoiesis in the development of anemia in children with renal disease. J Lab Clin Med 1985; 105: 449-458.

9. Radtke HW, Frei U, Erbes PM, Schoeppe W, Koch KM. Improving anemia by hemodialysis; effect on serum erythropoietin. Kidn Int 1980; 17: 382-387.

10. Chandra M, Clemans GK, McVicar M, Wilkes B, Bluestone PA, Maillaux LU. Serum erythropoietin levels and hematocrit in end-stage renal disease: infuence of the mode of dialysis. Am J Kidn Dis 1988; 12: 208-213.

11. Kuschner DS, Beckman BS, Fischer JW. Do polyamines play a role in the pathogenesis of the anemia of end-stage renal disease? Kidn Int 1989;36:171-174.

12. Dunn CDR, Trent $D$. The effect of parathyroid hormone on erythropoiesis in serum-free culutes of fetal mouse liver cells. Proc Soc Exp Biol Med 1981; 166: 556-561.

13. Freedman MH, Saunders EF, Cattran DC, Rabin EZ, Ribonuclease inhibition of erythropoiesis in anemia of uremia. Am I Kidn Dis 1983; $2: 530-533$.

14. Taniguchi S, Shihuya $T$, Harada $M, N h o Y$. Prostaglandin mediated suppression of in vivo growth of erythroid progenitor cells, Kidn Int 1989, 36: 712-718.

15. Birgegard G. Erythropoiesis and inflammation. Contrib Nephrol 1989; 76:330-341.

16. Kaiser L, Schwarz KA. Aluminium-induced anemia. Am J Kidn Dis 1985; 6:348-352.

17. Hemmeloff-Andersen KE. Folic acid status of patients with chronic renal failure maintained by tialysis. Clin Nephrol 1977; $8: 510-513$.

18. Cassidy MD, Elis HA, Dewar J, Famdon JR, Ward MK, Ker DNS. The anemia of chronic renal failure: is there an association with secondary hyperparathyroidism? Kidn Int 1984; 26: 897.

19. Carnot $P$, Deflandre $C$. Sur l'activité hemopoétique de serum au cours de la regulation du sang. CR Acad Sci 1906; 143: 384-386.

20. Jacobson LO, Goldwasser $E_{s}$ Fried W, Plzak L. The role of the kidney in erythropoiesis. Nature 1957; 179:633-634.

21. Goldwasser $\mathrm{E}$, White WF, Taylor KB. Further purification of sheep plasma erythropoietin. Biochem Biophys Acta 1962; 64: 487.

22. Goldwasser $E_{q}$ Kung CK. Progress in the purification of erythropoietin. Am Ny Acad Sci $1968 ; 149(1): 49-53$. 
23. Goldwasser E, Kung CK. Purification of erythropoietin. Proc Nat Acad Sci USA 1971; 68 (4): 697-698.

24. Eschbach JW, Mladenovic J, Garcia JF, Wahl PW. The anemia of chronic renal failure in sheep. J Clin Invest 1984; 74: 434-441.

25. Miyake T, Kung CHK, Goldwasser E. Purification of human erythropoietin. J Biol Chem 1977; 252: 5558-5564.

26. Jacobs K, Shoemaker C, Rudensdorf R. Isolation and characterisation of genomic and C DNA clones of human erythropoietin. Nature 1985; 313: 806-810.

27. Lin FK, Suggs $\mathrm{S}$, Lin $\mathrm{CH}$. Cloning and expression of the human erythropoietin gene. Proc Nat Acad Sci USA 1985; 82: 7580-7584.

28. Winearls CG, Oliver DO, Pippard MJ, Reid C, Downing MR, Cotes PM. Effects of human erythropoietin derived from recombinant DNA on the anemia of patients maintained by chronic hemodialysis. Lancet 1986; ii: 1175-1177.

29. Eschbach JW, Egrie JC, Downing MR, Browne JR, Adarnson JW. Correction of the anemia of end stage renal disease with recombinant human erythropoietin. NEJM 1987; 316: 73-78.

30. Bommer J, Alexiou C, Müller-Bühl U, Eifert J, Ritz E. Recombinant human erythropoietin therapy in hemodialysis patients - dose determination and clinical experience. Nephrol Dial Transpl 1987; 2: 238-242.

31. Zins B, Drucke T, Zingraff J, Berehri L, Kreis H, Naret C, Delors S, Castaigne JP, Peterlargo F, Casadevak N, Varet B. Erythropoietin treatment in anaemic patients on haemodialysis. Lancet 1986; ii: 1329.

32. Casati S, Passerini P. Campise MR. Benefits and risks of protracted treatment with recombinant human erythropoietin in patients having haemodialysis. BMJ 1987; 295: 1017-1020.

33. Lundin AP. Quality of life: subjective and objective improvements with recombinant human erythropoietin therapy. Sem Nephrol 1989; 9: 22-29.

34. Canadian Erythropoietin Study Group. Association between recombinant human erythropoietin and quality of life and exercise capacity of patients receiving hemodialysis. BMJ 1990; 300: 573-578.

35. MacDougall IC, Lewis NP, Saunders MJ, Cochlin DL, Davies ME, Hutton RD, Fox KAA, Coles GA, Williams JD. Long-term cardiorespiratory effects of amelioration of renal anemia by erythropoietin. Lancet 1990; 335: 489-493.

36. Böcker A, Reimers E, Nonnast-Daniel B, Kühn K, Koch KM, Scigalla P, Braumann $\mathrm{KM}$, Brinkhorst R, Boning D. Effect of erythropoietin treatment on $\mathrm{O}_{2}$ affinity and performance in patients with renal anemia. Contrib Nephrol 1988 (Karger, Basel); 66: 165-175.

37. Eschbach JW, Downing MR, Egrie JC, Browne JK, Adamson JW. USA multicenter clinical trial with recombinant human erythropoietin: results in hemodialysis patients. Contrib Nephrol (Karger, Basel) 1989; 76: 160-165.

38. Mayer G, Thun J, Cada EM, Stumvoll HK, Graf H. Working capacity is increased following recombinant human erythropoietin treatment. Kidn Int 1988; 34: 525-528.

39. Grunze M, Kohlmann M, Mulligan M, Grüner I, Koeppel M, Bommer J. Mechanisms of improved physical performance of chronic haemodialysis patients after erythropoietin treatment. Am I Nephrol 1990; 10 (suppl.2): 15-23.

40. Park JS, Park SK, Kim SB, Lim TW, Lee DK, Hong CD. Effect of recombinant human erythropoietin on muscle energy metabolism measured by $31 \mathrm{p}-\mathrm{NMR}$ spectroscopy in patients with end-stage renal disease. JASN 1991; 2: 384. 
41. Wolcott DL, Schweitzer S, Marsh NT. Recombinant human erythropoietin improves cognitive function and quality of life of chronic hemodialysis patients. Kidn Int 1988; 33: 242 .

42. Nissenson AR. Recombinant human erythropoietin: impact on brain and cognitive function, exercise tolerance, sexual potency and quality of life. Sem Nephrol 1989; 9 (no 1): 25-31.

43. Brown WS, Marsh JT, Wolcott D, Takushi R. Cognitive function, nood and P3 latency: effects of the amelioration of anemia in dialysis patients. Neuropsychologia 1991: 29: $35-45$.

44. Grimm G, Stockenhuber F. Schneeweiss B, Madl C. Improvement of brain function in hemodialysis patients treated with erythropoietin. Kidn Int 1990; 38: 480-486.

45. Schaefer RM, Kokot F, Heidland A. Normalisation of prolactin levels and improved sexual function in dialysis patients on hemodialysis. Nephrol Dial Transpl 1988; 3:501.

46. Kokot F, Wiecek A, Grzeszczak W, Klepacka J, Klin M. Influence of erythropoietin treatment on endocrine abnomalities in hemodialyzed patients. Contrib Nephrol 1989; 76: 257-272.

47. Fischer CK, Scigalla P, Park W, Becker H, Schöller R, Paust H, Broezicke H, Kessel $M$. Influence of $\mathrm{hEpo}$ therapy on the protein metabolism of hemodialysis patients with terminal renal insufficiency. Contrib Nephrol 1989; 76: 250-256.

48. Riedel E, Hampe H, Scigalla P, Nündel M, Kessel M. Correction of amino-acid metabolism by recombinant human erythropoietin therapy in hemodialysis patients. Kidn Int 1989; 36: 216-221.

49. Moia M, Vizzota L, Cattaneo M, Mannuci PM, Casati S, Ponticelli C. Improvement in the hemostatic defect of uremia after treatment with recombinant human erythropoietin. Lancet 1987; ii: 1227-1229.

50. Huraib S, Al-Momen AK, Gader AMA, Mitwalli A. Effect of recombinant human erythropoietin (ReHuEpo) on the hemostatic system in chronic hemodialysis patients. Clin Nephrol 1991; 36: 252-257.

51. Samtleben W, Baldamus CA, Bommer J, Fassbinder W, Nonnast-Daniel B, Gurland HJ. Blood pressure changes during treatment with recombinant human erythropoietin. Contrib Nephrol 1988; 66: 114-122.

52. Pollok M, Bommer J, Gurland HJ, Koch KM, Schoeppe W, Scigalla P, Baldamus CA. Effects of recombinant human erythropoietin treatment in end-stage renal failure patients: results of a multicenter phase II/III study. Contrib Nephrol 1989; 76: 201-211.

53. Sundal E, Kaeser K. Correction of anemia of chronic renal failure with recombinant human erythropoietin: safety and efficacy of one year's treatment in a European Multicenter Study of 150 haemodialysis dependent patients. Nephrol Dial Transpl 1989; 4: 979-987.

54. Eschbach JW, Egrie JC, Downing Mr, Browne JK, Adamson JW. The safety of epoietin-alfa: results of clinical trials in the United States. Contrib Nephrol 1991; 88: $72-81$.

55. Duling BR, Pittman RN. Oxygen tension: dependent or independent variable in local control of blood flow? Fed Proc 1975; 34 (11): 2012-2019.

56. Folkow B, Hallbäck M, Lundgren $Y$, Sivertsson R, Weiss L. Importance of adaptive changes in vascular design for establishment of primary hypertension, studied in man and in spontaneous hypertensive rats. Circulation Res 1973; 32/33 (suppl. I): 1-13.

57. Nonnast-Daniel B, Schäffer J, Frei U. Hemodynamics in hemodialysis patients treated with recombinant human erythropoietin. Contrib Nephrol 1989; 76: 283-291. 
58. Duke M, Abelmann WH. The hemodynamic response to chronic anemia. Circulation 1969; 39: 503-515.

59. Varat MA, Adolph RJ, Fowler NO. Cardiovascular effects of anemia. Am Heart J 1972; 83: 415-426.

60. Hori K, Onoyama K, Iseki K, Fujimi S, Fujishima M. Hemodynamic and volume changes by recombinant human erythropoietin in the treatment of anaemic hemodialysis patient. Clin Nephrol 1990; 33: 293-298.

61. Akiba T, Kurhara S, Katoh M, Marumo F. Hemodynamic changes of hemodialysed patients by erythropoietin treatment. Kidn Int 1989; 35: 237.

62. Buckner FS, Eschbach JW, Maley MR, Davidson RR, Adamson JW. Correction of the anemia in hemodialysis patients with recombinant human erythropoietin: hemodynamic changes and risks for hypertension. Kidn Int 1989; 35: 237.

63. Deschodı G, Granolleras C, Alsabadini B, Branger B, Koch KM, Shaldon S. Changes in cardiac output, blood pressure and peripheral resistance following treatment of renal anemia by recombinant human erythropoietin. Nephrol Dial Transpl 1988; 3: 494.

64. Eschbach JW, Abdulkadi MH, Browne JK. Recombinant human erythropoietin in anemic patients with end-stage renal disease. Results of a phase II multicenter clinical trial. Ann Int Med 1989; 111: 992-1000.

65. Sobota JT. Recombinant human erythropoietin in patients with anemia due to end-stage renal disease. Contrib Nephrol 1989; 76: 166-178.

66. Zehnder C, Blumberg A. Recombinant human erythropoietin in anemic patients on hemodialysis: benefits and risks. Schweiz Med Wochenschrift 1989; 119 (9): 269.

67. Murray JF, Escobar E, Rapaport E. Effects of blood viscocity on hemodynamic responses in acute normovolaemic anemia. Am J Physiol 1989; 216 (3): 638-642.

68. Guyton AC. Circulatory physiology: cardiac output and its regulation. W.B. Saunders Company, Philadelphia/London, 1986.

69. Capelli JP, Kasparian M. Cardiac work demands and left ventricular function in end-stage renal disease. Ann Int Med 1977; 86: 261-267.

70. Grossman W. Cardiac hypertrophy: useful adaptation or pathologic process? Am J Med 1980; 69: 576-584.

71. Silberberg JS, Rahal DP, Pattan DR, Sniderman AD. Role of anemia in the pathogenesis of left ventricular hypertrophy in end-stage renal disease. AM J Cardiol 1989; 64: 222-224.

72. Florenzano F, Diaz G, Reguezi C, Escobar E. Left ventricular function in chronic anemia: evidence of non-catecholamine positive inotropic factor in the serum. Am J Cardiol 1984; $54: 638-645$.

73. Matsumoto M, Ichimaru K, Horie A. Pruritis and mast-cell proliferation of the skin in end-stage renal failure. Clin Nephrol 1985; 23: 285-288.

74. Ichimaru K, Horie A. Micro-angiopathic changes of subepidermal capillaries in endstage renal failure. Nephron 1987; 46: 144-149.

75. Gilchrest B, Rowe JW, Mihi MC. Clinical and histological skin changes in chronic renal failure evidence for a dialysis-resistent transplant responsive micro-angiopathy. Lancet 1980; ii: 1271-1275.

76. Duke M, Herbert VD, Abelmann WH. Hemodynamic effects of blood transfusion in chronic anemia. NEJM 1964; 271: 975-980.

77. Neff MS, Kim KE, Persoff M, Anesti J, Swartz CK. Hemodynamics of uremic anemia. Circulation 1970; 43: 876-883. 
78. Steffen HM, Brunner R, Müller R, Degenhardt. S, Pollok M, Lang R, Baldamus CA. Peripheral hemodynamics, blood viscosity and the renin-angiotensin system in hemodialysis patients under therapy with recombinant human erythropoietin. Contrib Nephrol 1989; 76: 292-298.

79. Schaefer RM, Leschke M, Strauer B, Heidland A. Blood rheology and hypertension in hemodialysis patients treated with erythropoietin. Am J Nephrol 1988: 8: 449-453. 


\section{Recombinant human erythropoietin and its effects on macro- and microcirculation during normovolemia}

\section{A physiological study of hemodynamics, fluid status and skin microcirculation}

J.J.J.M. Wirtz ${ }^{1}$, K.M.L. Leunissen ${ }^{1}$, J.W.J. van Esser ${ }^{1}$, E.C. Cheriex ${ }^{2}$, D.W. Slaaf ${ }^{3}$, R.S. Reneman ${ }^{4}$, J.P. van Hooff ${ }^{1}$

Department of Nephrology ${ }^{1}$, Cardiology ${ }^{2}$, Biophysics $^{3}$, and Physiology ${ }^{4}$ University Hospital Maastricht, The Netherlands 


\section{Abstract}

In 9 chronic hemodialysis patients, treated with recombinant human erythropoietin (ReHuEpo), longitudinal studies were performed to investigate possible changes in macro- and microcirculatory parameters during normovolemia, as assessed echographically by determining the inferior vena cava diameter and adjusting dialysis dry weight. Hematocrit increased from $19 \pm 4$ to $33 \pm 5 \%$ ( $\mathrm{p}<0.001$ ). Systemic vascular resistance increased from $1020 \pm 259$ to $1283 \pm$ $245 \mathrm{dyne} / \mathrm{s} / \mathrm{cm}^{-5}(\mathrm{p}<0.02)$, while mean arterial pressure remained unchanged. Cardiac index decreased $\left(4.9 \pm 1.4\right.$ to $3.8 \pm 0.9$ liters $\left./ \mathrm{min} / \mathrm{m}^{2} ; \mathrm{p}<0.02\right)$, caused by a decrease in heart rate $(87 \pm 21$ to $75 \pm 16$ beats/min $p<0.02)$ and stroke index $\left(59.9 \pm 15.2\right.$ to $\left.51.0 \pm 10.7 \mathrm{ml} / \mathrm{min}^{2} ; \mathrm{p}<0.02\right)$. Red blood cell volume increased (468 \pm 105 to $\left.858 \pm 203 \mathrm{ml} / \mathrm{min}^{2}, \mathrm{p}<0.001\right)$ and plasma volume decreased inversely $\left(\left[{ }^{125} \mathrm{I}\right]\right.$ - albumin; $2008 \pm 338$ to $\left.1664 \pm 225 \mathrm{ml} / \mathrm{min}^{2} ; \mathrm{p}<0.001\right)$, whereas total blood volume remained unaltered ( $2476 \pm 397$ to $2518 \pm 352$ $\mathrm{ml} / \mathrm{m}^{2} ; \mathrm{n} . \mathrm{s}$.). Total body weight increased $(57.8 \pm 12$ to $62.1 \pm 12 \mathrm{~kg} ; \mathrm{p}<0.02)$, indicative of an anabolic effect of ReHuEpo therapy. Skin capillary circulation as measured by transcutaneous oxymetry at $37^{\circ} \mathrm{C}$ skin temperature impaired, reflected by the increase of the time to peak after arterial occlusion ( $82 \pm 21$ to $121 \pm 25 \mathrm{~s} ; \mathrm{p}<0.02)$. The reactive hyperemic response following the release of occlusion showed a significant increase at high hematocrit (10.7 \pm 4.2 to $16.6 \pm$ $5.3 \mathrm{mmHg} ; \mathrm{p}<0.02$ ), whereas resting transcutaneous $\mathrm{P}_{\mathrm{O} 2}$ values showed a slight but not significant increase $(2.3 \pm 1.3$ to $4.7 \pm 3.3 \mathrm{mmHg}$; n.s.). The high number of pathological capillaries in hemodialyzed patients might be an additional factor for the increase in systemic vascular resistance.

\section{Introduction}

Recombinant human erythropoietin (ReHuEpo) has been found to be a successful treatment of anemia in chronic renal failure [1-6]. The degree and rate of the increase in hematocrit (Hct) are dose dependent and compromised by the presence of inadequate iron stores, alluminum intoxication and chronic infectious diseases. The subjective and objective quality of life of chronic renal failure patients is improving during ReHuEpo therapy [7-10]. However, side effects have been reported, of which hypertension is the most frequent one [11-13]. The available data from multicenter trials showed a $20-45 \%$ incidence of development or aggravation of hypertension during the correction of renal anemia by ReHuEpo [14-16]. Predisposing circumstances are preexistent hypertension, a steep increase in Hct and the absolute Hct level achieved [11, 17]. As a possible explanation for the increase in blood pressure, several authors reported an increase in systemic vascular resistance (SVR), generally explained 
by a reduction of the anoxic vasodilation related to chronic anemia and by an increase in whole blood viscosity. The increased blood viscosity should be related to the reported qualitative and quantitative structural pathological capillaries in chronic renal failure and dialyzed patients [18-19], which could lead to microcirculatory flow disturbances. In this regard, and especially in the presence of pathological capillaries the actual fluid state also seems to be a crucial factor in macro- and microcirculatory dynamics [20].

The estimation of dialysis dry weight, based on clinical parameters, is unreliable [21]. During ReHuEpo treatment, the determination of dialysis dry weight is even more difficult, due to the increased Hct and the reported weight gain due to anabolism. As previously shown, serial echographic determination of the inferior vena cava provides accurate information about the actual fluid state and allows the adjustment of the optimal dialysis dry weight to the data obtained [22-23]. In this way, normovolemia can be reached and maintained throughout the period of ReHuEpo treatment.

The aim of this study was to investigate the effects of ReHuEpo treatment on macro- and microcirculatory parameters in chronic hemodialysis patients, vigorously maintaining the normovolemic state.

\section{Patients and methods}

Nine chronic hemodialysis patients ( 6 females, 3 males) with anemia were selected for macro- and microcirculatory evaluations during an 18-week period of ReHuEpo therapy. The mean age of the group was 42.1 years (28-70 years) and the mean duration of dialysis 6.6 years (1-14 years). Patients with severe hyperparathyroidism, signs of aluminium intoxication, diabetes mellitus or a history of clinically obvious cardiovascular disease were excluded.

All patients were normotensive at entrance of the study with or without antihypertensive medication, 6 of them using beta-blocking agents and 4 of the patients in combination with vasodilating drugs. Twenty-four hours before the investigations, all vasoactive medication were temporarily stopped. The studies were performed 20-24 hours after dialysis, the moment of optimal plasma volume preservation [24], at regular intervals during the treatment period of 18 weeks. Thus, patients were studied longitudinally and served as their own controls (group A).

To obtain information about the number of pathological capillaries in hemodialyzed patients, the morphology of the nail fold capillaries was studied in 20 chronic hemodialysis patients (group B). The mean age of these patients was $52.1 \pm 20.2$ years and they were on dialysis treatment for $3.3 \pm 2.6$ years. The results were compared with capillary morphology in 20 age and sex matched normal controls. 
Furthermore, 14 sex and age matched normal controls were studied to compare the outcomes of functional microcirculatory evaluations in this group (group C) with the results in group A at high Hct levels after 18 weeks of therapy.

ReHuEpo (Eprex, Cilag, Belgium) was administered intravenously 3 times a week after dialysis in group A, according to the so-called 'low and slow' dose schedule, starting at an initial dose of $50 \mathrm{U} / \mathrm{kg}$. Adjustments of the dose were done monthly, according to the response, defined as an increase or decrease of $5 \%$ or more as compared to the preceding Hct value. The target hemoglobin value was $6.2-7.5 \mathrm{mmol} / \mathrm{l}$. Oral iron suppletion up to $600 \mathrm{mg}$ a day was given in all but 2 patients, who obviously had adequate iron stores.

Hematological parameters were determined weekly, using routine laboratory methods. Iron parameters (serum ferritin, transferrin, total iron binding capacity) were investigated at monthly intervals.

The actual fluid state was determined and maintained by the serial assessment of the inferior vena cava diameter and the collapsibility index by means of echography. The measurements were performed with the patient in the suppine position after 10 minutes of rest. The transducer was placed in the subxiphoidal region, and long and short axis views of the inferior vena cava were recorded, just below the diaphragm in the hepatic segment. Simultaneously, a conventional electrocardiogram (ECG) was recorded. To avoid interference with $A$ and $\mathrm{V}$ waves, respectively, measurements of the diameter were done just before the $P$ wave on the ECG. The optimal collapsibility was registrated just at the beginning of deep inspiration to avoid valsalva-like manoeuvers [22]. To correct for interindividual differences in constitution, the data were corrected for body surface area in square meters. Then, the patients' dry weight could be adjusted to the normal range. The inter- and intra-observer variability of this method have been reported to be 5 and $2.5 \%$ for the diameter and $<10$ and $2.5 \%$ for the collapsibility index, respectively [21-22].

Mean arterial pressure (MAP; $\mathrm{mmHg}$ ) and heart rate (beats/min) were recorded during a 1-hour period of rest with the patient in the sitting position, by means of the Penaz method (Finapress BP monitor, Ohmeda 2300). The maximal difference between the MAP measured by this method and the pressure measured intra-arterially is less than $8 \mathrm{mmHg}$ [25].

Stroke volume was calculated from the cross-sectional area of the aortic valve and the maximal integral flow velocity in the ascending aorta, both assessed in early systole with the use of a Hewlett-Packard (770 20A) 3.5-MHz Duplex scanner. From these variables, cardiac output was calculated [26-28]. The interand intra-observer variability of this method have been reported to be less than $10 \%$ [29]. SVR was calculated using the conventional formula. Right atrial pressure could be delineated from the curvilinear relationship with the inferior vena cava diameter [21]. 
Plasma volume was determined using the ${ }^{125} \mathrm{I}$-albumin method [30]. Red blood cell (RBC) volume was calculated according to the serial Het method [31].

Morphological studies of the capillary circulation were done with the use of intravital videomicroscopy of the fingernail fold capillaries (Philips Video 40 camera, Leitz Wetzlar microscope, Sony videorecorder). The morphology of the capillaries was determined in the distal row (videoscreen $1800 \mu \mathrm{m}$, magnification $\times 160$ ), with special attention to the configuration of the capillaries.

In groups $\mathrm{A}$ and $\mathrm{C}$, transcutaneous oxymetry was performed at $37^{\circ} \mathrm{C}$ skin temperature on the dorsum of the hand on the side without dialysis fistula with the arm at heart level. Transcutaneous $\mathrm{PO}_{2}\left(\mathrm{TcP}_{2}\right.$ ) levels at rest, the peak value and the time to peak during the reactive hyperemia response after 3 minutes of arterial occlusion were determined [32-35]. The reproducibility of this method, expressed as percentage of variation from the means for each individual in serial determinations in several weeks, is about $10 \%$ [36]. TcPo2 recordings were made with a Radiometer TCM2TC oxygen monitor (Copenhagen, Denmark). For statistics the paired Student $t$ test was used for integral analysis. The nonpaired $t$ test for the difference in means was used to compare patient groups with controls. A p value of $<0.05$ was considered to be significant.

\section{Results}

Throughout the study Hct increased in the ReHuEpo treated patients from $19 \pm$ 4 to $33 \pm 5 \%$ ( $<<0.001)$, while normovolemia was maintained as indicated by the diameter and collapsibility index of the inferior vena cava. Total blood volume indeed remained unchanged, whereas $R B C$ volume increased significantly in accordance with the rise in Hct, and plasma volume decreased inversely (figure 1). Body weight increased significantly from $57.8 \pm 12$ to $62.1 \pm 12 \mathrm{~kg}$ $(\mathrm{p}<0.02)$ during the treatment period, indicative for an anabolic effect of ReHuEpo therapy. The macrocirculatory results are presented in figure 2. MAP did not change significantly. SVR increased significantly from values in the normal range to values above the upper nor$\mathrm{mal}$ limit of $1200 \mathrm{dyne} / \mathrm{s} / \mathrm{cm}^{-5}$. Cardiac index decreased significantly,

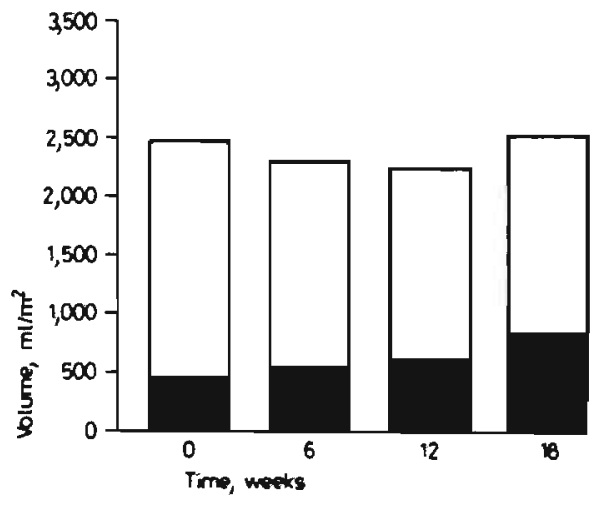

Figure 1: Effects of ReHuEpo treatment on RBC volume ( $\square$ ), plasma volume ( $\square$ ) and blood volume (plasma volume $+\mathrm{RBC}$ volume) 

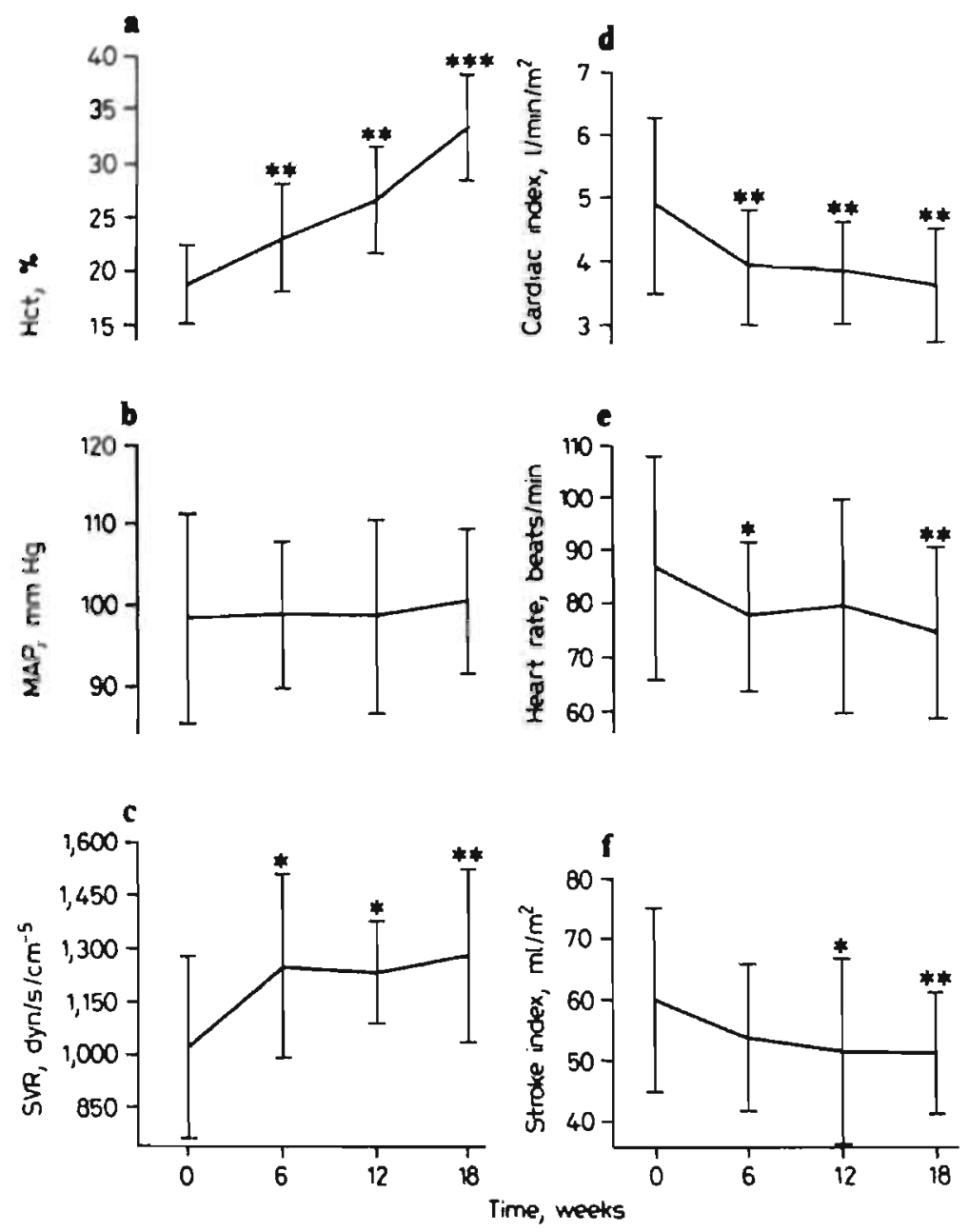

Figure 2: Effects of ReHuEpo on Hct (a; \%), MAP (b; mmHg), SVR (c; dyne/s/cm $\left.{ }^{-5}\right)$, cardiac index $\left(\mathrm{d} ; 1 / \mathrm{min} / \mathrm{m}^{2}\right)$, heart rate (e; beats $\left./ \mathrm{min}\right)$ and stroke index $\left(f ; \mathrm{ml} / \mathrm{m}^{2}\right){ }^{*} \mathrm{p}<0.05 ;{ }^{* *} \mathrm{p}<0.02$; ***p<0.001: compared to values before ( 0 weeks) ReHuEpo treatment.

due to a decrease in heart rate and stroke index.

In the 20 chronic hemodialysis patients (group B), the number of pathological capillary loops in the distal row of the fingernail fold has increased compared to normal subjects ( $48.7 \pm 18.1$ and $9.8 \pm 6.7 \%$, respectively; $p<0.001)$, with tortuosity in the arterial limb of the vessel, generally associated with a pronounced venodilation (figure 3 ).

The results of $\mathrm{TcPo}$ measurements in groups $\mathrm{A}$ and $\mathrm{C}$ are presented in table 1. The resting $\mathrm{TcPO}_{\mathrm{O} 2}$ values showed a small insignificant increase during 


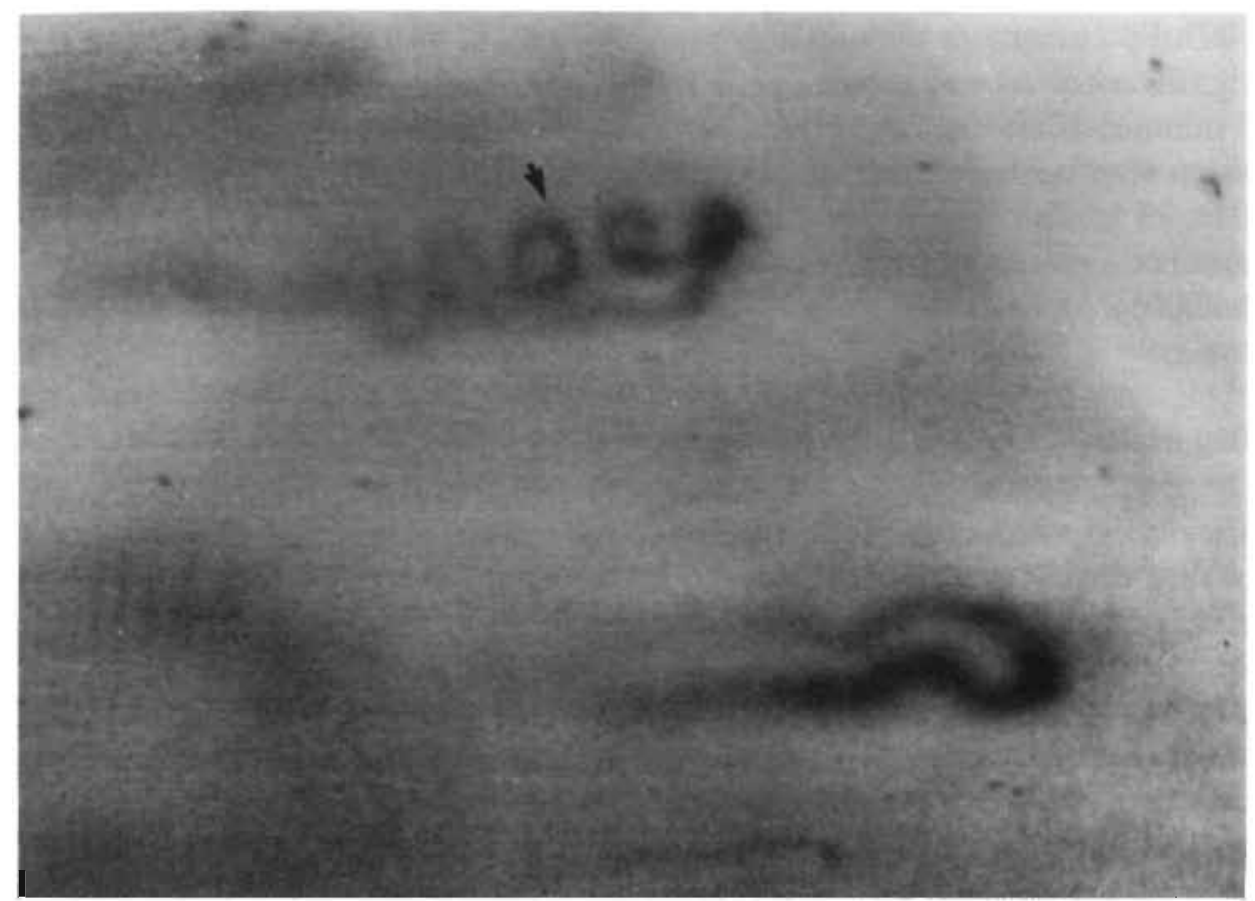

Figure 3: Pathological capillary loop with arterial tortuosity (arrow), generally accompanied by venous vasodilation.

Table 1: TcPo2 before (0 weeks) and during (6,12 and 18 weeks) ReHuEpo treatment in dialyzed patients (group A) compared to normal controls (group C) at optimal Hct

\begin{tabular}{|c|c|c|c|c|c|}
\hline \multirow[t]{2}{*}{ Parameter } & \multicolumn{4}{|c|}{ Patients (group A; n=9) } & \multirow{2}{*}{$\begin{array}{l}\text { Controls } \\
\text { (group C; } \\
\mathrm{n}=14 \text { ) }\end{array}$} \\
\hline & 0 weeks & 6 weeks & 12 weeks & 18 weeks & \\
\hline Rest TcPo2, mmHg & $2.3 \pm 1.3$ & $3.4 \pm 1.5$ & $2.7 \pm 1.1$ & $4.7 \pm 3.3^{\mathrm{a}}$ & $3.2 \pm 1.5$ \\
\hline Peak TcPo2, $\mathrm{mmHg}$ & $10.7 \pm 4.2$ & $16.0 \pm 4.3$ & $15.8 \pm 3.4$ & $16.6 \pm 5.3^{a . d}$ & $14.9 \pm 6.2$ \\
\hline TTP, s & $82 \pm 21$ & $95 \pm 11$ & $105 \pm 17^{c}$ & $121 \pm 25^{b . d}$ & $81 \pm 16$ \\
\hline Hct, \% & & & & $33 \pm 5$ & $40.2 \pm 4$ \\
\hline
\end{tabular}

${ }^{a} p=$ n.s. and ${ }^{b} p<0.001$ versus controls; ${ }^{c} p<0.05$ and ${ }^{d} p<0.02$ versus values before ReHuEpo therapy. TTP $=$ time to peak after arterial occlusion. 
ReHuEpo treatment with an improvement in 6 out of 9 patients. A similar but significant effect was noted in peak $\mathrm{Tc}_{\mathrm{O} 2}$ levels during reactive hyperemia after 3 minutes of arterial occlusion. The time necessary to reach the maximal peak value after occlusion increased significantly at 18 weeks of ReHuEpo therapy (Hct $33 \pm 5 \%$ ) compared to the initial value and to the values in the sex and age matched controls at an Hct of $40.2 \%(121 \pm 25$ and $81 \pm 16 \mathrm{~s}$, respectively; $\mathrm{p}<0.001)$.

\section{Discussion}

The development of ReHuEpo was expected to have an enormous impact on the quality of life of dialyzed patients. However, the increased morbidity, i.e. a higher incidence of dialysis fistula clotting, a decrease in dialysis efficacy and the occurrence of cerebral convulsions and hypertension [37], still raises the question as to whether there is an optimal Hct, because of the obvious relation between these complications and the rate of increase in Hct and the absolute Hct value achieved [17]. Hypertension, the incidence of which is estimated to be on the average of $30 \%$ and especially occurring in the preexistent hypertensive individual and during a steep increase in Hct, is generally related to an increase in SVR. The incorrect estimation of dialysis dry weight, often done on the basis of clinical parameters, may also play a crucial role in the incidence and pathophysiology of ReHuEpo related hypertension [17, 38].

Since the fluid status has an important, but to our opinion still underestimated, impact on micro- and macrocirculatory parameters in dialyzed patients, we performed our studies of the hemodynamic effects of ReHuEpo therapy in the normovolemic state. The actual volume state was determined by serial echographic assessment of the inferior vena cava diameter and collapsibility parameters, known to be in good correlation with blood volume, mean arterial pressure and plasma $\alpha$-human atrial natriuretic peptide levels [21]. As a result, total blood volume did not change throughout the study. The increase in RBC volume was accompanied by a decrease in plasma volume. Total body weight, however, increased, probably due to anabolism during ReHuEpo therapy [3941].

While maintaining the normovolemic state, MAP did not increase in our patients during ReHuEpo therapy, although there was a significant increase in SVR. Cardiac index decreased significantly, due to a decrease in heart rate and stroke volume.

Except for the findings of Verbeelen et al [42], other authors also reported a decrease in cardiac output, stroke volume and heart rate, and an increase in SVR during ReHuEpo therapy [34, 43-45]. In most of these studies, MAP increased significantly; however, the overall incidence of hypertension during ReHuEpo 
therapy reported in the literature is only about $30 \%$ with a range of $20-45 \%$. Similar findings were reported by Neff et al [46], who increased the Het of anemic dialyzed patients by serial blood transfusion to at least $40 \%$ within $6-12$ weeks, and saw an increase in the peripheral vascular resistance and a decrease in cardiac index, while MAP increased. Williams et al [47], increasing the Hct with an average value of $8 \%$ in a large and varied dialysis population, did not find an increase in predialysis blood pressures within 1 week after the blood transfusion. More detailed hemodynamic investigations unfortunately were not performed in this study [47].

Obviously, not all ReHuEpo treated patients develop hypertension, despite an increase in SVR, and it has been reported that individuals prone to hypertension had relatively high pre- and posttreatment cardiac output levels as compared to other patients treated with ReHuEpo, but remaining normotensive [45, 48]. In general, cardiac index and stroke volume decrease during the correction of anemia by ReHuEpo therapy, whereas SVR increases. Whether the MAP will rise, depends on the rate of increment in Hct, the ultimate Hct level achieved, the preexistence of hypertension and last but not least on the actual fluid status.

It is tempting to speculate on the pathogenesis of the decrease in stroke volume and the increase in SVR during ReHuEpo treatment. Since Löw et al [49] found an improvement of myocardial function, as indicated by an increased ejection fraction, an increased circumferential fiber shortening velocity and a slight decrease in stroke volume, it could quite well be that the decrease in cardiac pump function results from a diminished venous return and hence cardiac filling. The decrease in venous return could result from the increase in blood viscosity and SVR, accompanying the increase in Hct during ReHuEpo therapy. The improvement of peripheral oxygenation, by the increase in RBC mass and the persisting low hemoglobin oxygen affinity [50], reduces the necessity of compensatory mechanisms like sympathetic overactivity. Unfortunately, we did not determine the serum catecholamine levels in our study. Hauser et al [51] determined plasma catecholamine levels in hemodialyzed patients, treated with ReHuEpo but these investigations did not reveal a statistically significant difference in predialysis as well as postdialysis levels between the ReHuEpo treated dialyzed patients and control dialyzed patients [51].

The increase in SVR during ReHuEpo therapy could be explained by the improvement of peripheral oxygenation, which will reduce anoxic vasodilation. Unexplained, however, is the finding that SVR increases to levels above normal. It is unlikely that high levels of catecholamines are responsible for these relatively high SVR levels, since the plasma catecholamines do not seem to be increased under these circumstances [51]. ReHuEpo itself seems to have no direct vasopressor effect, but the possibility that it interferes in the vasoconstriction induced by hormones such as noradrenaline and angiotensin II cannot be 
excluded [52]. The increase in SVR is obviously also dependent on structural and functional changes in microcirculatory vessels [14].

The observed histological cutaneous microangiopathy in chronic hemodialysis patients [18-19] and the increased percentage of pathological tortuous capillaries in the nail fold as found in the present study, might contribute to the increase in SVR when viscosity is increased during ReHuEpo treatment. The functional alterations in the microcirculation, as reported in this study, are supporting this hypothesis. Rest values of $\mathrm{TcP}_{2}$ and peak values during reactive hyperemia at $37^{\circ} \mathrm{C}$ skin temperature both showed an increase at higher $\mathrm{Hct}$ levels, suggesting an improvement of peripheral oxygenation. However, except for the postocclusive peak TcPo2 values, these changes did not reach the level of significance. Time to peak value, after arterial occlusion, inducing arterial vasodilation, increased significantly at higher Hct levels. After 18 weeks of ReHuEpo treatment (Hct $33 \pm 5 \%$ ), time to peak was significantly longer in the patient group than in normal controls with an average Hct of $40.2 \%$. No differences existed in the time to peak values of the patient group at low Hct level $(19 \pm 4 \%)$ compared to the control group at high Hct level. The latter data suggest an impairment of capillary flow in hemodialyzed patients during the correction of anemia by ReHuEpo. This could be the result of the increased blood viscosity at higher Hct levels in combination with the pathological microcirculation noted in dialyzed patients.

The increased incidence of cerebral convulsions during ReHuEpo therapy [37], not consistently related to hypertension, for example might find its pathophysiologic explanation in the combination of these compromising factors. Blood cell velocity in the cerebral vessels has been shown to decrease by single-photon and emission computer tomography with ${ }^{133} \mathrm{Xe}$ [53] and especially in case of an underestimated dialysis dry weight, the subsequent strong decline of cardiac filling pressure and exaggerated hemoconcentration during dialysis might critically compromise cerebral perfusion.

In conclusion, maintaining the normovolemic state, ReHuEpo therapy in dialyzed patients did not lead to a rise in MAP despite the rise in SVR. The combination of pathological microcirculatory vessels and changes in theology might in part explain the increased SVR, in consequence leading to disturbances in microcirculatory flow.

\section{Acknowledgements}

This study has been made possible by the financial support of Cilag, Belgium. We thank the secretaries of our department, Desirée van Schoubroeck and Anke Hendriks, for the excellent secretary work. 


\section{References}

1. Eschbach JW, Egrie JC, Downing MR, Browne JK. Correction of the anemia of end-stage renal disease with recombinant human erythropoietin: Results of a combined phase I and II clinical trial. N Engl J Med 1987; 316: 73-78.

2. Winearls CG, Pippard MJ, Oliver DO, Reid C. Effects of human erythropoietin derived from recombinant human DNA on the anemia of patients maintained by chronic hemodialysis. Lancet 1986; ii: 1175-1177.

3. Sundal E, Kaeser U. Correction of anaemia of chronic renal failure with recombinant human erythropoietin: Safety and efficacy of one year's treatment in a European multicentre study of 150 haemodialysis dependent patients. Nephrol Dial Transpl 1989: 4: $979-987$.

4. Graf H, Mayer G, Cada EM, Thum J. Wirksamkeit von rekombinanten humanem Erythropoietin in der Behandlung der transfusionsabhängigen Anämie chronischer Dialysepatienten. Wien Klin Wochenschr 1987; 99: 855-859.

5. Ponticelli $\mathrm{C}$, Casati $\mathrm{S}$. Correction of anaemia with recombinant human erythropoielin. Nephron 1989; 52: 201-208.

6. Kreis H, Zins B, Naret C, Casadevall N, Goureau Y, Peterlongo F, Varet B, Najean Y, Jacquot C, Drieke T. Recombinant erythropoietin: Personal experience with a new treatment for the anemia of chronic renal failure. Transpl Proc 1989; 6 (suppl.2): 55-61.

7. Schaefer RM, Kokot F, Wemze H, Geiger H, Heidland A: Improved sexual function in hemodialysis patients on recombinant human erythropoietin: A possible role for prolactin. Clin Neprol 1989; 31: 1-5.

8. Schaefer RM; Hörl WH, Massry SG. Treatment of renal anemia with recombinant human erythropoietin. Am J Nephrol 1989; 9: 353-362.

9. Evans RW, Rader B, Egrie J, Adamson JW, Eschbach JW. Correction of anemia with ReHuEpo enhances the quality of life of hemodialysis patients. Kidney Int 1989; 35: 246.

10. Mayer G, Thum J, Cada EM, Stumvoll HK, Graf H. Working capacity is increased following recombinant human erythropoietin treatment. Kidney Int 1988; 34: 525-528.

11. Raine AEG. Hypertension, blood viscosity and cardiovascular morbidity in renal failure: Implications of erythropoietin therapy. Lancet 1988; i: 97-99.

12. Casati S, Passerini P, Campise MR, Graziani G, Cesana B. Benefits and risks of protracted treatment with human recombinant erythropoietin in patients having haemodialysis. Br Med J 1987; 295: 1017-1020.

13. Bommer J, Alexiou C, Muller-Buhl U, Eifert J, Ritz E. Recombinant human erythropoietin therapy in haemodialysis patients: Dose determination and clinical experience. Nephrol Dial Transpl 1987; 2: 238-242.

14. Nonnast-Daniel B, Schäffer J, Frei U. Hemodynamics in hemodialysis patients treated with recombinant human erythropoietin; in Berlyne GM, Giovannetti S (eds): Contr Nephrol. Basel, Karger 1989, 76: 283-291.

15. Samtleben W, Baldamus CA, Bommer J, Fassbinder W, Nonnast-Daniel B, Gurland HJ. Blood pressure changes during treatment with recombinant human erythropoietin; in Berlyne GM, Giovannetti S (eds): Contr Nephrol. Basel, Karger 1988; 66: 114-122.

16. Eschbach JW, Adamson JW. Correction of the anemia of hemodialysis patients with recombinant human erythropoietin: Results of a multicentre study (abstract). Kidney Int 1988; 33: 189. 
17. Jacquot CH, Ferragu-Itaguet M, LeFchre A, Berthelot J-M, Peterlongo F, Castaigne JP. Recombinant human erythropoietin and blood pressure. Lancet 1987; ii: 1083.

18. Ichimaru K, Horie A. Microangiopathic changes of subepidermal capillaries in endstage renal failure. Nephron 1987; 46: 144-149.

19. Gilchrest BA, Rowe JW, Mihm MC Jr. Clinical and histological skin changes in chronic renal failure: Evidence for a dialysis resistant transplant responsive microangiopathy. Lancet 1980; ii: 1271-1275.

20. Leunissen KML, Van den Berg BW, Cheriex EC, Slaaf DW, Reneman RS, Van Hooff JP. Influence of fluid removal during haemodialysis and macro- and skin microcirculation. Nephron 1990; 54: 162-168.

21. Leunissen KML. Haemodynamics during haemodialysis. Thesis, University of Limburg, 1988.

22. Cheriex EC, Leunissen KML, Janssen JHA, Mooy JMV, Van Hooff JP. Echography of the inferior vena cava is a simple and reliable tool for estimation of 'dry weight' in haemodialysis patients. Nephrol Dial Transpl 1989; 4: 563-568.

23. Moreno FLL, Hagan AD, Holmen IR, Pryor TA. Evaluation of size and dynamics of the inferior vena cava as an index of right-sided cardiac function. Am J Cardiol 1984; 53: 579-585.

24. Koomans HA, Geers AB, Dorhout Mees EJ. Plasma volume recovery after ultrafiltration in patients with chronic renal failure. Kidney Int 1984; $26: 848-854$.

25. Boehmer RD. Continuous, real-time noninvasive monitor of blood pressure: Penaz methodology applied to the finger. J Clin Monit 1978; 3: 282-287.

26. Huntsman LL, Stewart DK, Franklin SB. Noninvasive Doppler determination of cardiac output in man: Clinical validation. Circulation 1983; 67: 593-601.

27. Bouchard A, Blumlein S, Schiller NB. Measurement of left ventricular stroke volume using continuous wave Doppler echocardiography of the aortic valve. J Am Coll Cardiol 1987; 9: 75-83.

28. Schuster AH, Nanda NC. Doppler echocardiography measurement of cardiac output: Comparison with a non-golden standard. Am J Cardiol 1984; 53: 257-259.

29. Chandraratna PA, Nanna M, McKay C, Nimalasuriya A, Swinney R, Elkayam U, Rahimtoola SH. Determination of cardiac output by transcutaneous continuous-wave ultrasonic Doppler computer. Am J Cardiol 1984; 53: 234-237.

30. Keyes J, Carey J, Mosses D, Beyerwaltes W. Manual of Nuclear Medicine procedures, ed. 2. Cleveland, CRS press 1973, p. 95-98.

31. Tararin RC, Melsher HJ, Dustan MP, Frolick ED. Plasma volume changes with upright tilt, studies in hypertension and in syncope. J Appl Physiol 1970; 28: 121-126.

32. Ewald U. Evaluation of the transcutareous oxygen method used at $37^{\circ} \mathrm{C}$ for measurement of reactive hyperaemia in the skin. Clin Physiol 1984; 4: 413-423.

33. Newson TP, Rolfe P. The use of transcutaneous oxygen tension measurements for the assessment of the cutaneous microcirculation; in Tooke JE, Smaje LH (eds): Clinical investigations of the microcirculation, Boston, Martinus Nijhoff Publishing, 1987, p. 71-74.

34. Nonnast-Danicl B, Creutzig A, Kuhn K, Bachmann J, Reimers E. Effect of treatment with recombinant human erythropoietin on peripheral hemodynamics and oxygenation; in Berlyne GM, Giovannetti S (eds): Contr Nephrol. Basel, Karger, 1988; 66: 185-194.

35. Wiedemann HP, Oreus DK, Sivak ED: Transcutaneous oxygen monitoring. Cleve Clin Q 1985: 52: 483-488. 
36. Coleman LS, Dowd GSE, Bentley G. Reproducibility of TcPO2 measurements in normal volunteers. Clin Phys Physiol Meas 1986; 7: 259-263.

37. Eschbach JW, Downing MR, Egrie JC, Browne JK, Adamson JW. USA multicenter clinical trial with recombinant human erythropoietin (Am-Gen): Results in hemodialysis patients; in Berlyne GM, Giovannetti S (eds): Contr Nephrol. Basel, Karger 1989; 76: $160-165$.

38. Tomson CRV, Venning MC, Ward MK. Blood pressure and erythropoietin. Lancet 1988; i: 351.

39. Zehnter E, Poilok M, Ziegenhagen D, Braunsiepe P, Longere F, Baldamus CA. Urea kinetics in patients on regular dialysis treatment before and after treatment with recombinant human erythropoietin; in Berlyne GM, Giovannetti S (eds): Contr Nephrol. Basel, Karger, 1988; 66: 149-155.

40. Riedel E, Hampl H, Scigalla P, Nündel M, Kessel M. Correction of amino-acid metabolism by recombinant human erythropoietin therapy in hemodialysis patients. Kidney Int 1989; (suppl.27): S216-S221.

41. Canaud B, Polito-Bouloux C, Rivory JP, Taib J, Garred LJ, Florence P, Mion C. Erythropoietin induced changes in protein nutrition: Quantitative assessment by urea kinetic modeling analysis (abstract). Blood Purif 1989; 7: 288.

42. Verbeelen D, Bossuyt A, Smitz J, Herman A, Dratwa M, Jonckheer MH. Hemodynamics of patients with renal failure treated with recombinant human erythropoietin. Clin Nephrol 1989; 31: 6-11.

43. Buckner FS, Eschbach JW, Haley NR, Davidson RR, Adamson JW. Correction of the anemia in hemodialysis patients with recombinant human erythropoietin. Hemodynamic changes and risks for hypertension (abstract). Kidney Int 1989; 35: 237.

44. Deschodt G, Granolleras C, Alsabadini B, Branger B, Koch KM, Shaldon S. Changes in cardiac output, blood pressure and peripheral resistance following treatment of renal anemia by recombinant human erythropoietin. Nephrol Dial Transpl 1988; 3: 494.

45. Akiba T, Kurihara S, Katoh H. Hemodynamic changes of hemodialyzed patients by erythropoietin treatment. Kidney Int 1989; 35: 237.

46. Neff MS, Kim KE, Persoff M, Onesti G, Schwartz C. Hemodynamics of uremic anemia. Circulation 1971; 43: 876-883.

47. Williams B, Edmunds ME, Thompson JP, Burton PR, Feehally J, Walls J. Does increasing haemoglobin concentration and haematocrit have a pressor effect in dialysis patients. Nephrol Dial Transpl 1989; 4: 787-791.

48. Frei U. Cardiovascular effects of recombinant human erythropoietin treatment. Blood Purif (submitted).

49. Löw I, Grützmacher P, Bergmann M, Schoeppe W. Echocardiographic findings in patients on maintenance hemodialysis substituted with recombinant human erythropoietin. Clin Nephrol 1989; 3: 26-30.

50. Böcker A, Reimers E, Nonnast-daniels B, Kühn K, Koch KM, Scigalla P, Braumann $\mathrm{KM}$, Brunkhorst R, Böning D. Effect of erythropoietin treatment on $\mathrm{O}_{2}$ affinity and performance in patients with renal anemia; in Berlyne GM, Giovannetti $S$ (eds): Contr Nephrol. Basel, Karger, 1988; 66: 165-175.

51. Hauser AC, Stockenhuber F, Derfler K, Bulche P. Plasma catecholamine levels in haemodialysis patients treated with erythropoietin (abstract). EDTA-ERA 26th Annual Congress, Gothenburg, June 1989, p. 195.

52. Bund SJ, Heagerty A, Edmunds M, Walls J. Erythropoietin does not induce vasoconstriction directly in human subcutaneous resistance arterioles. Nephron 1989; 53: 173. 
53. Horina J, Holzer H, Ziak E, Winkler HM, Roob J. Changes of cerebral blood flow following erythropoietin treatment in patients with chronic renal failure (abstract). Nephrol Dial Transpl 1989; 4: 474. 


\section{CHAPTER II}

\section{The long term effects of recombinant human erythropoietin on macro- and microcirculation in chronic hemodialysis patients}

J.J.J.M. Wirtz ${ }^{1}$, K.M.L. Leunissen ${ }^{1}$, W. van Kuijk ${ }^{1}$, E.C. Cheriex ${ }^{2}$, D.W. Slaaf ${ }^{3}$, R.S. Reneman ${ }^{4}$, J.P. van Hooff ${ }^{1}$

Department of Internal Medicine ${ }^{1}$, Cardiology $^{2}$, Biophysics $^{3}$, and Physiology ${ }^{4}$

University Hospital and Cardiovascular Research Institute, Maastricht, The Netherlands

Blood Purification (in press) 


\section{Abstract}

Erythropoietin therapy (ReHuEpo) at short-term leads to an increase in systemic vascular resistance, a decrease in cardiac index and skin microcirculatory flow. Long-term adaptive changes might occur. We studied the effects of ReHuEpo therapy on macrocirculation and skin microcirculation in 8 normotensive and normovolemic hemodialysis patients before and after respectively 4 and 14 months of treatment. The reported macrocirculatory changes at short term were at long term not significantly different as compared to the initial values. Mean arterial pressure remained unaltered, as might be explained by the slow correction of the hematocrit and the decrease in cardiac output in all initially longlasting normotensive patients, who were maintained normovolemic. Left ventricular end diastolic dimensions decreased and also left ventricular muscle mass decreased depending on the initial left ventricular muscle mass. Skin oxygenation improved whereas maximal capillary flow decreased both at shortand long-term ReHuEpo treatment. The number of capillaries in the nailfold remained unchanged. However, the percentage of tortuosity decreased significantly during ReHuEpo therapy.

\section{Introduction}

Chronic anemia is associated with functional hemodynamic changes, like increased cardiac output and heart rate, and decreased peripheral vascular resistance [1-2]. Also structural cardiovascular changes are related to chronic anemia, as there are an increase in left ventricular end diastolic diameter and left ventricular muscle mass [3-6].

Correction of the anemic state by recombinant human erythropoietin (ReHuEpo) therapy in patients with renal anemia induced a decrease of cardiac output, due to a decrease of heart rate and venous return, and an increase of systemic vascular resistance [7-9].

The increase of systemic vascular resistance has been attributed to a loss of hypoxic vasodilation, to changes in humoral effects on resistance and to increased blood viscosity. In normal physiology approximately $50 \%$ of the systemic vascular resistance is located at the microcirculatory level (eg. vessels with an internal diameter of $100 \mu \mathrm{m}$ or less). The microcirculation of dialysis patients, as studied by intravital microscopy in the finger nailfold, revealed an increased incidence of pathological tortuous capillaries, especially in hypertensive but also in normotensive dialysis patients as compared to normal controls $(61 \%, 35 \%, 8 \%$ respectively) [10]. These microcirculatory changes in combination with the increased blood viscosity at higher hematocrit levels could in part be responsible for the increased peripheral vascular resistance during the correc- 
tion of renal anemia with ReHuEpo. The observed morphological changes in the microcirculation of dialysis patients could be related to uremic toxins, hypertension, and anemia, and turned out to be reversible after renal transplantation [11]. The effect of ReHuEpo on the microcirculatory morphology, however, is yet unknown.

Correction of renal anemia by ReHuEpo resulted also in macrocirculatory structural changes, like a decrease of preexistent left ventricular hypertrophy [12-18] and left ventricular dimensions [19-22]. The decrease of venous compliance during ReHuEpo therapy [7] is probably not related to structural change$\mathrm{s}$, but most likely to an increase in venous tone.

The aim of the current study was to investigate whether the reported early hemodynamic changes, i.e. increased systemic vascular resistance and decreased cardiac output, persisted in the course of longterm treatment with ReHuEpo. Furthermore, we investigated if longterm treatment with ReHuEpo, improving peripheral oxygenation, improved the structural abnormalities of the cardiovascular system of patients with end-stage renal failure, at both the macrocirculatory and microcirculatory level. Because hypertension also induces structural vascular changes, we investigated the effect of longterm ReHuEpo therapy on these parameters only in dialysis patients with longstanding normotension.

\section{Patients and methods}

Fifteen normotensive (postdialytic blood pressure $\leq 140 / 90 \mathrm{mmHg}$ ) chronic hemodialysis patients (group A; 5 females, 10 males) were initially included in the study. The mean age of the group was $46 \pm 17$ years (28-80). The patients were dialysed 3 times a week, using bicarbonate buffer and a biocompatible membrane (GFS 16, Gambro, Haemophane). The calculated Kt/V was $>1$ for each dialysis treatment.

Patients with severe hyperparathyreoidism, signs of aluminium intoxication, diabetes mellitus or cardiac dysfunction, defined as a left ventricular ejection fraction $<40 \%$, and/or clinically important valvular disease, were excluded. Also patients with left ventricular asynergy were considered not to be eligible.

All patients were normotensive at entrance of the study (for more than 6 months) with or without antihypertensive medication, 7 patients were using calcium entry blockers. None of them used other vasodilating agents, betablocking agents or ACE inhibitors. Twentyfour hours before the investigations all antihypertensive medication was temporarily stopped. The studies were performed 20-24 hours after dialysis, the moment of optimal plasma volume 
preservation [23]. The patients were studied longitudinally over 1 year and served as their own controls.

Furthermore, 8 sex and age ( $52.5 \pm 13$ years) matched normal controls (group B) were studied to compare the outcome of the functional microcirculatory evaluations in this group with the results obtained in the patient group. The hematocrit in group B was $39 \pm 3 \%$.

In group A ReHuEpo (Eprex, Cilag, Belgium) was administered intravenously 3 times a week after every dialysis, according to the so called "low and slow" dose schedule, starting at an initial dose of $50 \mathrm{U} / \mathrm{kg}$. Adjustments of the dose were carried out monthly according to the response as defined by an increase or a decrease of $5 \%$ or more as compared to the preceding hematocrit value. The target hemoglobin was set upon $10.5-11.6 \mathrm{~g} / \mathrm{dl}$. Oral iron suppletion upto 600 $\mathrm{mg} /$ day was given in all patients, and parenteral iron was temporarily used in only one patient.

Hematological parameters were determined initially at weekly intervals and two weekly during the maintenance fase after the target hematocrit had been reached, using routine laboratory methods. Iron parameters (serum ferritine, transferrin, total iron binding capacity) were checked every month.

The actual fluid state was determined and normovolaemia was maintained, using the method of serial assessment of the inferior caval vein diameter and the collapsibility index by means of echography [24] and adjusting the individual dialysis dry weight to the normal range. The inter- and intra-observer variability for our cardiovascular research laboratory was for the vena cava diameter less than $5 \%$ and $2,5 \%$ respectively, and for the collapsibility index less than $10 \%$ and $2,5 \%$ respectively.

The different macro- and microcirculatory parameters were evaluated before the study, after reaching the target hematocrit and after more than one year of ReHuEpo therapy.

\section{Macrocirculation}

The functional aspects of the macrocirculation were studied as follows:

Mean arterial pressure (MAP, $\mathrm{mmHg}$ ) and heart rate ( $\mathrm{HR}$, beats/min) were recorded during a one hour period of rest with the patient in the sitting position, using the Penaz method (Finapress BP monitor, Ohmeda 2300) [25-26].

Echocardiographic registration was performed, according to the recommendation of the American Society of Echocardiography [27-28]. Stroke volume (SV, $\mathrm{ml} / \mathrm{min}$ ) was determined from the data of the cross-sectional area of the aortic valve and the maximal integral flow velocity in the ascending aorta during 
early systole with the use of a Hewlett Packard (7700 20a) 3.5 megaherz Duplex scanner. Cardiac output $(\mathrm{CO}, 1 / \mathrm{min})$ was determined from SV and heart rate [29-31]. The intra- and interobserver variability of this method have been reported to be less than 10\% [30]. Stroke index (SI) and cardiac index (CI) are $\mathrm{SV}$ and $\mathrm{CO}$ per square meter body surface area.

Subsequently systemic vascular resistance (SVR, dyne $/ \mathrm{sec} / \mathrm{cm}^{-5}$ ) was calculated using the conventional formula (SVR $=$ [MAP-RAP]:CO $\times 80 ; \mathrm{RAP}=\mathrm{right}$ atrial pressure, which value can be delineated from its curvilinear relationship with the measured inferior caval vein diameter [24]).

Left ventricular ejection fraction (EF, \%) as well as fractional fiber shortening (FFS) were calculated according to Von Bibra et al [32].

Plasma volume (PV, $\mathrm{ml})$ was determined using the $\mathrm{I}^{125}$ albumin method [33], whereas red blood cell volume $(\mathrm{RBCv}, \mathrm{ml})$ was calculated according to the serial hematocrit method [34].

The geometric aspects of macrocirculation were studied by means of additional echocardiographic registrations including: left ventricular end-diastolic diameter (LVEDD, $\mathrm{mm} / \mathrm{m}^{2}$ ) and volume (LVEDV, $\mathrm{ml} / \mathrm{m}^{2}$ ) as well as end-systolic diameter (LVESD, $\mathrm{mm} / \mathrm{m}^{2}$ ) and volume (LVESV, $\mathrm{mm} / \mathrm{m}^{2}$ ), using the Teichholz formula [35]. Also the posterior wall end-diastolic thickness (PWEDWT, $\mathrm{mm} / \mathrm{m}^{2}$ ) and interventricular septal wall thickness (IVS-EDWT, $\mathrm{mm} / \mathrm{m}^{2}$ ) were measured, as was the left atrial diameter (LAD, $\mathrm{mm} / \mathrm{m}^{2}$ ). For the determination of total left ventricular volume $\left(\mathrm{LVV}, \mathrm{ml} / \mathrm{m}^{2}\right)$ and left ventricular mass (LVM, gram $/ \mathrm{m}^{2}$ ), the formula of Devereux and Reichek was applied [36]. The correlation of LVM, calculated according to this method, with necropsy findings has been observed to be high $(r=0.92)$ with only $6 \%$ of overestimation and with a very low intra- and interobserver variability [37].

\section{Microcirculation}

Functional information about the microcirculation was obtained with transcutaneous oxymetry (radiometer $\mathrm{TcM}_{2} \mathrm{Tc}$ oxygen monitor, Copenhagen, Denmark) at a skin temperature of $37^{\circ} \mathrm{C}$ [38-43]. The electrodes were placed on the dorsum of the hand at the side without dialysis fistula and with the arm at heart level.

Transcutaneous $\mathrm{PO}_{2}\left(\mathrm{Tc} \mathrm{PO}_{2}\right)$ levels at rest $(\mathrm{mmHg})$ as well as the peak value $(\mathrm{mmHg})$ and the time to peak value (TTP, sec) during reactive hyperaemia following the release of a 3 minutes arterial occlusion, were determined. The patient group as well as the control group were evaluated by this method, the reproducability of which, expressed as the percentage of variation from the means for each individual in serial determination, has been reported to be $\pm 10 \%$ [42]. 
Anatomical evaluations of the capillary circulation were done with the use of intravital videomicroscopy of the finger nailfold capillaries (Philips video 40 camera, Letz Wetzlar microscope, Sony videorecorder). The capillaries were studicd in the distal row (videoscreen $1800 \mu \mathrm{m}$, magnification x 160) paying attention not only to the number of capillaries, but also to their morphology i.e. tortuosity. Tortuosity was defined as one or more loops in the arterial limb of capillaries in the distal row. Tortuosity was scored as a percentage of the total number of capillaries in the distal row. The capillaries were studied in 3 microscopic fields in the nailfold. The skin temperature of the examined finger during the investigation was $30 \pm 1.6^{\circ} \mathrm{C}$.

\section{Statistics}

Statistical analyses were done with the Wilcoxon Rank-sumtest for intra-group results. The Mann-Whitney signed rank test was used to compare patients with controls. The data were expressed as means \pm S.D. Correlation coefficients were determined by the Pearson Rank test. In all tests a p-value of $<0.05$ was considered to be significant.

\section{Results}

Of the 15 patients initially included in the study only 8 of them could be evaluated at long term. Of the 7 patients not available for follow-up 3 were transplanted with a postmortal donor kidney, 1 patient changed to CAPD, 1 died at home by an unknown cause and 2 patients refused to participate in further evaluations.

The mean age of the evaluable group of 8 patients was $50.6 \pm 15.6$ years (31-80) with a mean duration of dialysis before the start of the study of 26 months (5-84).

During the correction phase of treatment with ReHuEpo, hematocrit $(\mathrm{Ht}, \%)$ increased from $21 \pm 2$ to $36 \pm 4 \%$ ( $p<0.001$ ). During the maintenance phase, after the target $\mathrm{Ht}$ had been reached at $4 \pm 1$ months (period I) and upto $14 \pm 2$ months (period II) of follow-up, Ht remained unaltered. 
Table 1: Hematocrit, hemodynamic results and body weight before and during \pm 14 months of ReHuEpo therapy in 8 normotensive dialysis patients

\begin{tabular}{lllll}
\hline & PTe & & I & II \\
\hline $\mathrm{Ht}(\%)$ & $21 \pm 2$ & $*$ & $36 \pm 3$ & $36 \pm 3^{\circ}$ \\
$\mathrm{MAP}(\mathrm{mmHg})$ & $95 \pm 9$ & & $101 \pm 11$ & $99 \pm 12$ \\
$\mathrm{SI}\left(\mathrm{ml} / \mathrm{b} / \mathrm{m}^{2}\right)$ & $52 \pm 8$ & $* * *$ & $47 \pm 7$ & $52 \pm 12$ \\
$\mathrm{CI}\left(\mathrm{l} / \mathrm{min} / \mathrm{m}^{2}\right)$ & $4.0 \pm 0.7$ & $* *$ & $3.4 \pm 0.6$ & $3.7 \pm 1.0$ \\
SVR $\left(\right.$ dyne $\left./ \mathrm{sec} / \mathrm{cm}^{-5}\right)$ & $1038 \pm 164$ & $* *$ & $1320 \pm 221$ & $1235 \pm 368$ \\
EF $(\%)$ & $57 \pm 7$ & & $54 \pm 9$ & $57 \pm 7$ \\
FFS $(\%)$ & $36 \pm 3$ & & $34 \pm 3$ & $34 \pm 3$ \\
BW $(\mathrm{kg})$ & $66.7 \pm 8$ & $* *$ & $70.3 \pm 8$ & $71.7 \pm 9^{\circ}$ \\
\hline
\end{tabular}

Significant differences are indicated by: ${ }^{*} p<0.001 ;{ }^{* *} p<0.02 ;{ }^{* * *} p<0.05 ;{ }^{\circ} p<0.001$; The asterixes represent significant differences between short-term results and the initial values. The open circles represent significant differences between the long-term results and the initial values; Pre : before ReHuEpo treatment; I: period I correction phase to reach target hematocrit level; II: period II maintenance phase at target hematocrit level.

\section{Macrocirculation}

A) Functional aspects (table I):

MAP did not change significantly. HR (-14.2\%) as well as stroke index (SI) $(-9.6 \%)$ and cardiac index $(\mathrm{CI})(-15.2 \%)$ decreased significantly at short term. However, at longterm the differences as compared with the initial values were not significant. SVR increased significantly during the correction phase with $+29.2 \%$ and again the difference at long term was not significant as compared to the initial value. EF and FFS did not change during the whole period of investigation. The data of $\mathrm{BV}$ and derived voluminae are depicted in figure $\mathrm{I}$. PV decreased inversely with $\mathrm{RBCV}$ to remain unchanged at long term, whereas $\mathrm{BV}$ remained unaltered. Body weight $(\mathrm{BW} ; \mathrm{kg}$ ) increased significantly at short term but remained unaltered at long term treatment.

B) Geometrical aspects (table II):

The indexed LVEDV (-10.8\%) and LVEDD (-8\%) decreased significantly during the correction phase and remained unaltered in the maintenance phase of $\mathrm{Ht}$, whereas the indexed values of LVESV and LVESD did not change at all. The PW-EDWT decreased, whereas the IVS-EDWT did not change. Also LAD remained unchanged. The indexed LVV as well as the LVM did not change significantly. However, in 6 out of 8 patients, LVM decreased with $-20 \%$. In the 


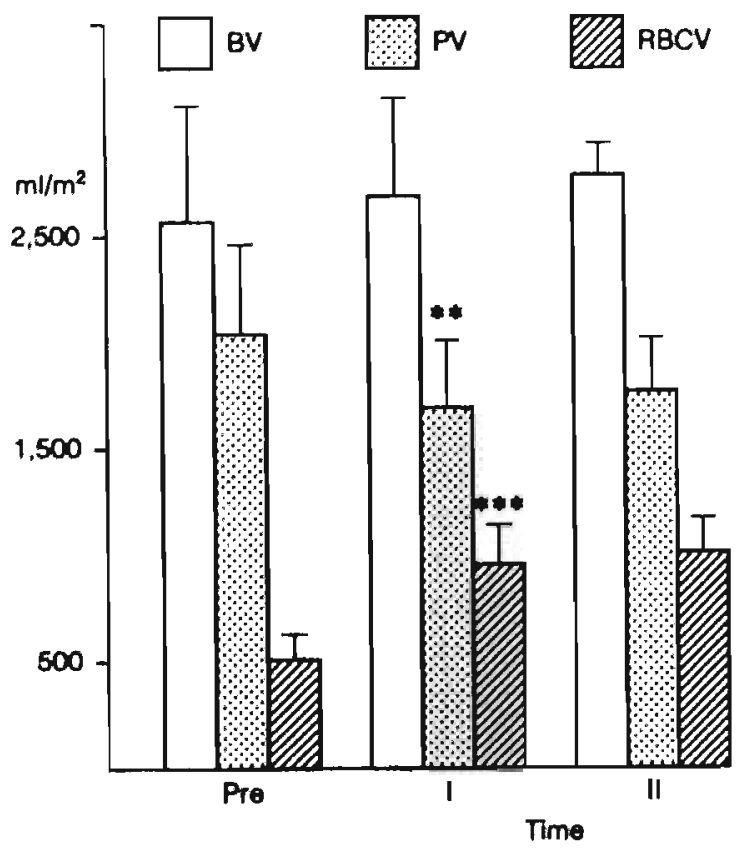

Figure 1: Blood volume (BV), plasma volume (PV) and red blood cell volume (RBCV) during treatment with ReHuEpo. Significant differences as compared with the initial values are indicated:

${ }^{* *} \mathrm{p}<0.01 \quad$ (pre vs. -I) ; $* * * p<0.001$ (pre vs.-I); Pre: before ReHuEpo treatment; I: period I correction phase to reach target hematocrit level; II: period II: maintenance phase at target hematocrit level.

Table 2: Echocardiographic results of 8 normotensive dialysis patients before and during long-term ReHuEpo therapy

\begin{tabular}{|c|c|c|c|c|c|}
\hline & Pre & & $I$ & & $\Pi$ \\
\hline $\mathrm{LVEDV} / \mathrm{m}^{2}(\mathrm{ml})$ & $71 \pm 18$ & $* *$ & $62 \pm 13$ & & $56 \pm 13^{\circ}$ \\
\hline $\mathrm{LVEDD} / \mathrm{m}^{2}(\mathrm{~mm})$ & $29 \pm 3$ & $* *$ & $27 \pm 3$ & & $26 \pm 3$ \\
\hline LVESV $/ \mathrm{m}^{2}(m l)$ & $25 \pm 9$ & & $24 \pm 8$ & & $21 \pm 7$ \\
\hline $\mathrm{LVESD} / \mathrm{m}^{2}(\mathrm{~mm})$ & $18 \pm 2$ & & $18 \pm 3$ & & $17 \pm 3$ \\
\hline PWEDWT $/ \mathrm{m}^{2}(\mathrm{~mm})$ & $6.0 \pm 0.8$ & & $5.8 \pm 1.1$ & & $5.5 \pm 0.7$ \\
\hline ivsEDWT/m² $(\mathrm{mm})$ & $6.2 \pm 1.3$ & & $5.8 \pm 0.9$ & & $5.8 \pm 1.0$ \\
\hline $\mathrm{LAD} / \mathrm{m}^{2}(m m)$ & $26 \pm 3$ & & $25 \pm 3$ & & $24 \pm 3$ \\
\hline $\mathrm{LVV} / \mathrm{m}^{2}(m l)$ & $275 \pm 99$ & & $260 \pm 76$ & & $236 \pm 32$ \\
\hline $\mathrm{LVM} / \mathrm{m}^{2}(g r)$ & $90.6 \pm 29.6$ & & $84.6 \pm 26.7$ & & $76.0 \pm 12.0$ \\
\hline
\end{tabular}

Significant differences are indicated by: ${ }^{* *} p<0.02 ;{ }^{\circ} \mathrm{p}<0.001$; The asterixes represent significant differences between short-term results and the initial values. The open circle represents a significant difference between the longterm result and the initial value; Pre: before ReHuEpo therapy; I: period I correction phase to reach target hematocrit level; II: period II maintenance phase at target hematocrit level. 


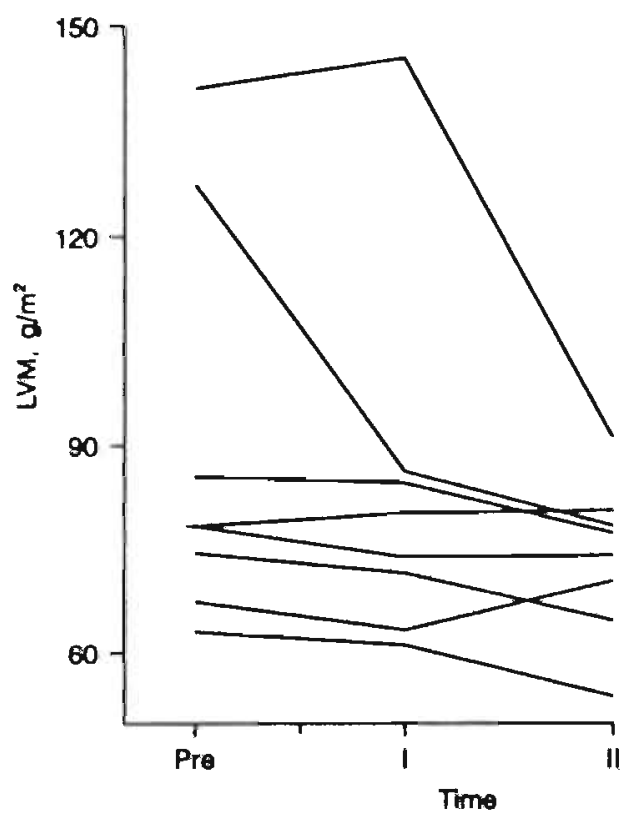

Figure 2: Individual values of left ventricular mass (LVM) during treatment with ReHuEpo.

Pre : before ReHuEpo treatment; I: period I correction phase to reach target hematocrit level; II: period II maintenance phase at target hematocrit level.

remaining 2 patients with a normal LVM, a small increase of LVM was observed with $+4.5 \%$, all of them however still remaining within the normal range (figure II).

A strong inverse relation was found between the initial LVM(i) and the decrease of the left ventricular muscle mass after long term treatment with ReHuEpo ( $r=0.92, p=0.001)$.

\section{Microcirculation}

A) Functional aspects:

The results of the $\mathrm{TcpO}_{2}$ measurements at $37^{\circ} \mathrm{C}$ subelectrode skin heating are depicted in figure 3 and compared to the data of the control group.

After reaching target $\mathrm{Ht}$-level at $37^{\circ} \mathrm{C}$, a significant increase in $\mathrm{TcpO}_{2}$ resting values and peak TcPO2 values following the release of an arterial occlusion was observed, suggesting an improvement of peripheral oxygenation. However, the TTP also increased significantly, suggesting an impairment in capillary flow. At long term treatment the same data were found (figure 3).

B) Anatomical aspects:

The data of intravital microscopy of the nailfold capillaries regarding the number of capillaries and the percentage of tortuosity, as studied in the distal 

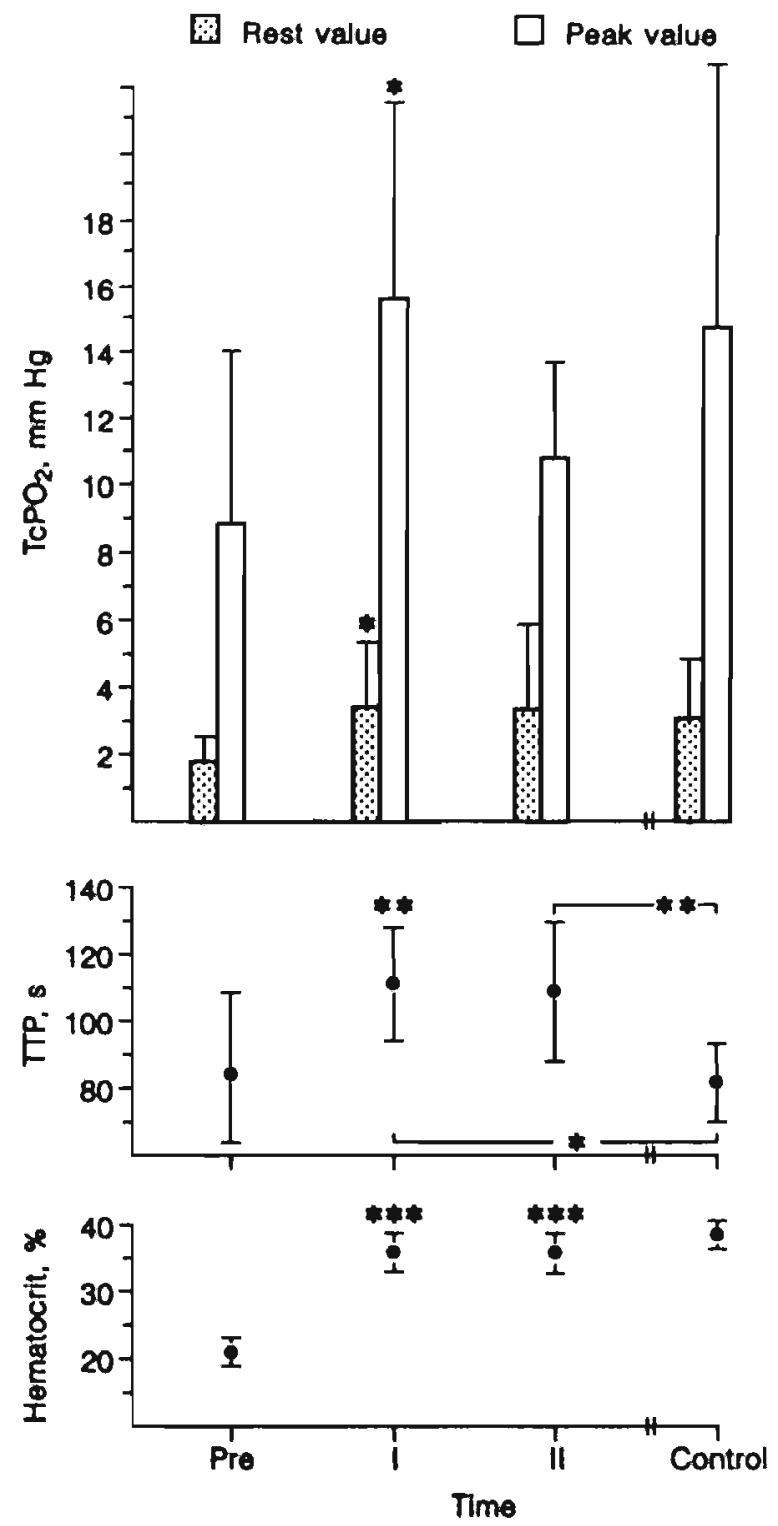

Figure 3: $\mathrm{TcPO}_{2}$ rest and peak values $(\mathrm{mmHg}$ ), time to peak (TTP) and hematocrit in the patient group A during treatment with ReHuEpo and in control subjects B. Significant differences are indicated between the two examinations and the initial values, and in addition in the TTP graph between the two examinations and the control group: * $p<0.05 ;{ }^{* *} p<0.01 ;{ }^{* * *} p<0.001$; Pre : before ReHuEpo treatment; I: period I correction phase to reach target hematocrit level; II: period II maintenance phase at target hematocrit level. 
Table 3: Microvascular structural data on 8 nomotensive dialysis patients before and during long-term ReHuEpo therapy

\begin{tabular}{llllll}
\hline & Pre & & I & & II \\
\hline $\begin{array}{l}\text { Number of } \\
\text { capillaries }\end{array}$ & $\begin{array}{l}9.7 \pm 2.3 \\
(5.7-13)\end{array}$ & ns & $\begin{array}{l}11.4 \pm 2.6 \\
(7.8-15)\end{array}$ & ns & $\begin{array}{l}11.4 \pm 2.5 \\
(7.6-14)\end{array}$ \\
$\begin{array}{l}\text { Tortuosity } \\
(\%)\end{array}$ & $34.7 \pm 23.1$ & $<0.05$ & $10.2 \pm 7.2$ & ns & $7.1 \pm 5.6^{\circ}$ \\
\hline
\end{tabular}

${ }^{\circ} \mathrm{p}<0.05$; The open circle represents a significant difference in percentage tortuosity between the longterm result and the initial values; Pre: before ReHuEpo therapy; I: period I correction phase to reach target hematocrit level; II: period II maintenance phase at target hematocrit level.

row, are given in table III. The total number of capillaries/ videoscreen did not change during ReHuEpo therapy. However, there was a significant decrease in the percentage of tortuous capillaries in the distal nailfold during ReHuEpo therapy.

\section{Discussion}

Correction of chronic renal anemia by ReHuEpo therapy, with in consequence an improvement of tissue oxygenation, revealed a decrease of cardiac output and an increase of systemic vascular resistance, leading to a significant increase of blood pressure in about $30 \%$ of the treated hemodialysis patients. Especially the patients with pre-existent hypertension were prone to develop a more severe hypertension [44].

The improved peripheral oxygenation with subsequent loss of autoregulatory hypoxic vasodilation [45-46], recovery of the lost responsivity of peripheral vascular smooth muscle cells for certain vasoconstrictor stimuli [47] and the direct influence of vasoactive humoral substances [48], have been suggested to be responsible for the increased systemic vascular resistance during treatment with ReHuEpo. To what extent direct effects of RehuEpo on the resistance vessels are involved, is still matter of debate [49-51].

Also increased blood viscosity in combination with the observed pre-existent structural vascular changes in hemodialysis patients could result in an increased vascular resistance. This hypothesis is supported by the fact that a direct and non-linear relation has been found between hematocrit and blood pressure [45] 
and that patients with pre-existent hypertension, knowing to have the most pronounced structural vascular changes, showed a significant rise in blood pressure [44]. So, functional changes due to ReHuEpo therapy combined with structural vascular changes could play a role in the increase of the systemic vascular resistance and blood pressure in ReHuEpo treated hemodialysis patients. The question is whether on long term ReHuEpo therapy functional and/or structural adaptations will lead to a normalisation of the hemodynamic state.

In this study cardiac index and stroke index decreased and systemic vascular resistance increased during short term treatment with ReHuEpo as was also observed by others [7-9]. Blood pressure did not change significantly while normovolaemia was maintained throughout the whole study period as indicated by the vena cava parameters and the constant total blood volume. Also, the preexistent normotensive state of all our patients and the decrease in cardiac output together with the gradual correction of hematocrit during treatment with ReHuEpo are expected to contribute to the avoidance of hypertension. As cardiac output is determined by blood volume, heart rate, cardiac contractility and venous return, the decrease in stroke volume might be secondary to a decrease in venous return since blood volume, left ventricular ejection fraction and fractional fiber shortening did not change, which is in agreement with previous observations $[7,15]$. London et al observed a decrease of venous compliance and a non-catecholamine related increase in venoconstriction in the extremities as compensation for the decreased venous return and hence cardiac filling [7].

After long term treatment cardiac index, stroke index, systemic vascular resistance and blood pressure were not different from values determined after the target hematocrit had been reached and no significant differences with the initial values before treatment could be detected anymore.

During treatment with ReHuEpo end-diastolic left ventricular dimension declined, whereas end systolic diameter and volume did not change. The decrease of left ventricular end diastolic diameter and volume can probably be explained by a decrease in venous return.

The PW-EDWT decreased, whereas the IVS-EDWT did not change. In our study the indexed left ventricular mass decreased during ReHuEpo treatment although not significantly for the whole group. The patients with the highest initial left ventricular mass showed the most pronounced decrease of left ventricular muscle mass during ReHuEpo therapy, whereas patients with a normal initial left ventricular muscle mass showed no change. The initial left ventricular muscle mass was found to correlate with the decrease of left ventricular muscle mass during ReHuEpo therapy. Blood pressure did not change in any patient and was in the normotensive range. A progressive decline and even normalisation of left ventricular mass has also been reported by MacDougall et al [13]. Löw et al 
did not find decreases in cardiac wall thicknesses but yet a decrease in left ventricular mass after 3 and 12 months of treatment with RehuEpo [14]. Satoh et al even observed increases of interventricular wall and posterior wall thicknesses together with a significant decrease in heart size in a selected group of patients with normal cardial function [15]. Canella et al [12] observed a significant reduction in left ventricular mass after 3 months of treatment with ReHuEpo when the target $\mathrm{Ht}$ had been reached and a further improvement after 6 months of treatment, whereas, the initial normal blood pressure remained unaltered as in our study. This suggests that the left ventricular hypertrophy of uremic anemia is partly determined by too low a hemoglobin concentration. Because blood volume also remained unchanged in our study, a decrease in AV fistula load, a reduction in neurosympathetic tone due to a decrease in plasma catecholamine levels [12], and/or inactivation of a not yet defined positive inotropic factor in anemic serum [52], have to be considered as a cause for the reported reversal of the increased left ventricular mass during treatment with ReHuEpo.

Regarding the functional microcirculatory investigations, a significant short term improvement in peripheral oxygenation was observed, as was also reported by Nonnast Daniels [46] and Kreutzig et al [43]. Also at long terrn we found rest tissue-PO2 to be higher, although not significant as compared to the pre-treatment value. The observation in the present study that the time to peak tissue $\mathrm{PO} 2$ following the release of an arterial occlusion, was increased during short term treatment, indicates hampering of microvascular flow at high flow rates. At long term we found still an increased time to peak tissue PO2, although not significant as compared to the pre-treatment values, but still significant different as compared to the control group with even a higher hematocrit level.

Whereas no change in the number of capillaries in the distal row of the finger nailfold could be found, videomicroscopy revealed a significant decrease in tortuosity of the capillaries during short term treatment, an effect that was maintained after long term treatment with ReHuEpo. This suggests that the improved skin oxygenation during treatment with ReHuEpo or ReHuEpo itself has an ameliorating effect on the configuration of the distal skin capillaries because dialysis treatment and efficacy was not changed during ReHuEpo therapy. This rapid normalisation of the structure of the capillaries in dialysis patients has also been reported after succesful renal transplantation [11].

Although there was an improvement of the configuration of distal nailfold capillaries, this did not result in an improved microvascular circulation at maximal vasodilation induced by ischemia. This might suggest that there are still structural abnormalities at the level of the arterioles.

In summary, during long term treatment with ReHuEpo blood pressure remained unchanged. Although there was a significant difference at 4 months in 
cardiac index, stroke index and systemic vascular resistance compared to the initial values, these differences were not significant anymore at 14 months. The cardiac function as indicated by the left ventricular ejection fraction and fractional fiber shortening, remained unchanged throughout the whole follow-up perind.

The end-diastolic left ventricular dimensions decreased, for which a decreased venous return might be responsible. The left ventricular mass declined, especially in patients with the highest initial mass.

At short term, skin oxygenation improved whereas maximal capillary flow decreased during treatment with ReHuEpo and both remained unchanged at long term. Whereas the number of countable capillaries in the finger nailfold remained unchanged, the percentage of tortuous capillaries decreased significantly. 


\section{References}

1. Duke M, Abelmann WH. The hemodynamic response to chronic anennia. Circulation 1969; 39: 503-515.

2. Varat MA, Adolph, R.J, Fowler, N.O. Cardiovascular effects of anemia. Am Heart J 1972; 83: 415-426.

3. London GM, Fabian F, Marchias SJ. Uremic cardiomyopathy: an inadequate left ventricular hypertrophy. Kidney Int 1978; 31: 973-980.

4. Kramer W, Wizemann V, Lämmlein G, Thormann J. Cardiac dysfunction in patients on maintenance hemodialysis: II. Systolic and diastolic properties of the left ventricle assessed by invasive methods. Contrib Nephrol 1986; 52: 97-109.

5. Capelli JP, Kasparian H. Cardiac work demands and left ventricular function in end stage renal disease. Ann Int Med 1977; 86: 261-267.

6. Silberberg JS, Rakal DP, Patton DR, Sniderman AD. Role of anemia in the pathogenesis of left ventricular hypertrophy in end stage renal disease. Am J Cardiol 1989; 64: 222-224.

7. London GM, Zins B, Pannier B. Vascular changes in hemodialysis patients in response to recombinant human erythropoietin. Kidney Int 1989; 36: 878-882.

8. Wirtz JJJM, Leunissen KML, Van Esser JWJ, Cheriex EC, Slaaf DW, Reneman RS, van Hooff JP. Recombinant human erythropoietin and is effects on macro- and microcirculation during normovolemia. Blood Purif 1990; 8: 285-294.

9. Hori K, Onoyama K, Iseki K. Hemodynamic and volume changes by recombinant human erythropoietin (ReHuEpo) in the treatment of anemic dialysis patients. Clin Nephrol 1990; 33: 293-298.

10. Van Hooff JP, Leunissen KML, Van den Berg BW. Capillary morphology in chronic hemodialysis patients. Int J Microcirc, special issue, August 1988; S126.

11. Gilchrest BA, Rowe JW, Mihm ML. Clinical and histological skin changes in chronic renal failure: evidence for a dialysis resistant, transplant responsive microangiopathy. Lancet 1980; ii: $1271-1275$.

12. Canella G, La Canua G, Sandrini M. Reversal of left ventricular hypertrophy following recombinant human erythropoietin treatment of anemic dialysed uremic patients. Nephrol Dial Transpl 1991; 6: 31-37.

13. McDougall IC, Lewis NP, Saunders MJ. Longterm cardiorespiratory effects of amelioration of renal anemia by erythropoietin. Lancet 1990; 335: 489-493.

14. Löw-Friedrich I, Grützmacher P, März W. Therapy with recombinant human erythropoietin reduces cardiac size and improves heart function in chronic hemodialysis patients. Am J Nephrol 1991; 11 : 54-60.

15. Satoh K, Masuda T, Ikeda Y. Hemodynamic changes by recombinant human erythropoietin therapy in hemodialyzed patients. Hypertension 1990; 15: 262-266.

16. McMahon LP, Johns JH, McKenzie A, Austin M. Haemodynamic changes and physical performance at comparative levels of hemoglobin after longterm treatment with recombinant erythropoietin. Nephrol Dial Transpl 1992; 7: 1199-1206.

17. Goldberg N, Lundin P, Delano B. Changes in left ventricular size, wall thickness and function in anemic patients treated with recombinant human erythropoietin. Am Heart J 1992; 124: 424-427. 
18. Martinez-Vea A, Bardaji A, Garcia C. Longterm myocardial effects of correction of anemia with recombinant human erythropoietin in aged patients on hemodialysis. Am J Kidne:y Dis 1992; 19: 353-357.

19. Tagawa $H$, Nagano $M$, Saito $H$. Echocardiographic findings in hemodialysis patients treated with recombinant human erythropoietin: proposal for a hematocrit most beneficial to hemodynamics. Clin Nephrol 1991; 35: 35-38.

20. Low I, Grützmacher P, Bergmann M. Echocardiographic findings in patients on maintenance hemodialysis substituted with recombinant human erythropoietin. Clin Nephrol 1989; 31: 26-30.

21. Itegaru-Hellring B, Buss J, Strauch M. Uraemische Kardiomyopathie: Echokardiografische Untersuchungen des links-ventrikulären Dynamik. Nieren- und Hochdruckkrankheiten 1984; 10: 396-400.

22. Schäfer GE, Kaltenbach M, Scheppew W. Hemodynamic response to chronic anemia in renal failure. Blood Purif 1983; 1: 134-135.

23. Koomans HA, Geers AB, Dorhout Mees EJ. Plasma volume recovery after ultrafiltration in patients with chronic renal failure. Kidney Intern. 1984; 26: 848-854.

24. Cheriex EC, Leunissen KML, Janssen JHA, Mooy JMV. Echography of the inferior vena cava is a simple and reliable tool for estimation of dry weight in hemodialysis patients. Nephrol Dial Transpl 1989; 4: 563-568.

25. Boehmer RD. Continuous real-time noninvasive monitoring of blood pressure: Penaz methodology applied to the finger. J Clin Monit 1978; 3: 282-287.

26. Kurki T, Smith NT, Head N, Dec-Silver $\mathrm{H}$. Noninvasive measurement from the finger; optimal measurement conditions and factors affecting reliability. J Clin Monit 1987; 3: 6-13.

27. Sahn DJ, DeMaria A, Kisslo J, Weyman A. The committee on M-mode standardization of the American Society of Echocardiography. Recommendations regarding quantitation in M-mode echocardiography: results of a survey of echocardiographic measurements. Circulation 1978; 58: 1072-1083.

28. Crawford MH, Grant D, O'Rourke RA, Starling MR. Accuracy and reproducability of new M-mode echocardiographic recommendations for measuring left ventricular dimensions. Circulation 1980; 61: 137-143.

29. Huntsman LL, Stewart DK, Franklin SB. Noninvasive Doppler determination of cardiac output in man: clinical validation. Circulation 1983; 67: 593-601.

30. Chandraratna PA, Nanna M, McKay C, Nimalauriya A. Determination of cardiac output by transcutaneous wave ultrasonic Doppler computer. Am J Cardiol 1984; 53: 234-237.

31. Bouchard A, Blumlein S, Schiller NB. Measurements of left ventricular stroke volume using continuous wave Doppler echocardiography of the ascending aorta and M-mode echocardiography of the aortic valve. J Am Coll Cardiol 1987; 9: 75-83.

32. Von Bibra, H, Castro, L, Autenrieth, G. The effects of arteriovenous shunts on cardiac function in renal dialysis patients. An echocardiographic evaluation. Clin Nephrol 1978; 9: 205-209.

33. Keyes J, Carey J, Mosses D, Beyerwaltes W. Manual of Nuclear Medicine Procedures (ed. 2, CRS press, Cleveland 1973), p. 95-98.

34. Tararin RC, Melsher HJ, Dustan MP, Frolic E. Plasma volume changes with upright tilt, studied in hypertension and in syncope. J Appl Physiol 1984; 4: 413-423.

35. Teichholz LE, Kreulen T, Herman MV. Problems in echocardiographic volume determination: echocardiographic angiographic correlations in the presence or absence of asynergy. Am J Cardiol 1976; 37: 7-11. 
36. Devereux RB, Alonso DR, Lutas EM, Gottlieb GJ. Echocardiographic assessment of left ventricular hypertrophy: comparison to necropsy findings. Am. J. Cardiol. 1986; 57: 450-458.

37. Devereux RB, Reichek N. Echocardiographic determination of left ventricular mass in man. Circulation 1976; 55: 613-618.

38. Nonnast-Daniel B, Creutzig A, Kuhn K, Bachmann J. Effect of treatment with recombinant human erythropoietin on peripheral hemodynamics and oxygenation. Contrib Nephrol 1988; 66: 185-194.

39. Wiedemann HP, Oreus DK, Sivak ED. Transcutaneous oxygen monitoring, Clevel Clin Q 1985; 52: 483-488.

40. Newson TP, Rolfe P. The use of transcutaneous oxygen tension measurements for the assessment of the cutaneous microcirculation. In: Tooke JH, Smaje LH. Clinical investigation of the microcirculation (Martinus Nijhoff Publishers, Boston, 1987, p. 71.74).

41. Ewald K. Evaluation of the transcutaneous oxygen method used at $37^{\circ} \mathrm{C}$ for measurement of reactive hyperaemia in the skin. Clin Physiol 1984; 4: 413-423.

42. Coleman LS, Dowd GSE, Bentley G. Reproducability of $\mathrm{TcPO}_{2}$ measurements in normal volunteers. Clin Phys Physiol Meas 1986; 7: 259-263.

43. Creutzig A, Caspary L, Nonnast-Daniel B. Skin microcirculation and regional peripheral resistance in patients with chronic renal anaemia treated with recombinant human erythropoietin. Eur J Clin Invest 1990; 20: 219-223.

44. Samtleben W, Baldamus CA, Bommer J, Fassbinder W. Blood pressure changes during treatment with recombinant human erythropoietin. Contr Nephrol 66: 114-122.

45. Neff MS, Kim KE, Persoff M, Onesti G. Hemodynamics of uremic anemia. Circulation $1971 ; 43: 876-883$.

46. Nonnast-Daniel B, Deschodt G, Brunkhorst R. Longterm effects of treatment with recombinant human erythropoietin on haemodynamics and tissue oxygenation in patients with renal anemia. Nephrol Dial Transpl 1990; 5: 444-448.

47. Duling BR, Pittmann RN. Oxygen tension: dependent or independent variable in local control of blood flow? Fed Proc 1975; 34: 2012-2019.

48. Jandeleit K, Heintz B, Gross-Heitfeld E, Kindler J. Increased activity of the autonomic nervous system and increased sensitivity to angiotensin II infusion after therapy with recombinant human erythropoietin. Nephron 1990; 56: 220-221.

49. Bund SJ, Heagerty A, Edmunds M. Erythropoietin does not induce vasoconstriction directly in human subcutaneous resistance arterioles. Nephron 1989; 53: 173.

50. Pagel H, Jelkmann W, Weiss C. Erythropoietin and blood pressure. Horm Metab Res 1989; $21: 224$.

51. Murray EJ, Jamgotchian N, Murray SS, Lee DBN. Erythropoietin hypertension: evidence for direct action on neutral aminoacid uptake and protein synthetic pattern in vascular smooth muscle cells. J Am Soc Nephrol 1990; 1: 497 (abstract).

52. Florenzano F, Diaz G, Regausi C, Escobar E. Left ventricular function in chronic anemia: evidence of noncatecholamine positive inotropic factor in the serum. Am J Cardiol 54: 638-654. 



\section{Influence of hematocrit level on plasma volume preservation and on hemodynamics during hemodialysis}

J.J.J.M. Wirtz' ${ }^{1}$, W.H.M. van Kuijk ${ }^{2}$, E.C. Cheriex ${ }^{3}$, L. Habets ${ }^{4}$, P.P.C.A. Menheere ${ }^{4}$, J.P. van Hooff ${ }^{2}$, K.M.L. Leunissen ${ }^{2}$

Department of Internal Medicine ${ }^{1}$

Laurentius Hospital, Roermond, The Netherlands

Department of Internal Medicine ${ }^{2}$, Cardiology ${ }^{3}$ and Clinical Chemistry ${ }^{4}$ University Hospital Maastricht, The Netherlands

Submitted. 


\section{Abstract}

At higher hematocrit levels during recombinant human erythropoietin (ReHuEpo) therapy, plasma volume is decreased, while total blood volume is constant. This could influence osmolality and oncotic pressure changes during hemodialysis and in consequence plasma volume preservation. Furthermore, hemoconcentration after hemodialysis will influence blood viscosity and in consequence venous retum and hemodynamic stability.

Nineteen chronic hemodialysis patients were studied during dialysis and ultrafiltration at low and high hematocrit levels. Plasma volume changes, osmolality and oncotic pressure were studied, as were left ventricular end diastolic diameter, stroke index and mean arterial pressure. Although compared to low hematocrit, oncotic pressure increase at high hematocrit was significantly higher, plasma osmolality at high hematocrit tended to be lower, resulting in a comparable plasma volume preservation at low and high hematocrit.

There was a significant decrease of stroke index at high hematocrit, which was related to the decrease of left ventricular end diastolic diameter, a preload parameter. However, blood volume changes were comparable, indicating a decreased venous retum related to an increased blood viscosity as a possible cause.

In conclusion, plasma volume preservation is equal at low and high hematocrit on basis of a counteractive effect of an increase of oncotic pressure and a decrease of osmolality at high hematocrit. The significant stroke index decrease at high hematocrit was influenced by the preload change (left ventricular end diastolic diameter) during hemodialysis at a comparable blood volume change, indicating changes in venous return which could be related to increased blood viscosity.

\section{Introduction}

Plasma volume preservation plays a pivotal role in dialysis induced hemodynamic instability. The main factors determining plasma volume preservation are the fluid status [1-3], the used buffer substrate [4-5], the venous compliance [6-9], the oncotic pressure [10-11] and osmolality changes [12-18].

Erythropoietine (ReHuEpo) therapy of dialysis patients reveals an increase in red blood cell volume (RBCV) and a decrease of plasma volume, while total blood volume does not change [19]. Because of the decreased plasma flow through the artificial kidney at higher hematocrit levels, combined ultrafiltration / dialysis could have different effects on osmolality and oncotic pressure change- 
$s$ as compared to ultrafiltration / dialysis at lower hematocrit levels. In consequence, this could influence plasma volume preservation.

Whether the decrease of plasma volume induces hemodynamic instability, will depend on the efficacy of the cardiovascular regulatory mechanisms [2]. Venous return can be maintained by venous constriction, inducing centralization of blood volume [7, 20-21]. Another important factor for venous return is the total blood viscosity, which among others depends on hematocrit. At higher hematocrit levels during ReHuEpo therapy, a plasma volume decrease during dialysis will induce even more hemoconcentration and consequently increased blood viscosity compared to lower hematocrit levels. As was published by London, venous tone was increased in ReHuEpo treated dialysis patients to maintain venous return [22]. A decrease of venous return will lead to a decrease of left ventricular end diastolic diameter as a preload parameter and a decrease of stroke volume.

We investigated at low and high hematocrit plasma volume preservation and hemodynamic changes during combined ultrafiltration/dialysis with special attention to left ventricular end diastolic diameter, being a preload parameter and to changes in stroke volume.

\section{Patients and methods}

Nineteen chronic hemodialysis patients with renal anemia were included in the study ( 8 men, 11 women). The mean age was 47 years (27-78 years).

Patients with severe hyperparathyroidism, signs of aluminium intoxication, diabetes mellitus or cardiac dysfunction, defined as a left ventricular ejection fraction $<40 \%$ and/or clinically important valvular disease were excluded. All patients were normotensive at entrance of the study with or without antihypertensive medication. Five out of 19 patients were using calcium entry blockers and/or $\beta$-blocking agents. None of them used ACE inhibitors. Vasoactive medication was temporarily stopped 48 hours before the investigations.

The patients were studied during a standardized midweek 3 hours dialysis treatment at low hematocrit (before ReHuEpo therapy) and also at a high hematocrit (during ReHuEpo therapy). The patients were their own controls. The dialysis treatment consisted of bicarbonate hemodialysis (a hemophane artificial kidney [GFS plus, Gambro], Kt/v $>1$, blood flow $250 \mathrm{ml} / \mathrm{min}$, dialysate flow $500 \mathrm{ml} / \mathrm{min}$ ). The dialysate composition was: sodium $140 \mathrm{mmol} / \mathrm{h}$, potassium $2.0 \mathrm{mmol} / \mathrm{l}$, calcium $1.75 \mathrm{mmol} / \mathrm{l}$, magnesium $0.5 \mathrm{mmol} / \mathrm{l}$, bicarbonate 34 $\mathrm{mmol} / \mathrm{l}$, acetate $3 \mathrm{mmol} / \mathrm{l}$, chloride $107.25 \mathrm{mmol} / \mathrm{l}$. The temperature of the dialysate was $37^{\circ} \mathrm{C}$. 
The patients were dialyzed to their clinical dry weight. The ultrafiltration volume was in each patient comparable in the low hematocrit dialysis treatment and in the high hematocrit dialysis treatment.

The ReHuEpo therapy was administered intravenously, starting at an initial dose of $150 \mathrm{IU} / \mathrm{kg} /$ week, given in a 3 dosages/week schedule. Adjustments of the dose were carried out monthly, according to the response as defined by an increase or a decrease of $5 \%$ or more as compared to the preceding hematocrit value. The goal for this study was a hematocrit of $>30 \%$. Oral iron supplementation was given in all patients.

Before and after the two studied hemodialysis treatments (at low and high hematocrit) in each patient, fluid status was determined using echography of the inferior caval vein [23]. Before each studied hemodialysis treatment, plasma volume was measured according to the $\mathrm{I}^{125}$ Albumin method [24]. Red blood cell volume was calculated from the plasma volume and the hematocrit: $\mathrm{RBCV}=$ $\mathrm{PV}_{\mathrm{in}}\left(\mathrm{Hct}_{\mathrm{in}} / 1-\mathrm{Hct}_{\mathrm{in}}\right)$. Changes of plasma volume during the dialysis treatment were calculated according to the serial hematocrit method: PVt $=$ RBCV.(1$\mathrm{Hct} / \mathrm{Hct}$ ) [25]. The plasma volume preservation (\%) is the cumulative fluid mobilization (VFM) in relation to the total ultrafiltration (VUF): VFM/VUF. The extracellular fluid mobilization (VFM) was calculated as the difference between VUF and the change of plasma volume at time $t:$ VFM $=$ VUF-(PVF ${ }^{-}$ PVt).

Furthermore, blood samples were taken in ice-chilled tubes before and after hemodialysis for determination of noradrenaline and adrenaline (HPLC method; interassay variance $<8 \%$ ), $\alpha$-ANP (RIA method; interassay variance $<12 \%$ ), plasma colloid osmotic pressure (COP; Wescor 4400 colloid osmometer), osmolality (Osm, Wescor 5500 Vapor Pressure Osmometer) and serum albumin (Alb; BCP, Dimension).

Hemodynamic monitoring consisted of a continuous blood pressure registration (mean arterial pressure; MAP) during the studied dialysis treatment using a Dynamap device. Also, before and after the studied dialysis treatments, stroke volume (SV) was determined by the Duplex doppler method (Hewlett Packard 770020A; 3.5 MegaHerz); stroke index (SI) and cardiac index (CI) were calculated from SV, heart rate and body surface area [26-27]. Also, left ventricular end diastolic diameter (EDD) and left ventricular end systolic diameter (ESD) were determined by echocardiography [28]. The fractional fiber shortening was calculated according to the formula (EDD-ESD):EDD x $100(\%)$.

Statistical analysis was done using the paired student t-test for comparison of pre- and postdialysis results. For comparison of hemodynamic changes during dialysis at low and high hematocrit, MANOVA was used. Stepwise, multivariate analysis was used to assess relative importance of factors influencing the 
decrease in stroke index during dialysis at high hematocrit. A p-value $<0.05$ was regarded as statistical significant.

\section{Results}

The mean hematocrit before ReHuEpo therapy was $0.22 \pm 0.04$ and during ReHuEpo therapy $0.33 \pm 0.04$ ( $p<0.001$ ). Plasma volume before dialysis at the low hematocrit was $3557.0 \pm 804.4 \mathrm{ml}$ and at high hematocrit $3118.9 \pm 707.5$ $\mathrm{ml}(\mathrm{p}<() .001)$, and the RBCV was respectively $1015.5 \pm 217.9 \mathrm{ml}$ and $1576.8 \pm$ $410 \mathrm{ml}(\mathrm{p}<0.001)$.

The initial hemodynamic parameters before each studied standardized dialysis treatment at low and high hematocrit were comparable (table 1) except for the mean arterial pressure. The ultrafiltration volume was comparable in each paired dialysis treatment at low and high hematocrit (2191 \pm 979 and $2451 \pm 975 \mathrm{ml}$ respectively, ns). Cardiovascular medication was not changed in the study period.

Plasma volume preservation during dialysis at low and at high hematocrit was comparable (figure 1). The total plasma volume decrease was $-282 \pm 340 \mathrm{ml}$ at low hematocrit and $-373 \pm 377 \mathrm{ml}$ at high hematocrit (ns) (figure 2), and the total blood volume after dialysis was $4290.5 \mathrm{ml}$ respectively $4322.7 \mathrm{ml}$ (ns). Osmolality decreased from $307.1 \pm 13.8$ to $291.8 \pm 9.7 \mathrm{mosm} / \mathrm{kg}(\mathrm{p}<0.001)$ at low hematocrit and from $302.0 \pm 8.3$ to $287.1 \pm 7.6 \mathrm{mosm} / \mathrm{kg}(\mathrm{p}<0.001)$ at high hematocrit. Osmolality after hemodialysis at high hematocrit was lower than osmolality at low hematocrit, although not significantly $(\mathrm{p}=0.08)$ (figure 3 ).

Oncotic pressure during dialysis did not increase significantly from $3.5 \pm 0.4$ to $3.7 \pm 0.5 \mathrm{kPa}$ at low hematocrit, but increased significantly from $3.2 \pm 0.3$ to $3.8 \pm 0.7 \mathrm{kPa}(\mathrm{p}<0.01)$ at high hematocrit. The increase of oncotic pressure was significantly higher during hemodialysis at high hematocrit $(0.6 \pm 0.6) \mathrm{com}-$ pared to the increase of oncotic pressure at the low hematocrit $(0.2 \pm 0.5)$ $(\mathrm{p}<0.02)$.

Plasma albumin levels during dialysis did not increase significantly (from $31.1 \pm 2.8$ to $31.9 \pm 3.0 \mathrm{~g} / \mathrm{l}$ ) at low hematocrit, but increased significantly (from $29.7 \pm 2.7$ to $31.7 \pm 3.9 \mathrm{~g} / \mathrm{l}, \mathrm{p}<0.01$ ) at high hematocrit. The increase of albumin levels was significantly higher during dialysis at high hematocrit $(2.0 \pm 2.9 \mathrm{~g} / \mathrm{l})$ compared to the increase of albumin at the low hematocrit $(0.8 \pm 2.8 \mathrm{~g} / \mathrm{l})$ $(p<0.01)$,

During the studied standardized dialysis treatments, EDD and ESD decreased significantly as did body weight and VCD in both paired dialysis treatments at 
Table 1: Hemodynamic parameters before and after dialysis at low (uncorrected) and high (corrected) hematocrit ( $\mathrm{Ht}$ ).

(VCDI = indexed caval vein diameter determined echocardiographically)

\begin{tabular}{|c|c|c|c|c|c|c|}
\hline & \multicolumn{3}{|l|}{ Low $\mathrm{Ht}$} & \multicolumn{3}{|l|}{ High $\mathrm{Ht}$} \\
\hline & Before & & After & Before & & After \\
\hline EDD $m m$ & $50.4 \pm 5.5$ & $(0.01)$ & $48.5 \pm 6.8$ & $50.4 \pm 5.2$ & $(0.001)$ & $46.9 \pm 7.1$ \\
\hline $\mathrm{ESD} m m$ & $33.4 \pm 5.5$ & $(0.02)$ & $31.8 \pm 6.3$ & $34.3 \pm 6.2$ & $(0.001)$ & $31.2 \pm 7.5$ \\
\hline CI $\mathrm{l} / \mathrm{min} / \mathrm{m}^{2}$ & $4.01 \pm 0.8$ & & $3.8 \pm 0.5$ & $3.9 \pm 0.6$ & $(0.01)$ & $3.3 \pm 0.6$ \\
\hline SI $m l l b / m^{2}$ & $54.1 \pm 10.0$ & & $49.7 \pm 8.8$ & $55.1 \pm 9.9$ & $(0.001)$ & $42.1 \pm 11.6$ \\
\hline HR $\mathrm{b} / \mathrm{min}$ & $75 \pm 8$ & & $78 \pm 11$ & $72 \pm 9$ & $(0.02)$ & $83 \pm 14$ \\
\hline VCDI $m m / m^{2}$ & $10.2 \pm 3.3$ & $(0.001)$ & $8.7 \pm 3.2$ & $10.2 \pm 2.7$ & $(0.001)$ & $8.3 \pm 2.6$ \\
\hline Weight $k g$ & $67.2 \pm 9.8$ & $(0.001)$ & $65.3 \pm 9.4$ & $67.4 \pm 10.5$ & $(0.001)$ & $65.2 \pm 10.3$ \\
\hline $\mathrm{MAP} m m H g$ & $94.9 \pm 10.8$ & & $91.8 \pm 12.6$ & $102.5 \pm 14.7$ & $(0.05)$ & $96.8 \pm 16.7$ \\
\hline Adrenaline $n g / m l$ & $0.90 \pm 0.90$ & $(0.01)$ & $0.45 \pm 0.43$ & $1.02 \pm 0.62$ & $(0.001)$ & $0.62 \pm 0.40$ \\
\hline Noradrenaline $n g / m l$ & $3.36 \pm 1.74$ & & $2.68 \pm 1.3$ & $3.14 \pm 1.61$ & & $3.01 \pm 1.71$ \\
\hline
\end{tabular}

low and high hematocrit. The decrease of CI, SI and MAP, and the increase of heart rate (HR) was only significant during the dialysis treatment at high hematocrit (table 1). Fractional fiber shortening was comparable at low and high hematocrit: predialysis $33.9 \pm 4.4 \%$ and postdialysis $34.6 \pm 5.7 \%$ at low hematocrit and predialysis $32.3 \pm 6.1 \%$ and postdialysis $34.6 \pm 6.9 \%$ at high hematocrit (ns). Adrenaline decreased significantly during dialysis and also noradrenaline decreased, although not statistically significant. $\alpha$-ANP decreased to the same extent in both dialysis treatments at low and at high hematocrit (from 229.2 \pm 99 to $140.0 \pm 87, \mathrm{p}<0.001$; and from $229.6 \pm 94.9$ to $147.8 \pm 97 \mathrm{pg} / \mathrm{ml}, \mathrm{p}<0.001$; respectively). 


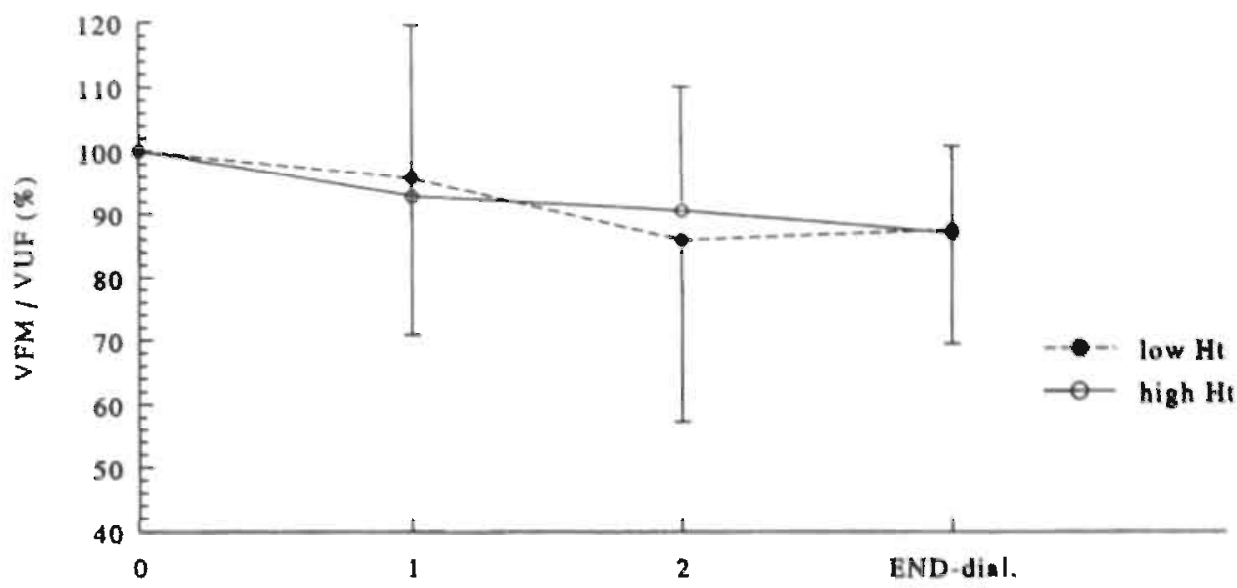

Figure 1: Plasma volume preservation at low and high hematocrit (before and after ReHuEpo) during a standardized bicarbonate dialysis.

VFM/VUF $=$ fluid mobilization divided by ultrafiltration volume $\mathrm{x} 100 \%$

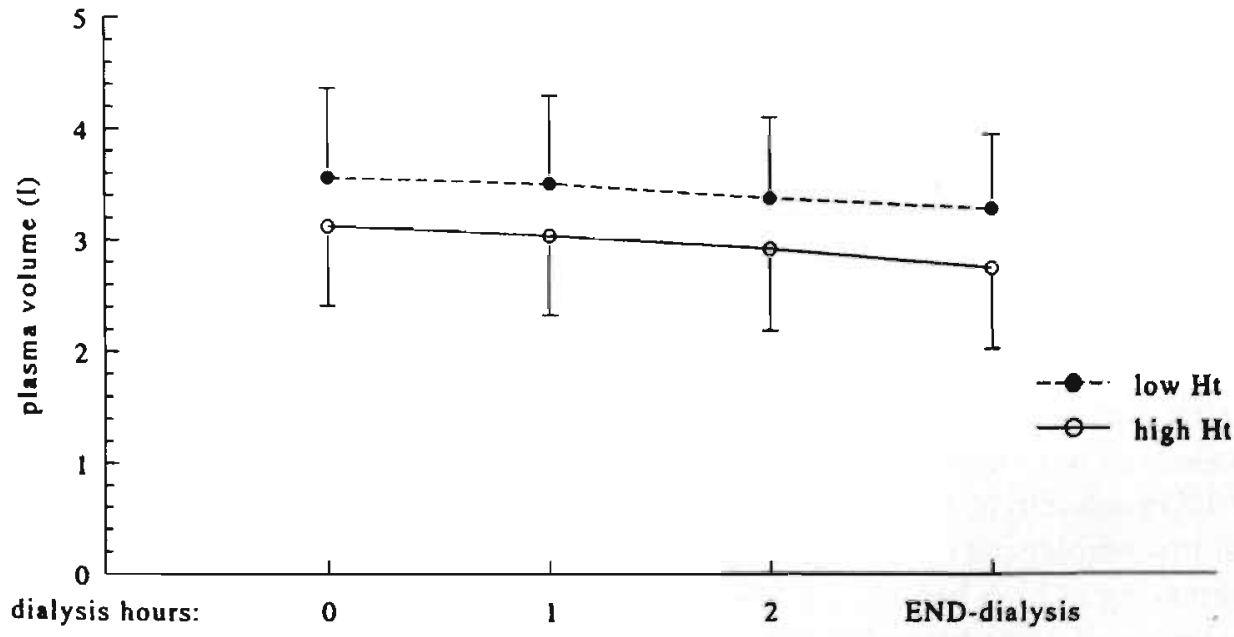

Figure 2: Changes in plasma volume at low and high hematocrit during a standardized bicarbonate dialysis. 
Table 2: Comparison of hemodynamic parameters at low and high hematocrit $(\mathrm{Ht})$ before and after dialysis.

\begin{tabular}{|c|c|c|c|c|c|}
\hline & \multicolumn{3}{|l|}{ Before } & \multicolumn{2}{|l|}{ After } \\
\hline & Low $\mathrm{Ht}$ & & High $\mathrm{Ht}$ & Low $\mathrm{Ht}$ & High Ht \\
\hline $\mathrm{CI} L / \mathrm{min} / \mathrm{m}^{2}$ & $4.01 \pm 0.8$ & & $3.9 \pm 0.6$ & $3.8 \pm 0.5 \quad(0.01)$ & $3.3 \pm 0.6$ \\
\hline $\mathrm{SI} m / / b / m 2$ & $54.1 \pm 10.0$ & & $55.1 \pm 9.9$ & $49.7 \pm 8.8(0.02)$ & $42.1 \pm 11.6$ \\
\hline $\mathrm{HR} b / \min$ & $75 \pm 8$ & & $72 \pm 9$ & $78 \pm 11$ & $83 \pm 14$ \\
\hline VCDI $\mathrm{mm} / \mathrm{m}^{2}$ & $10.2 \pm 3.3$ & & $10.2 \pm 2.7$ & $8.7 \pm 3.2$ & $8.3 \pm 2.6$ \\
\hline Weight $k g$ & $67.2 \pm 9.8$ & & $67.4 \pm 10.5$ & $65.3 \pm 9.5$ & $65.2 \pm 10.3$ \\
\hline MAP $\mathrm{mmHg}$ & $94.9 \pm 10.8$ & 0.05 & $102.5 \pm 14.7$ & $91.8 \pm 12.6$ & $96.8 \pm 16.7$ \\
\hline Adrenaline $n g / m l$ & $0.89 \pm 0.90$ & & $1.02 \pm 0.62$ & $0.45 \pm 0.43$ & $0.62 \pm 0.40$ \\
\hline Noradrenaline $n g / m l$ & $3.36 \pm 1.74$ & & $3.14 \pm 1.61$ & $2.68 \pm 1.31$ & $3.01 \pm 1.71$ \\
\hline
\end{tabular}

VCDI = indexed caval vein diameter determined echocardiographically

There was a significant difference in SI and CI, but not in HR after dialysis at low compared to high hematocrit (table 2). Furthermore, MAP before dialysis was significantly higher at high hematocrit compared to low hematocrit (table 2). Comparing the changes during dialysis at low and at high hematocrit of the different parameters revealed a significant difference for $\Delta$ SI during dialysis at low hematocrit $\left(\Delta S I-4.3 \pm 9.4 \mathrm{ml} / \mathrm{b} / \mathrm{m}^{2}\right)$ compared to the values at high hematocrit $\left(\Delta S I-12.9 \pm 11.4 \mathrm{ml} / \mathrm{b} / \mathrm{m}^{2}, \mathrm{p}<0.01\right)$, and a significant difference for $\Delta H R$ during dialysis at low hematocrit $(\Delta \mathrm{HR}+3.0 \pm 9.0 \mathrm{~b} / \mathrm{min})$ compared to the values at high hematocrit $(\Delta H R+10.3 \pm 13.0 \mathrm{~b} / \mathrm{min}, \mathrm{p}<0.02)$. The decrease in EDD tended to be higher at high hematocrit $(-3.5 \pm 3.5 \mathrm{~mm})$ compared to values at low hematocrit $(-1.8 \pm 2.5 \mathrm{~mm}, \mathrm{p}=0.07)$.

Studying at high hematocrit $\Delta$ SI after hemodialysis as dependent variable, and hematocrit after hemodialysis, end diastolic diameter after hemodialysis and $\triangle \mathrm{BV}$ as predictive variables in multiregression analysis revealed a significant multiple $r(r=0.64, p<0.01)$ for EDD only. 


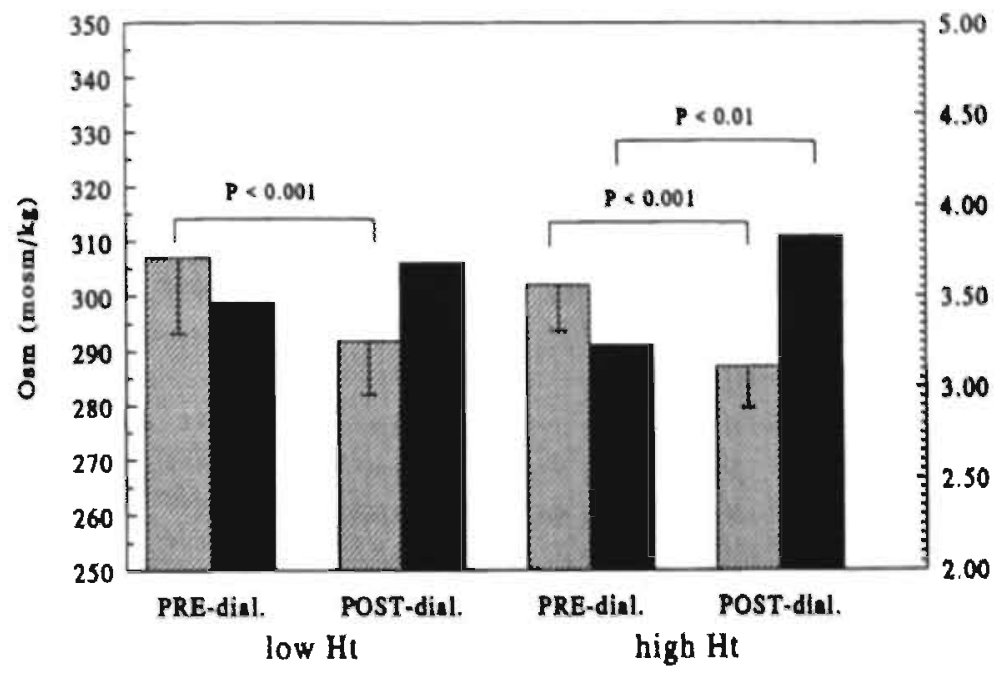

Figure 3: Osmolality (Osm) and colloid oncotic pressure (COP) before and after hemodialysis at low (before ReHuEpo) and high (after ReHuEpo) hematocrit.

\section{Discussion}

Erythropoietin (ReHuEpo) therapy leads to an increase of red blood cell volume with a concomittant decrease of plasma volume, while total blood volume remains constant [19]. The removal of the same amount of fluid by ultrafiltration at a higher hematocrit level with a lower initial plasma volume would lead to a relative higher increase of colloid oncotic pressure during dialysis compared to dialysis at a lower hematocrit. Moreover, the decreased plasma volume at higher hematocrit levels will decrease the plasma flow through the artificial kidney at the same blood flow, which could influence the decrease of osmolality. Both colloid oncotic pressure [10-11] and osmolality [12-18] are important factors in determining plasma volume preservation during dialysis.

In the present study, plasma volume preservation was identical in the same patients at low and high hematocrit levels. Although the increase in colloid oncotic pressure was significantly higher at high hematocrit levels, there was a tendence to lower osmolality levels after dialysis at higher hematocrit levels. An increase of colloid oncotic pressure will improve plasma volume preservation by inducing a fluid shift from the interstitial to intravascular pool, whereas a greater fall in osmolality will deteriorate plasma volume preservation because of a shift of fluid from intravascular/interstitial to the intracellular pool. The 
explanation for the observed difference between the higher percentage of increase in colloid osmotic pressure as compared to the percentage of increase in serum albumin levels during dialysis, at low as well as at high hematocrit, could be related to the Donnan effect.

The same ultrafiltration volume with the same decrease of blood volume at low and high hematocrit, as could also be concluded from comparable decreases in $\alpha$-ANP, during a standardized dialysis treatment revealed a significant decrease of mean arterial pressure and stroke index at high hematocrit, while at a low hematocrit no significant hemodynamic changes could be measured. This could be explained by differences in left ventricular contractility or by changes in preload due to a different distribution of blood volume.

The dialysis protocol was the same at low and high hematocrit with regard to the buffer concentration, calcium concentration and the used dialyzer, resulting in comparable changes of ionized calcium and acid-base status, factors known to be involved in cardiac contractility. Furthermore, no differences could be found in the levels of adrenaline and noradrenaline after dialysis at low and high hematocrit.

Indeed, in this study fractional fiber shortening as a parameter of left ventricular contractility was not significantly different at low and high hematocrit.

The left ventricular end diastolic diameter as a preload parameter decreased significantly during both paired dialysis treatments. Although not significantly, the decrease in left ventricular end diastolic diameter tended to be higher at high hematocrit. In multiregression analysis, studying the decrease of stroke index at high hematocrit as dependent variable and hematocrit postdialysis, left ventricular end diastolic diameter postdialysis and $\Delta$ blood volume as predictive variables revealed a significant relation of $\Delta$ stroke index with the left ventricular end diastolic diameter postdialysis. This indicates that a decreased preload at high hematocrit levels played a role in the decrease of stroke index. However, the blood volume changes were comparable at low and high hematocrit. This can only be explained by a decrease of venous return due to differences in distribution of blood volume. Venous return is dependent on an increase of peripheral vascular resistance, inducing a passive venoconstriction, which is only a temporary effect. A continuous increased peripheral vascular resistance, however, will reduce venous return. Venous return is also dependent on active venoconstriction and on the venous resistance. Peripheral vascular resistance is known to be increased continuously during ReHuEpo therapy, resulting in a negative effect on venous return, whereas venous tone was shown to be increased which would improve venous return [22]. Increased blood viscosity during ReHuEpo therapy would decrease venous return by an increased venous resistance [20]. In an animal experimental study of Murray et al, mean cardiac output was plotted against mean hematocrit ratios obtained during control periods and after isovolemic exchange with dextran solutions of three different 
molecular weights. Recipients of low molecular weight dextran had higher cardiac outputs at comparable hematocrits [29]. In the present study, we could not find at high hematocrit a relation between postdialysis hernatocrit, one of the factors determining blood viscosity, and the postdialysis left ventricular end diastolic diameter and stroke index, which does not rule out an effect of total blood viscosity. So, it seems that the causes of the intradialytic hemodynamic changes at high hematocrit levels are multifactorial. For clinical practice we have to realize that hypovolemia after hemodialysis will exaggerate all the factors which are possibly involved in the intradialytic hemodynamic changes at high hematocrit, as there are peripheral vascular resistance and blood viscosity with an increased risk of hemodynamic instability, especially in patients with a compromised cardiac function.

In conclusion, plasma volume preservation during dialysis at low and high bematocrit levels is the same, although on basis of different changes in colloid oncotic pressure and osmolality. At higher hematocrit levels, stroke index decreased significantly and was related to the decrease of left ventricular end diastolic diameter, a preload parameter, although blood volume changes were comparable. This might indicate a decreased venous retum. 


\section{References}

1. Stiller S, Thömmes A, Königs F, Scallenberg U, Mann M. Characteristic profiles of circulating blood volume during dialysis therapy. ASAIO Trans 1989; 35: 530-532.

2. Guyton AC. Textbook of medical physiology. 7th Edition, Philadelphia/London/ Toronto, WB Saunders \& Co, 1986.

3. Koomans HA, Geers AB, Dorhout Mees EJ. Plasma volume recovery after ultrafiltration in patients with chronic renal failure. Kidney Int 1984; 26: 848-854.

4. Hsu CH, Swartz RD, Sanermeyer MG, Ray A. Bicarbonate hemodialysis: influence on plasma refilling and hemodynamic stability. Nephron 1984; 38: 202-208.

5. Leunissen KML, Cheriex EC, Janssen JHA, Teule GJJ, Mooy JMV, Ramentol M, Van Hooff JP. Influence of left ventricular function on changes in plasma volume during acetate and bicarbonate dialysis. Nephrol Dial Transpl 1987; 2: 99-103.

6. London GM, Safar ME, Levenson JA, Simon AC, Temnar MA. Renal filtration fraction, effective vascular compliance and partition of fluid volumes in sustained essential hypertension. Kidney Int 1981; 20: 97-103.

7. Greenway CV, Wayne Laut W. Blood volume, the venous system, preload and cardiac output. Can J Physiol Pharmacol 1986; 64: 383-387.

8. Rothe CF. Venous system; physiology of capacitance vessels. In: Handbook of Physiology, 1983. Sect 2 Cardiovascular system. Vol. 3: Peripheral circulation and organ blood flow, chapter 13. Bethesda, Am Physiol Soc, p 397-452.

9. Kooman JP, Gladziwa U, Böcker G, Van Bortel LMAB, Van Hooff JP, Leunissen KML. Role of the venous system in hemodynamics during ultrafiltration and bicarbonate dialysis. Kidney Int 1992; 42: 718-726.

10. Kjellstrand CM, Rosa AA, Skideman JR. Hypotension during hemodialysis: osmolality fall is an important pathogenetic factor. ASAIO J 1980; 3: 11-19.

11. Fauchold P. Effect of ultrafiltration on body fluid volumes and transcapillary colloid osmotic gradient in hemodialysis patients. Contrib Nephrol 1989; 74: 170-175.

12. Rodriguez M, Pederson JA, Llach F. Effect of dialysis and ultrafiltration on osmolality, colloid oncotic pressure and vascular refilling rate. Kidney Int 1985; 28: 808-813.

13. Leunissen KML, Noordzij TC, Van Hooff JP. Pathophysiologic aspects of plasma volume preservation. Contrib Nephrol 1990; 78: 201-211.

14. Daugirdas JT. Dialysis hypotension; a hemodynamic analysis. Kidney Int 1991; 39 : 233-246.

15. Fleming SJ, Wilkinson JS, Greenwood RN, Aldridge C, Baker LR, Cattel WR. Effect of dialysate composition on intercompartimental fluid shift. Kidney Int 1987; 32: 267-273.

16. Aguilera D, Diab N, Faivre JM. Influence of sodium dialysate variation on hemodynamic stability. Kidney Int 1988; 34(suppl.25): 187-189.

17. Kimura J, Van Stone JC, Bauer JH. Model prediction of plasma volume change induced by hemodialysis. J Lab Clin Med 1984; 104: 932-938.

18. Krämer BK, Ress KM, Ulshöfer TM, Rister T. Hemodynamic and hormonal effects of lower high sodium hemodialysis. Kidney Int 1988; 34: 192-195.

19. Wirtz JJJM, Leunissen KML, Van Esser JW, Cheriex EC, Slaaf DW, Reneman RS, Van Hooff JP. Recombinant human erythropoietin and its effects on macro- and microcirculation during normovolemia. Blood Purif 1990; 8: 285-294. 
20. Öberg. B. The relationship between active constriction and passive recoil at various distending pressures. Acta Physiol Scand 1967; 71: 233-247.

21. Greenway CV, Seaman KL, Innes IR. Norepinephrine on venous compliance and unstressed volume in cat liver. Am J Physiol 1985; 248: 468-476.

22. London GM, Zins B, Pammic B, Naret C, Berthelot JM, Jacquot C, Safar M, Drueke T. Vascular changes in hemodialysis patients in response to recombinant human erythropoietin. Kidney Int $1989 ; 36: 878-882$.

23. Cheriex EC, Leunissen KML, Janssen JHA, Mooy JMV, Van Hooff JP. Echography of the inferior vena cava is a simple and reliable tool for estimation of dry weight in hemodialysis patients. Nephrol Dial Transpl 1989; 4: 563-568.

24. Keyes J, Carey J, Mosses D, Beyerwalter W. Manua! of nuclear medicine procedures. Edition 2, Cleveland CRS Press 1973, p 95-98.

25. Tararin RC, Melsher HJ, Dustan MP. Frolich EL. Plasma volume changes with upright tilt, studies in hypertensives and in syncope. J Appl Physiol 1970; 28: 12.1-126.

26. Bouchard A, Blumlein S, Schiller NB. Measurement of left ventricular stroke volume using continuous wave Doppler echocardiography of the ascending aorta and $\mathrm{M}$-mode echocardiography of the aortic valve. J Am Coll Cardiol 1987; 9: 75-83.

27. Chandraratna PA. Nanna M, McKay C, Nimalasuriya A. Determination of cardiac output by transcutaneous wave ultrasonic Doppler computer. Am J Cardioll 1984; 53 : 234-237.

28. Sahn DJ, DeMaria A, Kisslo J. The committee on M-mode standardization of the American Society of Echocardiography: recommendations regarding quantitation in M-mode echocardiography. Results of a survey of echocardiographic measurements. Circulation 1978; 58: 1072-1083.

29. Murray JF, Escobar E, Rapaport E. Effects of blood viscosity on hemodynamic responses in acute normovolemic anemia. Am J Physiol 1969; 216: 638-642. 



\section{CHAPTER}

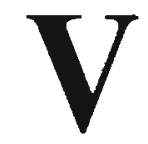

\section{Recombinant human erythropoietin and dialysis fistula function}

J.M. Wirtz' , W.H.M. van Kuyk ${ }^{1}$, J.H.M. Tordoir ${ }^{2}$, J.P. van Hooff ${ }^{1}$, K.M.L. Leunissen ${ }^{1}$

${ }^{1}$ Department of Nephrology

${ }^{2}$ Department of Vascular Surgery

University Hospital Maastricht, Maastricht, The Netherlands

Blood Purification in Perspective: New insights and future trends. 1992; II: 37-42. Editors: N.K. Man, J. Botella, P. Zucchelli. ICAOT Press, Cleveland, Ohio. 


\section{Abstract}

Erythropoietin (ReHuEpo) treatment may lead to an increased incidence of fistula thrombosis, probably related to changes in blood viscosity, hemostasis, hemodynamics, and actual fluid status. In 10 normovolemic hemodialysis patients, we studied the relative contribution of each factor on Cimino fistula flow during ReHuEpo therapy. We used Duplex scanning to detect fistula stenosis and Brachial Artery Spectral Analysis to measure fistula flow. At higher hematocrit ( $22 \pm 3 \rightarrow 37 \pm 3 \%, \mathrm{p}<0.001$ ) (achieved in $8.0 \pm 3$ months) grade of stenosis at anastomotic level as well as at different levels in the efferent cephalic vein was unchanged. The diastolic as well as the systolic frequency in the brachial artery decreased, indicating decreased flow. Blood viscosity (BV; $\left.230 \mathrm{~S}^{-1}\right)$ increased. Cardiac index $(\mathrm{Cl})$ decreased whereas mean arterial pressure (MAP) was unchanged. Multiregression analysis only disclosed a significant correlation between $\Delta \mathrm{Cl}-\Delta$ systolic flow $(r=0.74, p<0.02)$ and $\triangle \mathrm{MAP}-\Delta$ diastolic flow $(r=-0.71, p<0.05)$ in the brachial artery.

\section{Introduction}

Dialysis fistula function is of utmost importance to assure an efficient dialysis treatment. Dialysis fistula occlusion will include many problems, both for the patient as well as for the treating physician. Dialysis fistula failure, in the period before treatment with recombinant human erythropoietin (ReHuEpo), was mainly related to progressive anatomical lesions.

Since thrombosis of the fistula is usually caused by venous stasis associated with progressive stenotic lesions at the anastomotic level, but also in the efferent vein due to intimal hyperplasia [1], preexistent anatomical factors like the amount and degree of venous stenosis and peripheral arterial disease determine the outcome of fistula formation [2]. Schwab et al reported that increased venous extracorporeal pressures of $>150 \mathrm{mmHg}$, when untreated, lead to an increased incidence of fistula thrombosis when compared to those whose stenotic lesions had been treated by percutaneous transluminal angioplasty [3].

Reilly et al [4] compared in a retrospective study patients on maintenance dialysis, not treated with ReHuEpo, with and without fistula thrombosis, and found a higher extent of platelet aggregation, a lower threshold response to ADP, a higher beta-thromboglobulin level, and a higher whole blood viscosity at low shear rate in thrombotic patients. Multivariate regression analysis in a prospective study by the same authors to the patency of newly constructed AV-fistulas disclosed that the preoperative platelet counts, beta-thromboglobulin level, and plasma viscosity were the best predictors for fistula thrombosis during a followup of 1-18 months. 
Treatment with ReHuEpo has been reported to lead to an increased incidence of dialysis fistula thrombosis. Factors like increased blood viscosity, prothrombotic changes in platelet function and other hemostatic and fibrinolytic parameters, and the observed decrease in cardiac output all might contribute. In addition, the female sex [5], diabetes mellitus [6], and hypovolemia could imply a greater risk on flow related complications during treatment with ReHuEpo. The presence of anatomic fistula lesions together with the above mentioned ReHuEpo related factors could lead to fistula flow changes, predisposing to fistula thrombosis.

The aim of our prospective study was to determine the influence of potential risk factors for shunt thrombosis during treatment with ReHuEpo on fistula flow.

\section{Patients and methods}

Ten chronic anemic (hematocrit $=\mathrm{Ht}<25 \%$ ) patients $(6$ female, 4 male) with a Brescia/Cimino fistula were selected. The mean age of the group was $54 \pm 16$ (27-80 years). Patients with cardiac dysfunction (defined as left ventricular ejection fraction $<40 \%$ ), with diabetes mellitus, aluminium intoxication, and severe hypertension ( $p$ diast $\geq 100 \mathrm{mmHg}$ ) were excluded from the study.

The patients were treated with ReHuEpo (Eprex, Cilag, Belgium), administered intravenously after every dialysis according to the so called low and slow dose schedule. The dose was adjusted monthly, depending on the response and aiming at a target $\mathrm{Ht}$ of $\pm 35 \%$.

Five of the patients did not use antihypertensive and/or cardiovascular drugs. The other patients were treated with calcium entry blockers (Nifedipine Retard).

The actual fluid status of the patient was determined by serial assessment of the inferior caval vein diameter and collapsibility index by means of echography, and dry weight adjusted according to the inferior caval vein parameters of normovolemia [7].

All investigations were performed $20-24 \mathrm{~h}$ after dialysis, the moment of most optimal plasma volume preservation [8]. The investigations were done before treatment with ReHuEpo and after reaching the target $\mathrm{Ht}$ of $\pm 35 \%$ whereby each patient served at his own control.

\section{Fistula function}

The examination of the Brescia/Cimino AV-fistula was performed by duplex scanning and spectral analysis with an ATL Ultramar IV Duplex scanner. These examinations were done with the patient in the supine position after a period of 
10 min of rest. A $10 \mathrm{mHz}$ B-mode sector transducer was used for the localization and detection of arteries and veins and for a constant $60^{\circ}$ angle of insonation with respect to the vessel axis. A $5 \mathrm{mHz}$ pulsed Doppler beam was used to perform quantitative spectral analysis.

Diagnosis of fistula stenosis, which might interfere with our interpretation of the effect of ReHuEpo on fistula flow, was performed by the determination of the maximal frequency shift (MFS) in the Doppler spectrum at the anastomotic level, and the peak systolic frequencies (PSF) at the proximal cephalic vein ( \pm 2 $\mathrm{cm}$ proximal of the anastomosis; PV), but also at the distal level (DV) of the efferent vein in the upper arm. The coefficient of variation was less than $5 \%$.

In addition, the blood pressure in the thumb at the fistula side (TP), also an indicator of especially the AV-anastomotic patency and flow, was measured in the supine patient after a period of $15 \mathrm{~min}$ of rest. Systolic thumb pressure was determined by slowly deflating a $20 \mathrm{~mm}$ wide cuff around the base of the thumb, inflated to a suprasystolic level while the first inflow was recorded with a photoplethysmographic cell, used as a pulse sensor (Medasonic Vasculab). Thumb pressure was measured with open fistula and during digital compression of the efferent vein. A low pressure at open fistula and an increase of $>25 \mathrm{mmHg}$ after compression was considered to represent a valid fistula function. Furthermore, the thumb-to-brachial artery blood pressure index (T/B index) with open (O) respectively compressed (C) fistula was calculated as an additional parameter for the anastomotic patency [2].

Indirect duplex ultrasound scanning measurements of the fistula function, recording the afferent fistula flow, were performed by brachial artery (a) spectral analysis. The absence or presence of diastolic flow $(\mathrm{DFa}=$ diastolic flow with open fistula - diastolic flow during efferent vein compression) and the magnitude peak systolic flow ( $\mathrm{PsFa}=$ systolic flow at open fistula) is indicative for fistula flow.

The duplex ultrasound scanning method as described is a noninvasive method reported to possess high diagnostic accuracy when digital substraction angiography was used as the golden standard. Especially when the peak systolic frequency was used as parameter and the cut-off value of 12 and $8 \mathrm{kHz}$ for the anastomotic level respectively the efferent vein were accepted, the predictive value of this method for significant stenosis was rather high: a positive predictive value and a negative predictive value of $86 \%, 76 \%$ and $82 \%, 99 \%$ for the detection of anastomotic stenoses and stenoses in the efferent vein respectively [9].

All fistulas were functioning clinically satisfactorily as represented by an adequate flow for dialysis ( $>250 \mathrm{ml} / \mathrm{min}$ ) before the start of the study. Venous pressure (VP) in the extracorporeal circuit, an indicator of efferent venous fistula flow, was recorded during dialysis by the venous pressure monitor of a Gambro AK-100 hemodialysis machine, at an extracorporeal blood flow of 250-300 
$\mathrm{ml} / \mathrm{min}$, through 16 gauge needles. Of 3 consecutive dialysis treatments, before and after treatment with ReHuEpo, the data were averaged to cope with the variability in venous pressures caused by needle placement. Under these conditions, venous dialysis pressures $>150 \mathrm{mmHg}$ were considered abnormal and to represent significant obstruction according to Schwab et al. [3].

\section{Macrocirculatory indices}

\section{Cardiac index and mean arterial pressure}

Stroke volume was calculated from the cross-sectional area of the aortic valve and the maximal integral flow velocity in the ascending aorta, both assessed in the early systole of the cardiac cycle, with the use of a Hewlett-Packard (770-20A) $3.5 \mathrm{mHz}$ Duplex scanner. From these variables, the cardiac index (CI) $\left(\mathrm{L} / \mathrm{min} / \mathrm{m}^{2}\right)$ was calculated [10]. The inter- and intraobserver variability of this method has been reported to be less than $10 \%$ [1].

Mean arterial pressure (MAP) ( $\mathrm{mmHg}$ ) was recorded during a 1-h period of rest with the patient in the sitting position by means of the Penaz method (Finapress, BP-monitor Ohmeda 2300) at the contralateral arm without fistula [12].

\section{Heparin need}

During the dialysis sessions, the administered dose of heparin $(U / h)$, needed to avoid clotting in the extracorporeal system, was registered before treatment with ReHuEpo and after the target $\mathrm{Ht}$ had been reached. Usually, dosages were increased at the moment of observed clotting in the venous bubble trap and in the fibers of the artificial kidney with steps of $250 \mathrm{U}$ maintenance dose/h of dialysis.

\section{Rheologic parameters}

Whole blood viscosity (BV) was determined using a Wells-Brookfield microviscosimeter (model LVT-C/P); $2 \mathrm{ml}$ of heparinized fresh whole blood was immediately handled at shearrates (SR) of $230 \mathrm{~S}^{-1}$ and $11.50 \mathrm{~S}^{-1}$, respectively, at a constant temperature of the jacketed sample cup of $37^{\circ} \mathrm{C}$. From the scale, the shear stress (SS; dyne $/ \mathrm{cm}^{2}$ ), created by the rotating spindle in the blood filled 
sample cup, could be registered. The actual BV subsequently could be calculated from the formula:

$$
\mathrm{BV}(\operatorname{cps})=\frac{S S \times 100}{S R}
$$

The accuracy of this system has been reported to be within $1 \%$ of whatever range is employed. Sensitivity and reproducibility is within $0.2 \%$.

Red blood cell aggregation (Eaggr) was determined with an automatic aggregometer (Myrenne): one droplet of heparinized fresh blood was immediately sheared at $3 \mathrm{~S}^{-1}$, and the result could be read on the digital screen [13]. Red blood cell deformability (Eflex) was examined by ektacytometry [14] and expressed in the so called elongation index after resuspension in a solution of phosphate buffer $(1: 400)$ with a high molecular polymer, resulting in a high osmolar suspension $(600 \mathrm{mosmol} / \mathrm{kg})$.

\section{Laboratory examinations}

Ht and the amount of platelets (PC) were determined weekly with routine laboratory methods. Skin bleeding time (BT) as an indicator of the primary hemostatic function was evaluated according to the Ivy method and expressed in $\mathrm{min} / \mathrm{s}$.

\section{Statistical analysis}

For the statistical analysis, we used the student's t-test for paired data. A p value of $\leq 0.05$ was considered as significant.

\section{Results}

During treatment with ReHuEpo, the $\mathrm{Ht}$ increased significantly during the follow-up period of $8.0 \pm 3$ months from $0.22 \pm 0.3$ to $0.37 \pm 0.3$ ( $\mathrm{p}<0.001)$. The data on fistula function are depicted in table 1. The MFS at the anastomosis did not change as did PV as well as DV. Also $\triangle \mathrm{TP}$ did not change during the course of treatment as did the $T / B(O)$ and $T / B(C)$ index.

$\mathrm{DFa}$, at brachial artery level, decreased significantly whereas in the PSFa a nonsignificant decrease was observed. VP during dialysis showed a significant increase at unchanged blood flow rates. However, the observed changes were within the upper limit for significant stenosis. CI decreased significantly (table 
Table 1: Parameters of fistula function and hemodynamic parameters before and after starting ReHuEpo treatment at a Ht level of \pm 0.37

\begin{tabular}{llll}
\hline & Pretreatment & P & $\begin{array}{l}\text { Posttreatment } \\
8.0 \pm 3 \text { months }\end{array}$ \\
& & & \\
\hline MFS $(\mathrm{kHz})$ & $13.6 \pm 4$ & NS & $13.5 \pm 4$ \\
PV $(\mathrm{kHz})$ & $6.5 \pm 3.5$ & NS & $4.7 \pm 4.3$ \\
DV $(\mathrm{kHz})$ & $2.3 \pm 0.7$ & NS & $1.9 \pm 0.3$ \\
$\Delta T P(\mathrm{mmHg})$ & $41 \pm 15$ & NS & $52 \pm 26$ \\
T/B $(\mathrm{O})$ & $0.77 \pm 0.24$ & $=0.08$ & $0.64 \pm 0.24$ \\
T/B $(\mathrm{C})$ & $1.06 \pm 0.23$ & NS & $1.04 \pm 0.18$ \\
DFa $(\mathrm{kHz})$ & $2.6 \pm 0.6$ & $<0.01$ & $1.8 \pm 0.4$ \\
PSFa $(\mathrm{kHz})$ & $4.7 \pm 0.7$ & 0.07 & $4.2 \pm 0.8$ \\
VP $(\mathrm{mmHg})$ & $53 \pm 20$ & $<0.025$ & $72 \pm 18$ \\
$\mathrm{CI}\left(\mathrm{L} / \mathrm{min} / \mathrm{m}^{2}\right)$ & $4.0 \pm 0.6$ & $<0.05$ & $3.5 \pm 0.5$ \\
$\mathrm{MAP}(\mathrm{mmHg})$ & $97 \pm 12$ & NS & $100 \pm 9$ \\
\hline
\end{tabular}

1). MAP did not change throughout the study, and in none of the patients did antihypertensive medication have to be started or adjusted (table 1).

The administered maintenance dose of heparin (HN) during dialysis had to be increased throughout the period of treatment from $250 \pm 288$ to $375 \pm 212$ $\mathrm{U} / \mathrm{h}(\mathrm{p}<0.05)$.

The rheologica data are presented in table 2. BV increased significantly at both share rates of 230 and $11.50 \mathrm{~S}^{-1}$, respectively. Eaggr also showed a significant increase. Eflex, as expressed in the elongation index (\%), did not change at both shear rates of 106 and $1350 \mathrm{~S}^{-1}$, respectively. PC did not significantly increase whereas the BT shortened (table 3).

Multiregression analysis with the changes in fistula flow parameters (DFa, $\mathrm{PSFa}$ ) as dependent variables, and $\triangle \mathrm{CI}, \triangle \mathrm{MAP}, \mathrm{Ht}$, rheologic parameters and platelet count as predictive variables, revealed a significant predictive value of $\triangle \mathrm{CI}$ on $\triangle \mathrm{PSFa}$ (multiple $\mathrm{r} 0.74, \mathrm{p}<0.02$ ) and a significant negative predictive value of $\triangle \mathrm{MAP}$ on $\triangle \mathrm{DFa}$ (multiple $\mathrm{r}-0.71, \mathrm{p}<0.05$ ). All other variables did not reach significance. $\mathrm{BV}$ at a shear rate $230 \mathrm{~S}^{-1}$ was related to $\Delta \mathrm{CI}$ although not significantly $(r=0.52, p=0.07)$. 
Table 2: Rheologic parameters before and after starting ReHuEpo treatment at a $\mathrm{Ht}$ level of 0.37

\begin{tabular}{|c|c|c|c|}
\hline & Pretreatment & $\mathrm{P}$ & $\begin{array}{l}\text { Posttreatment } \\
8.0 \pm 3 \text { months }\end{array}$ \\
\hline \multicolumn{4}{|l|}{$\mathrm{BV}(\mathrm{cps})$} \\
\hline $11.5 \mathrm{~S}^{-1}$ & $2.7 \pm 1.0$ & $<0.01$ & $3.3 \pm 1.3$ \\
\hline $230 \mathrm{~S}^{-1}$ & $3.5 \pm 0.4$ & $<0.02$ & $4.8 \pm 1.0$ \\
\hline $\begin{array}{l}\text { Eaggr } \\
\text { Eflex }(\%)\end{array}$ & $5.5 \pm 3.1$ & $<0.01$ & $6.7 \pm 3.4$ \\
\hline $\begin{array}{c}106 \mathrm{~S}^{-1} \\
(\mathrm{n}=18-31 \%)\end{array}$ & $26 \pm 8$ & NS & $27 \pm 8$ \\
\hline $\begin{array}{c}1.350 \mathrm{~S}^{-1} \\
(\mathrm{n}=56-68 \%)\end{array}$ & $58 \pm 7$ & NS & $59 \pm 6$ \\
\hline
\end{tabular}

Table 3: Hemostatic parameters before and after starting ReHuEpo treatment at a $\mathrm{Ht}$ level of 0.37

$\begin{array}{ll}\text { Pretreatment } & \text { P } \\ & 8.0 \pm 3 \text { months }\end{array}$

\begin{tabular}{llll}
\hline $\operatorname{Pc}\left(10^{9} / \mathrm{L}\right)$ & $194 \pm 71$ & NS & $211 \pm 67$ \\
$\operatorname{BT}(\min / \mathrm{s})$ & $4 \min 14 \mathrm{~s} \pm 1 \min 20 \mathrm{~s}$ & $=0.05$ & $3 \mathrm{~min} 26 \mathrm{~s} \pm 1 \mathrm{~min} 13 \mathrm{~s}$
\end{tabular}

\section{Discussion}

The most common cause of late fistula failure is thrombosis [5], due to a stenosis in the proximal vein at or just above the anastomosis. Intimal hyperplasia from turbulent flow or repeated punctures [15] are considered to be etiologic factors. However, blood flow problems during dialysis will occur only in case of severe stenosis $(>90 \%)$. Progressive vascular sclerosis is responsible for diminution of blood flow and subsequent occlusion by thrombosis. The incidence of thrombotic occlusion can be further enhanced by treatment with ReHuEpo. Despite conflicting data, dialysis fistula thrombosis has been reported to occur in an increased frequency during treatment with ReHuEpo [16, 17].

There are circumstances, which might increase the risk on fistula thrombosis during ReHuEpo treatment: the progressive and natural course of especially 
anastomotic and efferent vein stenoses [1], or a decrease of afferent and/or efferent fistula flow. The latter could be due to macrocirculatory changes [18, 19], changes in rheology [20] and/or hemostatic changes induced by ReHuEpo therapy $[21,22]$, or due to a combination of these factors.

In this study we did not observe changes in the maximal frequency shift at anastomotic level and the peak systolic frequencies at the different levels in the efferent vein of the fistula before treatment with ReHuEpo and after reaching the target $\mathrm{Ht}$, indicating that no significant stenosis developed during the followup period. The thumb pressure measurements, as an indirect representation of especially the anastomotic patency, confirmed this observation. Furthermore, we did not experience any hindrance in the arterial inlet flow during dialysis. Blood flow rates of at least $250 \mathrm{ml} / \mathrm{min}$ could be maintained in the follow-up period. The small but significant increase of extracorporal venous pressures at constant blood flow rates of $250-300 \mathrm{ml} / \mathrm{min}$ during dialysis would indicate venous stenoses. However, the absolute venous pressure values were still below the upper limit ( $150 \mathrm{mmHg}$ ) of significant stenosis as indicated by Schwab et al. [3].

At brachial artery level, the diastolic as well as the peak systolic flow decreased, indicating a decrease in afferent fistula flow. MacDougall et al. did not find any decrease in fistula flow by means of Doppler examinations of the fistula during treatment with ReHuEpo. However, in their study important methodologic information is lacking. The measured parameters and also the exact time of the investigations in relation to dialysis are not given, nor did they consider the actual fluid status of the patient, known to interfere with flow data at the moment of investigation [23].

Concerning the factors which might induce a decreased fistula flow, a progression of anatomical lesions in our study could already be excluded. The evaluation of the macrocirculation disclosed a stable blood pressure during treatment with ReHuEpo, and normovolemia was maintained. However, cardiac output decreased significantly and could induce a diminution in fistula flow.

According to the observation of other authors, the actual blood viscosity increased [20], as did the erythrocyte aggregation, and both could also negatively influence dialysis fistula flow. In our study we did not observe changes in red blood cell flexibility as indicated by the elongation index, and all values were within the normal range to the corresponding shear rate. Some studies, however, reported an improvement of the red blood cell deformability during treatment with ReHuEpo in hemodialysis patients, probably due to a normalization in the composition and/or functional restoration of the red cell membrane [24]. Theoretically, one might expect that in the macrovessels of the dialysis fistula, the red blood cell deformability should play a minor role.

Concerning the hemostatic parameters in this study, only the platelet count and skin bleeding time were measured. The platelet count was not different, and 
the skin bleeding time improved in our patients. In an earlier study, we investigated the hemostatic and fibrinolytic system more extensively, and next to an improvement in bleeding time, we observed that treatment with ReHuEpo included an increase in in vitro platelet aggregation by way of a lower ADP threshold, a decrease in protein-C and $-S$ (total and free) antigen levels, and a decrease in protein- $\mathrm{C}$ activity. Furthermore, increased plasminogen activator inhibitor (PAI) activity levels in patients with fistula thrombosis compared to patients without thrombosis were observed [2I].

Multiregression analysis with changes of fistula flow (DFa, PSFa) as dependent variables and $\triangle \mathrm{CI}, \triangle \mathrm{MAP}, \mathrm{Ht}$, rheologic parameters and platelet count as predictive variables, only revealed a significant effect of the change in cardiac index on the $\triangle \mathrm{PSF}$ a whereas $\triangle \mathrm{MAP}$ had a significant negative predictive effect on $\triangle \mathrm{DFa}$. The decrease in $\mathrm{CI}$ is related to the increase of blood viscosity at high shear rates but is also due to a decrease in pulse rate as well as stroke index as was pointed out in earlier reports $[18,19,25]$. The negative correlation of a decrease of diastolic fistula flow $\triangle \mathrm{DFa}$ and the increase of blood pressure is related to the increase of systemic vascular resistance during ReHuEpo therapy [18].

In conclusion, during treatment with ReHuEpo fistula flow decreases. The decrease in $\mathrm{CI}$, which is inversely related to blood viscosity, seems to be a major determining factor. Fistula thrombosis during ReHuEpo therapy, however, is of multifactorial origin: anatomical lesions in the fistula in combination with a decrease of fistula flow, the prothrombotic changes, and the underestimation of dialysis dry weight during treatment with ReHuEpo all may contribute. 


\section{References}

1. Palder SB, Kìrkman RL, Whittemore AD, Hakim RM, Lazarus JM. Vascular access for hemodialysis. Patency rates and results of revision. Ann Surg 1985; 202: 35-39.

2. Tordoir JHM. Non-invasive diagnostic studies of arteriovenous fistulas for hemodialysis. Thesis, Maastricht, The Netherlands, 1989.

3. Schwab S3, Raymond JR, Saeed M, Newman GE. Prevention of hemodialysis fistulat thrombosis. Early detection of venous stenoses. Kid Int 1989; 36: 707-711.

4. Reilly DT, Wood RFM, Bell PRF. A prospective study of the correlation between rheological factors and fistula failure. In: Kootstra J, Joming PJG, eds. Access Surgery. Lancester MTP Press Lid. 1983; 51-57.

5. Kinnaert P, Vereerstraeten $P$, Toussaint $C$, Van Geertnyden $J$, Nine years experience with internal arteriovenous fistulas for hemodialysis: a study of some factors influencing the results. Brit I Surg 1977; 64: 242-246.

6. Aman LC, Smith DW, On HK, Levin NW. Vascular access survivall in diabetic and non-diabetic hemodialysis patients. In: Kootstra G, Jorning PGJ, eds. Access Surgery. Lancester: MTP Press Lid. 1983: 179.190.

7. Cheriex EC, Leunissen KML, Janssen JHA, Mooy JMV, Van Hooff JP. Echography of the inferior vena cava is a simple and reliable tool for estimation of 'dry weigh' in hemodialysis patients. Nephrol Dial Transpl 1989; 4: 563-568.

8. Koomans HA, Geers AB, Dorhout Mees EJ. Plasma volume recovery after ultrafiltration in patients with chronic renal failure. Kidn Int 1984; $26: 848-854$.

9. Tordoir JHM, De Bruin HG, Hoeneveld H, Eikelboom BC, Kitslaar PJEHM. Duplex ultrasound scanning in the assessment of arteriovenous fistulas created for hemodialysis access: comparison with digital substraction angiography. J Vasc Surg 1989; 10: 122-128.

10. Bouchard A, Blumlein S, Schiller NB. Measurement of left ventricular stroke volume using continuous wave Doppler echocardiography of the ascending aorta and M-mode echocardiography of the aortic valve. J Am Coll Cardiol 1987; 9: 75-83.

11. Chandrarama PA, Nanna M, Mckay C, Nimalasuriya A. Determination of cardiac output by transcutaneous continuous wave ultrasonic Doppler computer. Am J Cardiol 1984; 53: 234-237.

12. Boehmer RD. Continuous, real-time noninvasive monitor of blood pressure: Penaz methodology applied to the finger. J Clin Monit 1978; 3: 282-287.

13. Kiesewetter H, Radtke U, Schneider R, Mussler K, Scheffler A, Schmid-Schönbein H. Mini-erythrocyte aggregometer. A new apparatus for rapid quantification of the extent of erythrocyte aggregation. Biomed Technik 1982; 209-213.

14. Bessis M, Mohandas N. Automated ektacytometry, a new method of measuring red cell deformability and red cell indices. Blood Cells 1980; 6: 315-327.

15. Kemkes BM, Borchard F, Complications and surgical treatment after angio-access. Kootstra G, Jörning PJG. Access Surgery. Lancester: MTP Press Ltd. 1983: 203-210.

16. Sundal E, Kaeser U. Correction of anemia of chronic renal failure with recombinant human erythropoietin: safety and efficacy of one year's treatment in an European multicenter study of 150 hemodialysis dependent patients. Nephrol Dial Transpl 1989; 4: $979-987$. 
17. Canadian Erythropoietin Study Group. Association between recombinant human erythropoietin and quality of life and exercise capacity of patients receiving hemodialysis. Br Med J 1990; 300: 573-578.

18. Wirtz JJJM, Leunissen KML, Van Esser JWJ, Cheriex EC, Slaaf DW, Reneman DS, Van Hooff JP. Recombinant human erythropoietin and its effects on micro- and macrocirculation during normovolemia. Blood Purif 1990; 8: 285-294.

19. London GM, Zins B, Pannier B, Naret C. Vascular changes in hemodialysis patients in response to recombinant human erythropoietin. Kidn Int 1989; 36: 878-882.

20. Schaefer RM, Leschke M, Strauer BE, Heidland A. Blood rheology and hypertension in hemodialysis patients treated with erythropoietin. Am J Nephrol 1988; 8: 449-453.

21. Wirtz JJJM, Van Esser JWJ, Hamulyak K, Leunissen KMI, Van Hooff JP. The effects of recombinant human erythropoietin on hemostasis and fibrinolysis in hemodialysis patients. Clin Nephrol 1992; 38: 277-282.

22. Huraib S, Al-Momen AK, Gader AMA, Mitwalli A. Effect of recombinant human erythropoietin on the hemostatic system in chronic hemodialysis patients. Nephrol Dial Transpl 1991; 36: 252-257.

23. MacDougall IC, Davies ME, Hallett l, Cochlin DL, Hutton RD. Coagulation studies and fistula blood flow during erythropoietin therapy in hemodialysis patients. Clin Nephrol 1991; 6: 862-867.

24. Meier W, Paulitschke M, Lerche D, Schmidt G. Action of ReHuEpo on mechanical membrane properties of red blood cells in children with end-stage renal disease. Nephrol Dial Transpl 1991; 6: 110-116.

25. Hori $\mathrm{K}$, Onoyama $\mathrm{K}$, Iseki $\mathrm{K}$. Hemodynamic and volume changes by recombinant human erythropoietin in the treatment of anemic hemodialysis patients. Clin Nephrol 1990; 33: 293-298. 
The effects of recombinant human erythropoietin on hemostasis and fibrinolysis in hemodialysis patients

J.J.J.M. Wirtz ${ }^{1}$, J.W.J. van Esser ${ }^{1}$, K. Hamulyak ${ }^{2}$, K.M.L. Leunissen ${ }^{1}$ and J.P. van Hooff ${ }^{1}$

Department of Nephrology ${ }^{1}$ and Hematology ${ }^{2}$

University Hospital Maastricht, Maastricht, The Netherlands

Clinical Nephrology, 1992; 38 (5): 277-282 


\section{Abstract}

Thromboembolism might complicate the treatment of patients with chronic renal failure with Recombinant Human Erythropoietin (ReHuEpo). In order to detect prothrombotic changes, a number of hemostatic and fibrinolytic parameters was determined during ReHuEpo treatment of fifteen chronic hemodialysis patients (mean age 47.1 years; ten females, five males). To avoid the influence of hemoconcentration and/or dilution, the patients were kept normovolemic, using the method of echography of the inferior vena cava diameter. In a first group of eight patients, we investigated platelet count and function. During ReHuEpo, a significant rise of hematocrit $(19 \pm 3$ to $34 \pm 5 \% ; \mathrm{p}<0.001)$ was observed. Bleeding time shortened (7'33" $\pm 3^{\prime} 39^{\prime \prime}$ to $3^{\prime} 41^{\prime \prime} \pm 3^{\prime} 19^{\prime \prime}$; $\mathrm{p}<0.001)$ and platelet count increased $\left(222 \pm 45\right.$ to $\left.254 \pm 4910^{9} / \mathrm{p} ;<0.005\right)$. The initial negative in vitro spontaneous platelet reactivity became positive in two of them, whereas the decrease in ADP threshold in the whole group (2.0 \pm 0.1 to $1.0 \pm 0.4 \mu \mathrm{mol} ; \mathrm{p}<0.02)$ indicated an increased induced platelet reactivity. In all patients prothrombotic changes were observed. The protein- $\mathrm{C}$ antigen and protein- $\mathrm{C}$ activity and the total and free protein- $\mathrm{S}$ antigen decreased significantly. The plasminogen activator inhibitor (PAI) activity in the whole group did not change significantly $(6.4 \pm 4.1$ to $5.4 \pm 4.8 \mathrm{AU} / \mathrm{ml})$. However, in the patients with fistula thrombosis $(n=3)$, higher values in all test points were found compared to those without thrombosis.

\section{Introduction}

One of the major breakthroughs of the last decade in the treatment of patients with chronic renal failure is the development of recombinant human erythropoietin (ReHuEpo). ReHuEpo produces a rise in hemoglobin levels and leads to a significant increase of well being of patients with end-stage renal disease [1-6]. Unfortunately, ReHuEpo therapy has serious side effects, such as hypertension. Despite conflicting data it might also predispose to thrombotic fistula occlusion [7-10], the occurence of which could partly be due to alteration$s$ of hemostatic function.

A number of potentially thrombogenic factors has been described. During ReHuEpo therapy bleeding time as well as the in vitro platelet reactivity improve. A number of potentially prothrombotic factors has been described, such as an increased in vitro platelet reactivity, that probably contributes to the also reported significant shortening of the bleeding time together with the increased hematocrit [11-21].

Impairment of the fibrinolytic response is associated with a thrombotic tendency, especially in case of prolonged high levels of plasminogen activator 
inhibitor (PAl) activity [22-27]. Other well-known risk factors include decreased levels of the anticoagulant proteins: antithrombin-IIt and the protein-C and $-\mathrm{S}$. The protein-C/S pathway plays a dual role by the inactivation of the activated coagulation factors $\mathrm{V}$ and VIII, leading to a subsequent decrease in thrombin function, and the profibrinolytic release of the tissue derived plasminogen activator and the degradation of PAI type 1 .

Detailed information about the involvement of the fibrinolytic system in the occurence of RelHuEpo-related thromboembolism is scarce. An increase in fibrinogen [15-16], but also a decrease in the plasma levels of protein-C and -S [28-29], however, have been reported.

The aim of this study was to reinvestigate the changes of platelet function during ReHuEpo treatment, and to study whether alterations in the fibrinolytic system may play a role in the thrombogenic complications during ReHuEpo treatment.

\section{Patients and methods}

Two groups of stable chronic hemodialysis patients were studied. None of them had overt diabetes mellitus and/or high levels of cholesterol or triglycerides and none was using medication, interfering with hemostasis and/or fibrinolysis.

ReHuEpo (Eprex, Cilag, Belgium) was administered intravenously after every dialysis, according to the "low and slow" dose schedule, starting at an initial dose of $50 \mathrm{U} / \mathrm{kg}$ with monthly adjustment according to response, aiming at a target hemoglobin level of $10.5-11.6 \mathrm{~g} / \mathrm{dl}$.

To avoid the influence of hemoconcentration and/or hemodilution, all patients were kept normovolemic adjusting dry weight every two weeks, using the method of echographic evaluation of the inferior vena cava [30]. Blood samples were obtained before ReHuEpo treatment and at two intervals when hematocrit had increased at least $5 \%$ compared to the preceding value. The samples were drawn 20-24 hours after dialysis at 11.30 hours a.m., using a 19 gauge needle and minimal stasis. Full blood counts were performed in EDTA anticoagulated blood, using an automatic electronic counter (HI, Technicon) within 2 hours after sampling. For the study of hemostatic and fibrinolytic parameters blood was collected in $0.109 \mathrm{M}$ sodium-citrate (9:1). Platelet poor plasma was prepared immediately in a refrigerated centrifuge at $4^{\circ} \mathrm{C}$ at $2000 \mathrm{x} \mathrm{g}$ and stored at $-70^{\circ} \mathrm{C}$ until assayed. In the first group of eight patients skin bleeding time, platelet counts and platelet aggregation studies were performed. The second group consisted of 15 patients, in whom fibrinolytic (PAI activity) and other hemostatic measurements (AT III, protein-C and -S antigens) were performed. In the last seven patients of the second group (= group IIB) additional measure- 
ments were performed (protein-C activity, tissue plasminogen activator antigen and plasminogen activity).

The following laboratory methods were used:

1. Platelet function was studied by: 1) bleeding time according to the Ivy method, and 2) the spontaneous platelet aggregation (SPA) and ADP threshold concentration in fresh citrated platelet rich plasma using a Payton aggregometer [31].

2. Antithrombin III activity (\%), protein-C activity (\%), plasminogen (\%) and PAI activity (\%) were all measured in an amidolytic assay (using KABI-kits $\mathrm{AB}$, Sweden), according to the manufacturers instructions.

3. Protein-C antigen (\%) and its cofactor protein-S antigen (\%), and the tissue plasminogen activator antigen $(\mathrm{ng} / \mathrm{ml})$ were measured by an enzyme linked immunosorbent assay (Diagnostica Stago, France).

4. Free protein-S antigen was measured in the supernatant after precipitation of bound protein-S with PEG 8000.

The coefficient of variation of the amidolytic assays and the antigen determinations with ELISA are $6 \%$ and $10 \%$ respectively.

\section{Statistics}

Student's t-test for paired data and Wilcoxon's nonparametric test for paired rank data were used for statistical analysis. Next to these a Student's t-test for unpaired data and a Mann-Whitney test was used for the analysis of PAI activity $(\mathrm{AU} / \mathrm{ml})$ in the patients of group II, for those without and those with dialysis fistula thrombosis. All data have been analyzed using the SPSS-pc statistical program, version III. A p-value of $<0.05$ was considered to be significant. It was decided that, if non-parametric tests should give different results to those of the parametric tests as far as the acceptance or rejection of nullhypotheses was concerned, this had to be reported in the text or in the tables. This was not the case in our data, so all results are presented as means with standard deviations and only results of parametric tests are reported.

\section{Results}

According to the accepted targets, the moments of reinvestigation were reached after intervals of $2.2 \pm 0.7$ months and $3.2 \pm 1.0$ months respectively. In the patients of group I hematocrit increased from $19 \pm 3$ to $34 \pm 5 \%(p<0.001)$, the platelet count (PC) increased and bleeding time (BT) shortened. Before treatment with ReHuEpo in vitro spontaneous platelet aggregation occurred in none of the patients. However, in two of them the in vitro spontaneous platelet 
Table 1: Platelet count and bleeding time in group I $(n=8)$ during treatment with ReHuEpo

\begin{tabular}{lllllll}
\hline & PTe & & II & & III & P (Pre-III) \\
\hline Hematocrit (\%) & $19 \pm 3$ & $*$ & $27 \pm 4$ & $*$ & $34 \pm 5$ & $<0.001$ \\
Platelet count $\left(\times 10^{9} /\right)$ & $222 \pm 45$ & ns & $244 \pm 51$ & ns & $254 \pm 49$ & $<0.005$ \\
Bleeding time (min.sec) & $7.33 \pm 3.39 *$ & $4.38 \pm 1.44$ & $*$ & $3.41 \pm 3.19$ & $<0.001$ \\
ADP threshold concentrations & $2.0 \pm 0.1$ & $*$ & $0.7 \pm 0.4$ & $*$ & $1.1 \pm 0.4$ & $<0.02$ \\
(normal 1-4 $\mu \mathrm{m}$ ) & & & & & & \\
\hline
\end{tabular}

${ }^{*} \mathrm{p}<0.001 ;{ }^{* * *} \mathrm{p}<0.05$

Table 2: Hemostatic parameters and PAI activity levels in group II during treatment with ReHuEpo.

\begin{tabular}{lllll}
\hline & Pre & II & III & P (Pre-III) \\
\hline Hematocrit (\%) & $19 \pm 3^{* * *}$ & $27 \pm 4^{* * *}$ & $33 \pm 5$ & $<0.001$ \\
Antithrombin III (normal 80-120\%) & $92 \pm 13^{*}$ & $85 \pm 15$ & $88 \pm 13$ & $\mathrm{~ns}$ \\
Protein-C antigen (nomal 60-130\%) & $114 \pm 30^{* *} 89 \pm 23$ & $88 \pm 16$ & $<0.04$ \\
Total Protein-S antigen (normal 60-130\%) & $125 \pm 21^{* *} 105 \pm 21$ & $108 \pm 31$ & $<0.02$ \\
Free Protein-S antigen (normal 30-50\%) & $49 \pm 11^{*}$ & $43 \pm 14$ & $42 \pm 11$ & $<0.02$ \\
Protein-C activity (normal 70-140\%) & $121 \pm 17$ & $108 \pm 26^{* *}$ & $105 \pm 21$ & $<0.03$ \\
PAI activity (normal median value/12 AU/ml) $7 \pm 4$ & $7 \pm 5$ & $5 \pm 5$ & $\mathrm{~ns}$ \\
\hline
\end{tabular}

Between the investigations pre-II and II-III only the significant P-values are presented. ${ }^{* * *} \mathrm{p}<0.001 ;{ }^{* *} \mathrm{p}<0.03 ;{ }^{*} \mathrm{p}<0.05$

aggregation became positive (during treatment) with an increase in optical density of $50 \%$ after 11 and 15 minutes respectively. The normal ADP threshold concentration decreased significantly in all patients, indicating an increased induced platelet reactivity. Although there was a significant increase in the second treatment interval, the values found were still in the low normal range and significantly different from the initial treatment value (table 1 ).

In group II hematocrit increased from $19 \pm 3$ to $33 \pm 4 \%(p<0.001)$. The antithrombin III levels showed a slight but significant transient decrease within the normal range. In all patients protein- $\mathrm{C}$ antigen levels and its cofactor protein-S antigen (total and free) decreased significantly. Also, protein-C activity levels decreased significantly. However, all changes occurred within the 
Table 3: Additional fibrinolytic measurements in group IIB $(n=7)$ during treatment with ReHuEpo

Pre II III P (Pre-III)

TPA antigen (normal $1.12 \mathrm{ng} / \mathrm{ml}$ )

$\begin{array}{llll}4.7 \pm 2.3 & 5.2 \pm 3.3 & 4.8 \pm 2.6 & \text { ns } \\ 98 \pm 15 & 96 \pm 13 & 89 \pm 11 & <0.04\end{array}$

Table 4: Mean ( \pm SD) PAI activity (AU/ml) in the patients of group II, for those without and those with dialysis fistula thrombosis.

\begin{tabular}{lllll}
\hline & Pre & II & III & P (Pre-III) \\
\hline Non-thrombotic $(n=12)$ & $6.4 \pm 2.9$ & $6.6 \pm 3.6$ & $3.8 \pm 2.7$ & $<0.03$ \\
& 1 & 1 & 1 & \\
& $n s$ & $n s$ & $p<0.01$ (t-test) & \\
& I & & p $<0.03$ (Mann-Whitney test) \\
Thrombotic $(n=3)$ & $8.2 \pm 8.0$ & $14.2 \pm 14.0$ & $12.0 \pm 6.0$ & ns \\
\hline
\end{tabular}

normal range. The PAI activity did not alter significantly in the whole group (table 2).

In group IIB (see table 3 ) the tissue plasminogen activator (TPA) antigen remained unaltered in contrast to the plasminogen activity, which decreased significantly.

There was no significant correlation between protein-C activity and PAI-activity $(r=-0.16 ; p=0.72$ ). Also the decrease of protein- $C$ antigen was not significantly related to the PAI activity $(r=-0.45 ; p=0.26)$.

Fistula thrombosis occurred in two patients of group I and three patients of group II.

table 4 shows that in the non-thrombotic patients of group II PAI activity levels decreased, while in the thrombotic patients the PAI activity levels tended to increase and were higher at all test points compared to the non-thrombotic ones. Using the unpaired Student's t-test, the PAI activity levels of the nonthrombotic individuals at III were significantly lower than those with shunt thrombosis ( $\mathrm{p}<0.01$ : t-test; $\mathrm{p}<0.03$; Mann-Whitney test). 


\section{Discussion}

Our observation that during ReHuEpo treatment bleeding time is improving and the platelet count is increasing, confirms the data of others [11-12, 16, 32]. The improvement in bleeding time might be caused by an increase of red blood cell size and mass, both enhancing platelet adhesion by increasing the rate of radial transport of centrally flowing platelets to the vessel wall [33-35]. The improvement in bleeding time could also be related to the elevation of factor VIII clotting activity (F VIII:C) as well as the von Willebrand factor antigen (VWF:AG) and its ristocetin cofactor (vWF:Ricof), all of which are known to participate in the binding of platelets to the vessel wall [32]. Red blood cell deformability seems to influence the platelet vessel wall interaction as well, in a less pronounced way and especially at higher shear rates, with an inversed relationship between deformability and platelet adherence [36]. Improvements in viscoelastic properties of the red cell membrane with a subsequent increase in red cell deformability during ReHuEpo treatment are reported and in consequence might negatively affect the adhesion stimulating influence of the increased red cell volume and mass [37].

The increase of in vitro platelet reactivity, spontaneously and after threshold doses of ADP, is in accordance with the observations made by others [13-20]. This increased platelet aggregation might be due to an increased plasma membrane $\mathrm{Na}-\mathrm{H}$ antiporter activity [38] and the increase in platelet free calcium mobilization from the intracellular dense tubular system [11,27]. Subsequently, platelet aggregation may be evoked by the intracellular release of aggregationstimulating constituents, the activation of the arachidonate pathway and mediation in the receptor-dependent extrinsic platelet activation [39]. The mechanism of release of the intracellular platelet calcium by ReHuEpo is greatly unknown, but analogy might exist with the effects of ReHuEpo on proliferation and differentiation of more mature erythroid progenitors (CFU-E) and on the proliferation of immature erythroblasts, where the intracellular free $\mathrm{Ca}^{2+}$-concentration is supposed to play a mediating role in the effects of hematopoietic growth factors [40].

No consensus exists to which extent antithrombin III levels are influenced by ReHuEpo therapy. We have found that antithrombin III remained unaltered, except for a small but significant transient decrease within the normal range. An increase $[16,32]$ as well as a decrease of antithrombin III during ReHuEpo have been reported [41-42]. However, detailed information about study design in these reports is lacking, so even attempts to explain these inconsistent findings remain speculative. More consensus exists about the influence of ReHuEpo on the protein-C and $-\mathrm{S}$ system. McDougall et al. observed a significant decrease of levels of both protein-C and protein-S antigen [28-29]. We found a significant decrease of both antigens. Because activity levels may be expected to be 
independent to changes in plasma volume during ReHuEpo treatment, protein-C activity was additionally measured and found to be significantly decreased as well.

A decrease of protein-C activity theoretically might lead to an increase of the PAI activity levels and to a decrease in tissue plasminogen activator levels. Regression analysis, however, between the difference of the PAI activity and protein- $\mathrm{C}$ activity and protein- $\mathrm{C}$ antigen levels disclosed no significant relationship.

Regarding the patients who developed thrombotic fistula occlusion, compared with those who did not, no significant differences in the enhanced platelet function and counts, the increase of the in vitro platelet reactivity as well as other hemostatic and fibrinolytic parameters, except for the PAI activity levels, were observed. PAI activity can behave as an acute phase reactant [43]. However, our observation of increased PAI activity levels in the thrombotic individuals as compared to the non-thrombotic ones already before the thrombotic complications were diagnosed, is not in accordance with the phenomenon of an acute phase reactant. Although, we cannot exclude an already ongoing process of fistula thrombosis at the moment of observed increased PAI activity levels. Whether the increased PAI activity levels are causally related to the ReHuEpo related thrombotic complications, cannot be concluded from these results because of the small number of patients in this study and the multifactorial origin of fistula thrombosis.

In conclusion, during treatment with ReHuEpo, changes in the hemostatic as well as the fibrinolytic system are found, which might contribute to the observed thrombotic tendency. 


\section{References}

1. Canadian Erythropoietin Study Group. Association between recombinant human erythropoietin and quality of life and exercise capacity of patients receiving haemodiallysis. Br Med J 1990; 300: 573.

2. Lundin AP. Quality of life: subjective and objective improvements with recombinant human erythropoietin therapy. Seminars Nephroll 1989; 9 (no. 1, suppl.1): 22.

3. Mayer G, Thum J, Cada EM, Stummvoll HK. Working capacity is increased following recombinant human erythropoietin treatment. Kidn Int 1988; $34: 525$.

4. Nissenson AR. Recombinant human erythropoietin on brain and cognitive function, exercise tolerance, sexual potency and quality of life. Seminars, Nephrol 1989; 9 (no. 1, suppl.2): 25.

5. Eschbach JW, Adamson JW. Recombinant human erythropoietin: implications for nephrology. Am J Kidn Dis 1988; 11: 203.

6. Böcker A, Reimers E, Nonnast-Daniel B. Effect of erythropoietin treatment on 02 affinity and performance in patients with renal anemia. Contrib Nephrol 1988; 66: 165.

7. Sundal $E$, Kaeser U. Conrection of anemia of chronic renal failure with recombinant human erythropoietin: safety and efficacy of one years treatment in a European multicentre study of 150 hemodialysis dependent patients. Nephrol Dial Transpl 1989; 4: 979 .

8. Casati S, Passerini P, Campise MR, Graziani G. Benefits and risks of protracted treatment with human recombinant erythropoietin in patients having hemodialysis. $\mathrm{Br}$ Med J 1987; $295: 1017$.

9. Zehnder C, Blumberg A. Recombinant human erythropoietin in anemic patients on hemodialysis. Benefits and risks. Schweiz Med Wochenschrift 1989; 119 (9): 269.

10. Eschbach JW, Abdulkadi MH, Browne JK. Recombinant human erythropoietin in anemic patients with end-stage renal disease. Results of a phase II multicenter clinical trial. Ann Int Med 1989; 111: 992-1000.

11. Geet $\mathrm{C}$ van, Van Damme-Lombaerts $\mathrm{R}$, Proesmans W. Increase in platelet free calcium mobilization during erythropoietin administration to uremic children. Nephrol Dial Transpl 1989; 4: 479 (abstract).

12. Moia M, Vizzotto L, Cattaneo M, Mannuci PM. Improvement in the hemostatic defect of uremia after treatment with recombinant human erythropoietin. Lancet 1987; ii: 1227.

13. Dreyling KW, Steinhauer HB, Geiger $\mathrm{H}$. Platelet function under recombinant human erythropoietin therapy in hemodialysis patients. Nephrol Dial Transpl 1989; 4: 472 (abstract).

14. Geet $C$ van, Hauglustaine D, Verresen L, Vanrusselt M. Hemostatic effects of recombinant human erythropoietin in chronic hemodialysis patients. Thrombosis and Haemostasis 1989; 61 (1): 117.

15. Grutzmacher $P$, Bergmann $M$, Schoeppe $W$. Thrombocyte function and plasmatic coagulation under EPO therapy. Nephrol Dial Transpl 1989; 4: 473 (abstract).

16. Bommer J, Welsch W, Andrassy K, Ritz E. Coagulation in dialysis patients under recombinant human erythropoietin therapy. J Am Soc Nephrol 1990; 1: 395 (abstract).

17. El Shahawy MA, Francis R, Akmal M. Recombinant human erythropoietin shortens bleeding time and corrects abnormal platelet aggregation in hemodialysis patients. J Am Soc Nephrol 1990; 1: 397 (abstract). 
18. Cases A, Escolar G, Reverter J. Effect of recombinant human erythropoietin on primary hemostasis in uremic patients. Proc EDTA-ERA, 27th Annual Congress, Vienna, 1990, September 5-8 (abstract).

19. Junco E, Huerta AR, Chacon MSR. Hemostasis and platelet aggregation under erythropoietin on hemodialysis patients. Proc EDTA-ERA, 27th Annual Congress, Vienna, September 5-8, 1990 (abstract).

20. Martin J, Cervero A, Sanchez M. Influence of recombinant human erythropoietin on platelet function in anemic hemodialysis patients. Proc EDTA-ERA, 27th Annual Congress, Vienna, September 5-8, 1990 (abstract).

21. Taylor JE, Belch J, Mactier R. Platelet aggregation in hemodialysis patients treated with erythropoictin. Proc EDTA-ERA, 27th Annual Congress, Vienna. September 5-8, 1990 (abstract).

22. Nilsson IM, Ljungner $H$, Tengbom $L$. Two different mechanisms in patients with venous thrombosis and defective fibrinolysis: low concentration of plasminogen activator or increased concentration of plasminogen activator inhibitor. Br Med J 1985; 290: 1453.

23. Paramo JA, Alfara MJ, Rocha E. Postoperative changes in the plasmatic levels of tissue-type plasminogen activator and its fast acting inhibitor - relationship to deep vein thrombosis and influence of prophylaxis. Thrombosis and Haemostasis 1985; 54: 713.

24. Juhan-Vague I, Valadier J, Alessi MC, Aillaud MF. Deficient t-PA release and elevated PA inhibitor levels in patients with spontaneous or recurrent deep venous thrombosis. Thrombosis and Haemostasis 1987; 57: 67.

25. Hamsten A, Wiman B, De Faire U, Blombäck M. Increased plasma levels of a rapid inhibitor of tissue plasminogen activator in young survivors of myocardial infarction. New Engl J Med 1985; 313: 1557.

26. Sprengers ED, Kluft C. Plasminogen activator inhibitors. Blood 1987; 69: 381 .

27. Ware JA, Clark BA, Smith M, Salzman EW. Abnormalities of cytoplasmic $\mathrm{Ca}^{2+}$ in platelets from patients with uremia. Blood 1989; 73: 172.

28. McDougall IC, Davies ME, Hutton RD. Reduction in protein-C and protein-S levels after treatment with recombinant human erythropoietin. Nephrol Dial Transpl 1989; 4: 476 (abstract).

29. McDougall IC, Davies ME, Hallet I, Cochlin DL. Coagulation studies and fistula blood flow during erythropoietin in hemodialysis patients. Nephrol Dial Transpl 1991; 6: 862-867.

30. Chericx EM, Leunissen KML, Janssen JHA, Mooy JMV, Van Hooff JP. Echography of the inferior vena cava is a simple and reliable tool for estimation of 'dry weight' in hemodialysis patients. Nephrol Dial Transpl 1989; $4: 563$.

31. Gordge MP, Faint RW, Rylance PB, Neild GH. Platelet function and the bleeding time in progressive renal failure. Thrombosis and Haemostasis 1988; 60: 83.

32. Huraib S, Al-Momen AK, Gader AMA, Mitwalli A. Effect of recombinant human erythropoictin (ReHuEpo) on the hemostatic system in chronic hemodialysis patients. ('lin Nephrul 1991: 36: 252-257.

33. Turitto VT, Weiss HJ. Red blood cells: their dual role in thrombus formation. Science 1980: $207: 541$.

34. Livio M, Marchesi D, Remuzzi G, Gotti E. Uremic bleeding: role of anemia and beneficial effect of red cell transfusions. Lancet 1982; ii: 1013.

35. Aarts PAM, Bolhuis PA, Sakariassen KS, Heethaar RM. Red blood cell size is important for adherence of blood platelets to artery subendothelium. Blood 1983; 62: 214. 
36. Aarts PAM, Heethaar RM, Sixma JJ. Red blood cell deformability influences plateletS-vessel wall interaction in flowing blood. Blood 1984; 64: 1228.

37. Meier W. Paulitschke M, Lerche D, Schmidt G. Action of ReHuEpo on mechanical membrane properties of red blood cells in children with end-stage renal disease. Nephrol Dial Transpl 1991; 6: 110.

38. Wu-Chang-Young, Shih-Luen Chen, Hsiao Rong Perng. Erythropoietin stimulates platelet Na-H-antiporter activity and platelet aggregation. J Am Soc Nephrol 1990; 1: 325 (abstract).

39. Fuster V, Badimon L, Badimon J, Adamas PC. Drugs interfering with platelet function: mechanisms and clinical relevance. In: XIth Congress of Thrombosis and Haemostasis. Verstraete M, Vermijten J, Lijnen R, Amout J (eds) Leuven University Press, Brussels, 1987; 349-419.

40. Miller BA, Scaduto RC, Tillotson DL, Botty JJ. Erythropoietin stimulates a rise in intracellular free calcium concentration in single early human erythroid precursors. J Clin Invest 1988; 82: 309.

41. Murphy BG, Maxwell AP, Brown JH, McNamee PT. Treatment with recombinant human erythropoietin is accompanied by a reduction in antithrombin III activity. Proc EDTA-ERA, 27th Annual Congress, Vienna, September 5-8, 1990, p. 253 (abstract).

42. Tomura S, Nakamura Y, Deguchi F, Chida Y. Enhanced blood coagulation / fibrinolysis in chronic hemodialysis patients receiving recombinant erythropoietin treatment. Proc EDTA-ERA, 27th Annual Congress, Vienna, September 5-8, 1990 (abstract).

43. Kruithof EKO, Gundinchet A, Bachmann F. Plasminogen activator inhibitor 1 and plasminogen activator inhibitor 2 in various disease states. Thrombosis and Haemostasis 1988; 59: 7-12. 


\section{CHAPTER

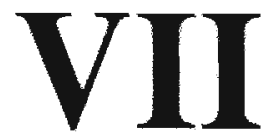

\section{Summary and conclusions}

The strong association between chronic renal failure and its characteristic normochromic, normocytic and hypoproliferative type of anemia has been recognized already for a long time. A decreased production of the hormone erythropoietin in relation to the level of anemia and the subsequently limited feedback response between erythropoiesis and erythropoietin production resulting from the loss of viable renal tissue, has been the most widely accepted mechanism for the decreased marrow stimulation in kidney disease, ultimately leading to anemia.

The anemia of chronic renal failure patients, especially if maintained on hemodialysis, contributes to the already decreased quality of life and leads to considerable morbidity for which until recently only periodic blood transfusions offered temporarily relief. However, repeated red blood cell transfusions included the risks of transmission of transfusion associated infections, iron overload, the generation of cytotoxic antibodies and further erythroid suppression.

Since the concept was postulated that red blood cell production could be influenced by a hormonal factor, ongoing research ultimately lead to the identification, isolation and purification of the natural hormone erythropoietin, which finds it main source in the peritubular capillary endothelial cells and interstitial fibroblasts of the kidney, and is known to exert its erythropoietic effects on erythroid progenitor populations in the bone marrow after hypoxic stimulation. The identification and cloning of the human erythropoietin gene and its subsequent transmission in a suitable mammalial vector created the possiblity to 
obtain unlimited amounts of the so called recombinant human erythropoietin (ReHuEpo) for therapeutic application.

In many clinical trials since then, ReHuEpo proved its efficacy to correct the disabling anemia in patients with chronic renal failure resulting in improvement of general well being including cardial and sexual performance, physical exercise capacity and uremic bleeding tendency. Furthermore, it resulted in the elimination of transfusion dependency and in the reduction of transfusion related iron overload. However, also side effects of treatment with ReHuEpo have been encountered of which the clinically most important are: (1) the development and/or aggravation of hypertension mainly due to the increased blood viscosity and increased peripheral vascular resistance, and (2) clotting problems in the extracorporeal hemodialysis system requiring increased heparin dosages during dialysis, and thrombosis of high risk dialysis fistulae and other vasculature due to the increased whole blood viscosity, the changed hemostasis, and the decreased peripheral circulatory flow.

The increasing hematocrit during ReHuEpo therapy was expected to have important effects on macrocirculation in chronic hemodialysis patients but even more on microcirculation due to changes in cardiac output and blood viscosity in relation to the structural vascular changes in dialysis patients. Furthermore, an optimal determination of fluid status would be of hemodynamically more importance at high compared to low hematocrit, because of the changes in plasma volume / red blood cell volume ratio and the effect of hemoconcentration at hypovolaemia.

The present study was performed to evaluate the effects of treatment with ReHuEpo on macrocirculation and skin microcirculation and fluid status in normotensive chronic hemodialysis patients after short term treatment (reaching the target hematocrit) and long term treatment (in the maintenance phase of hematocrit) (chapter I and II).

In chapter III, the effects of high hematocrit (during ReHuEpo therapy) on plasma volume preservation and fluid handling compared to the effects at low hematocrit (before ReHuEpo therapy) are evaluated. Furthermore, the effects of low and high hematocrit on intradialytic hemodynamic parameters are studied.

Chapter IV deals with the effects of ReHuEpo on dialysis fistula function in relation to the observed changes in viscosity parameters, primary hemostasis and macrocirculation.

In chapter $V$ the effects of ReHuEpo on indices of hemostasis and fibrinolysis are studied also in relation to the observed increased frequency of dialysis fistula thrombosis. 


\section{Chapter I}

Treatment with ReHuEpo resulted in a significant increase of hematocrit. The systemic vascular resistance increased and cardiac index decreased significantly, the latter due to a significant decrease of stroke index as well as heart rate, while mean arterial pressure remained unchanged. Red blood cell volume increased and plasma volume decreased significantly, whereas total blood volume remained unchanged maintaining normovolemia using the method of echography of the inferior caval vein. Skin capillary circulation, as measured by transcutaneous oxymetry, decreased whereas peripheral oxygenation increased. The observation of an increased number of pathological capillary loops in the distal row of the finger nailfold of dialysis patients compared to controls, studied by intravital videomicroscopy, raised the question whether the pathological capillaries might be causally involved in the increase of systemic vascular resistance and the decrease of skin capillary flow, during treatment with $\mathrm{Re}$ HuEpo and its concomitant increase of blood viscosity.

\section{Chapter II}

During long term treatment with ReHuEpo, maintaining the target hematocrit after the induction phase of treatment, the observed significant changes in cardiac index, stroke index and systemic vascular resistance after short term treatment were no longer different from the initial values. Mean arterial pressure remained unchanged throughout the whole study period as did blood volume. The significant increase of red blood cell volume and the significant decrease of plasma volume after short term treatment remained unaltered at long term. Left ventricular ejection fraction and the fractional fiber shortening did not change during the whole period of investigation.

The left ventricular end diastolic diameter and volume decreased after short term treatment and remained significantly decreased at long term, for which a decreased venous return could be responsible.

The total left ventricular volume, the end systolic diameter and volume, the end diastolic posterior and interventricular wall thicknesses and left arterial diameter did not change significantly during the whole study period.

Although left ventricular mass (LVMI) did not change significantly for the whole group, in 6 out of the 8 evaluated patients the LVMI decreased. A strong relation between the initial LVMI and the decrease of LVMI after long term treatment with ReHuEpo could be found.

The observed improvement in peripheral oxygenation, studied by transcutaneous oxymetry at $37^{\circ}$ skin electrode heating, after short term treatment with ReHuEpo did not change at long term. Also the significant impairment in 
skin capillary flow at short term did not change after long term treatment. The intravital videomicroscopic studies of the finger nail fold capillaries revealed a significant decrease in the percentage of pathologic tortuous capillaries after short term but also at long term treatment whereas the total number of capillaries per videoscreen did not change.

The improvement in configuration of the nail fold capillaries in the absence of an improved skin microcirculatory flow suggests persisting structural abnormalities at the level of the arterioles.

\section{Chapter III}

The influence of the changed red blood cell volume / plasma volume ratio at higher hematocrit on plasma volume preservation during dialysis is described in this chapter.

It tumed out that plasma volume preservation at high hematocrit was comparable with the plasma volume preservation at low hematocrit. Although the increase of colloid oncotic pressure during dialysis was higher at higher hematocrit, this did not result in a better plasma volume preservation. There was a tendency for plasma osmolality to be lower after hemodialysis at higher hematocrit, which could counteract the effect of the higher increase of colloid oncotic pressure.

Furthermore, in this study intradialytic hemodynamic parameters were studied at low and high hematocrit, because hemoconcentration after dialysis could influence venous retum and stroke index.

The results showed a significant decrease of stroke index after dialysis at high hematocrit, which was related to the decrease of left ventricular end diastolic diameter, being a preload parameter. The change in blood volume was comparable, indicating that a decrease of venous return could play an important role. An increase of venous resistance due to increased blood viscosity could be involved.

\section{Chapter IV}

The occurrence of fistula thrombosis during treatment with ReHuEpo is multifactorial of origin: changes in blood viscosity, hemostasis, hemodynamics and fluid status may all contribute especially when pre-existent vascular abnormalities like venous stenosis and/or peripheral arterial disease are present.

In chronic hemodialysis patients fistula function parameters and indices of blood viscosity and primary hemostasis, cardiac index and mean arterial pressure were evaluated and interrelated during treatment with ReHuEpo. Hema- 
tocrit, whole blood viscosity (at high and low shear rates) and red blood cell aggregation (low shear rate) increased significantly. Cardiac index decreased significantly whereas mean arterial pressure remained unchanged. Bleeding time decreased whereas the amount of platelets remained unaltered. Duplex scanning and spectral analysis of the fistula disclosed a significant reduction in the diastolic brachial antery (afferent) flow as well as a non-significant decrease in the systolic brachial artery flow. No other changes suggestive for progressive stenotic lesions in the fistula could be traced by direct and/or the indirect thumb blood pressure measurements at open and compressed fistula. Venous pressure in the extracorporeal system at unchanged blood flow during dialysis increased significantly, however, within the normal range.

Multiregression analysis with the changes in fistula flow parameters as dependent variables revealed a significant predictive value of the change ( $\Delta$ ) in cardiac index on the $\Delta$ systolic brachial artery flow and a significant negative predictive value of mean arterial pressure on the $\Delta$ diastolic brachial artery flow, which is related to the increase of systemic vascular resistance during treatment with ReHuEpo.

\section{Chapter V}

In order to detect prothrombotic changes, a number of hemostatic and fibrinolytic parameters were determined before and after ReHuEpo therapy in chronic hemodialysis patients.

In a first group of patients we observed, after hematocrit raised to $34 \%$, a shortening of the bleeding time and an increase of platelet count. The initial negative in vitro spontaneous platelet reactivity became positive in a minority of the patients after reaching the target hematocrit although the ADP treshold decreased significantly in the whole group, indicating an increased platelet reactivity after ReHuEpo therapy.

In a second group of patients prothrombotic changes were observed. The protein- $\mathrm{C}$ antigen and protein-C activity and the total and free protein-S antigen, being anticoagulant proteins, decreased significantly during ReHuEpo therapy.

The plasminogen activator inhibitor (PAI) activity did not change for the whole group. However, in the patients who developed fistula thrombosis higher values of PAI in all test points were found compared to those without thrombosis. 


\section{Conclusion}

Treatment with ReHuEpo corrected the characteristic anemia of chronic renal failure patients maintained on hemodialysis, and in consequence ameliorated physical performance due to improved tissue oxygenation.

ReHuEpo also induced important changes in macro- and microcirculation. At higher levels of hematocrit, cardiac index decreased on basis of a decreased heart rate and stroke index. The decrease in stroke index was probably related to a decrease of venous return, as a result of increased blood viscosity. More important, long term studies revealed a decrease of left ventricular muscle mass. This indicates that treatment of renal anemia already in the predialysis phase could improve the cardiovascular state of these patients.

Peripheral vascular resistance increased during ReHuEpo therapy, resulting in hypertension in some of the treated patients. There was a decrease of maximal microcirculatory flow after ischaemia, indicating a possible effect of increased blood viscosity in combination with structural microcirculatory abnormalities. Although, after 4 months of ReHuEpo therapy the pathological configuration of the nailfold capillaries in dialysis patients improved, there still was a decreased maximal circulatory flow after ischemia.

During treatment with ReHuEpo the plasma volume preservation at higher hematocrit was comparable with the plasma volume preservation at lower hematocrit before ReHuEpo treatment. Although colloid oncotic pressure increase was higher at high hematocrit, this effect was counteracted by a more exaggerated decrease of plasma osmolality.

In the intradialytic period the decrease of stroke index was significantly higher at high hematocrit compared to low hematocrit in the same patients with the same ultrafiltration volume. This was related to changes in preload, probably due to a decrease of venous retum at higher hematocrits. Hypovolemia after hemodialysis may induce exaggerated hemoconcentration that may lead to a decrease of stroke index and hemodynamic instability. The hemoconcentration at hypovolemia may also lead to an impairment of capillary flow and tissue perfusion.

Together with the observed prothrombotic alterations in hemostasis and/or fibrinolysis and especially in the presence of pre-existent anatomic lesions in the dialysis fistula, hypovolaemia during treatment with ReHuEpo increases the risk at shunt thrombosis and other thrombotic complications. 


\section{CHAPTER}

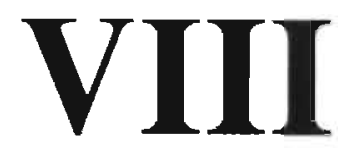

\section{Samenvatting}

De associatie van chronische nierinsufficiëntie met een normochrome, normocytaire en hypoproliferatieve anemie is reeds lang bekend. Een verminderde produktie van het hormoon erythropoietine in relatie tot de graad van bloedarmoede en het dientengevolge minder effektieve terugkoppelingsproces tussen erythropoiese en erythropoietineproduktie, wordt in het algemeen als de belangrijkste oorzaak gezien voor de verminderde beenmergstimulatie bij patiënten met nierziekten.

De anemie bij dialysepatiënten is een belangrijke oorzaak van de afgenomen kwaliteit van leven en van de verminderde inspanningstolerantie, en kan leiden tot een aanzienlijke morbiditeit. Periodieke bloedtransfusies boden slechts tijdelijk soelaas. Deze bloedtransfusies hielden echter ook het risiko in van overdracht van infektieziekten, ijzerstapeling, en het ontstaan van cytotoxische antistoffen.

Sedert het gepostuleerde concept dat de erythropoiese kon worden beïnvloed door een hormonale faktor, heeft intenstief onderzoek geleid tot de identifikatie, isolatie en de zuivering van het natuurlijke hormoon erythropoietine, dat wordt geproduceerd in de peritubulaire capillaire endotheelcellen en de interstitiële fibroblasten van de nier. Erythropoietine oefent zijn werking uit op de vroege voorlopercellen van de rode bloedcelreeks in het beenmerg. De produktie van erythropoietine wordt gestimuleerd door lokale renale hypoxemie.

De identifikatie en vervolgens het clonen van het humane erythropoietine gen, en de transmissie ervan in een geschikt zoogdier als vector, maakte het 
mogelijk om te beschikken over zeer grote hoeveelheden van het zogenaamde recombinante humaan erythropoietine (ReHuEpo). Hierdoor kon ReHuEpo ook worden aangewend voor therapeutische doeleinden.

Sedertdien heeft ReHuEpo in veel klinische studies zijn effektiviteit aangetoond ten aanzien van de korrektie van de renale anemie. Het korrigeren van de anemie bij chronische nierinsufficiënte patiënten leidde tot een verbetering van het algeheel welbevinden, zoals een verbeterde inspanningstolerantie en psychische alertheid. Daamaast was er sprake van een afgenomen bloedingsneiging. Andere voordelen waren de verminderde transfusie-afhankelijkheid en de reduktie van de ijzerstapeling, die het gevolg was van de herhaalde bloedtransfusies in het verleden.

Behandeling met ReHuEpo bleek echter ook gepaard te gaan met bijwerkingen, waarvan de belangrijkste voor de kliniek zijn: (1) het onstaan en/of verergering van de hypertensie, (2) verhoogde stollingsneiging in het extracorporele hemodialysesysteem met als gevolg een verhoogde heparinebehoefte tijdens dialyse, en (3) verhoogde kans op thrombose van dialysefistels en andere thrombo-embolische komplikaties.

Als gevolg van de stijging van de hematocriet kon worden verwacht dat de behandeling met ReHuEpo bij chronische hemodialysepatiënten belangrijke effekten zou kunnen hebben op de macro-en microcirculatie. Dit als gevolg van veranderingen van het hartminuutvolume en van de bloedviscositeit in relatie tot de strukturele vasculaire veranderingen zoals die bij dialysepatiënten worden gezien.

Bovendien leek een optimale instelling van de vochtstatus c.q. het dialysestreefgewicht bij een hoge hematocriet van hemodynamisch groter belang dan bij een lage hematocriet als gevolg van de veranderingen in de plasmavolume / rode bloedcelvolume ratio en de effekten van hemoconcentratie tijdens hypovolemie.

In de eerste hoofdstukken van dit proefschrift worden de effekten geëvalueerd van de behandeling van ReHuEpo op de macrocirculatie, de huid-microcirculatie en de vochtstatus in normotensieve chronische hemodialysepatiënten na korte termijn therapie, waarbij de hematocriet-streefwaarde werd bereikt (hoofdstuk I) en na lange termijn behandeling, gedurende welke de bereikte hematocriet werd gehandhaafd (hoofdstuk II).

In hoofdstuk III worden de effekten geëvalueerd van een ReHuEpo geïnduceerde hoge hematocrietwaarde op de plasma volumepreservatie en de vochtstatus tijdens en na dialyse, en vergeleken met de effekten van een lage hematocriet op deze parameters vóór behandeling met ReHuEpo. Bovendien worden de effekten van de hoge en lage hematocrietwaarden bestudeerd op de intradialytische hemodynamische parameters. 
In hoofdstuk IV worden de effekten van een hogere hematocriet als gevolg van behandeling met ReHuEpo op de dialyseshuntfunktie weergegeven in relatie tot de waargenomen veranderingen in de viscositeitsparameters, primaire hemostase en macrocirculatie.

In hoofdstuk $\mathrm{V}$ worden de effekten van behandeling met ReHuEpo bestudeerd op diverse indices voor hemostase en fibrinolyse, en wordt de relatie met dialyseshuntthrombose onderzocht.

\section{Hoofdstuk I}

Behandeling met ReHuEpo resulteerde in een signifikante toename van de hematocriet. De systemisch vasculaire weerstand steeg en het geïndexeerde hartminuutvolume daalde signifikant als gevolg van een zowel signifikante daling van het slagvolume als van de hartfrequentie. De gemiddelde arteriële bloeddruk bleef onveranderd. Het erythrocytenvolume daalde en het plasmavolume steeg, beiden signifikant, terwijl het totale bloedvolume onveranderd bleef. Dit onder handhaving van de normovolemie middels de methode van de echografie van de vena cava inferior.

De capillaire circulatie in de huid na ischemische vasodilatatie, zoals gemeten middels transcutane oxymetrie, verminderde terwijl de perifere oxygenatie toenam. Opvallend was dat er bij intravitaalmicroscopie een verhoogd aantal pathologische distale capillaire lissen in de vingemagelriem van dialysepatiënten werd gevonden in vergelijking met normale kontrolepersonen.

\section{Hoofdstuk II}

Gedurende de lange termijn behandeling met ReHuEpo, waarbij de bereikte hematocriet-streefwaarde werd gehandhaafd, bleken de signifikante veranderingen in het geïndexeerde hartminuutvolume en slagvolume, en de systemische vasculaire weerstand van de korte termijn behandeling niet langer te veschillen met de uitgangswaarden. Zowel de gemiddelde arteriële bloeddruk als het bloedvolume bleven onveranderd gedurende de hele studieperiode.

De signifikante toename van het erythrocytenvolume en de signifikante afname van het plasmavolume na de korte termijn therapie bleven onveranderd op lange termijn. De cardiale linker ventrikel ejektiefraktie veranderde niet gedurende de onderzoeksperiode.

De linker ventrikel eind-diastolische diameter en volume namen signifikant af na korte termijn behandeling en dit bleef op lange termijn konstant. Dit zou gerelateerd kunnen zijn aan een verminderde veneuze terugvloed. 
Het totale linker ventrikelvolume, de eind-systolische diameter en -volume, de eind-diastolische achterwand en interventriculaire wanddikte en de linker atrium diameter veranderden niet signifikant gedurende de studieperiode.

Hoewel de geïndexeerde linker ventrikel spiermassa (LVM) voor de gehele groep niet signifikant veranderde, nam hij in zes van de acht geëvalueerde patiënten af. Er werd een sterke relatie gevonden tussen de initiële LVM index en de afname van de LVM index na lange termijn behandeling met ReHuEpo.

De waargenomen verbetering in de perifere oxygenatie na korte termijn behandeling met ReHuEpo, zoals bestudeerd door middel van transcutane oxymetrie, veranderde niet tijdens de lange termijn studie, zoals ook gold voor de signifikante afname van de capillaire flow in de huid.

De intravitale videomicroscopische studies van de distale capillairen in de nagelriem van de vingers toonden een signifikante afname in het percentage pathologische tortueuze capillairen, zowel na korte termijn als na lange termijn behandeling met ReHuEpo, terwijl het totaal aantal capillairen per videoveld niet veranderde. De verbetering in configuratie van de distale capillairen in de nagelriem, bij afwezigheid van een verbetering van de microcirculatie in de huid na ischemische vasodilatatie, suggereert dat er persisterende strukturele afwijkingen zijn op het niveau van de arteriolen.

\section{Hoofdstuk III}

In dit hoofdstuk wordt de invloed van de veranderde erythrocytenvolume / plasmavolume ratio bij een hoge hematocrietwaarde bestudeerd op de plasmavolumepreservatie tijdens hemodialyse.

Het bleek dat de plasmavolumepreservatie bij een hoge hematocrietwaarde vergelijkbaar was met die bij een lage hematocrietwaarde. Hoewel de toename van de plasma colloïd-osmotische druk tijdens dialyse bij een hoge hematocrietwaarde hoger was als bij een lage hematocrietwaarden, resulteerde dit niet in een betere plasma volumepreservatie. Mogelijk dat de iets lagere osmolaliteit na dialyse bij een hogere hematocriet het effekt van de hogere colloid-osmotische druk op de plasma volumepreservatie tegenwerkt.

Bovendien werd in deze studie de intradialytische hemodynamiek betudeerd bij zowel lage als hoge hematocriet.

De resultaten toonden een signifikante afname van het geïndexeerde slagvolume na de dialyse bij hoge hematocrietwaarden, terwijl dit bij lage hematocriet niet het geval was. De afname van het geïndexeerde slagvolume bij hoge hematocriet was signifikant gerelateerd aan de afname van de linker ventrikel eind-diastolische diameter, een parameter voor de cardiale vulling (preload). De mate van afname van het bloedvolume was bij hoge en lage hematocriet vergelijkbaar, hetgeen suggereert dat een afname van veneuze terugvloed naar 
het hart hieraan ten grondslag ligt. Een toename van de veneuze weerstand als gevolg van de verhoogde bloedviscositeit na behandeling met ReHuEpo zou hiervoor een verklaring kunnen zijn.

\section{Hoofdstuk IV}

Het optreden van thrombose van de shunt tijdens behandeling met ReHuEpo wordt door meerdere faktoren bepaald. Verandering in de bloedviscositeit, de hemostase, de hemodynamiek en de vochtstatus na therapie met ReHuEpo spelen hierbij een rol. De primaire risikofaktor, echter, is de aanwezigheid van preëxistente vasculaire afwijkingen zoals arteriële en veneuze stenosen in de AV-fistel.

Doorbloedingsparameters van de dialyseshunt, indices van bloedviscositeit, primaire hemostase, geïndexeerd hartminuutvolume en de gemiddelde arteriële bloeddruk werden geëvalueerd.

De hematocriet en de totale bloedviscositeit (bij hoge en lage schuifsnelheden) namen signifikant toe. Het geïndexeerde hartminuutvolume nam signifikant af waarbij de gemiddelde arteriële bloeddruk onveranderd bleef. De bloedingstijd verkortte signifikant, terwijl het aantal plaatjes onveranderd bleef. Duplex Doppler onderzoek en Spectral Scanning van de dialyseshunt toonde een signifikante afname in de diastolische flow van de arteria brachialis zowel als een niet signifikante afname in de systolische flow van de arteria brachialis.

Andere veranderingen, die suggestief zouden kunnen zijn voor progressieve stenotische lesies in de dialyseshunt, konden middels direkte methodieken en/of indirekte duim-bloeddrukmetingen bij open en gecomprimeerde dialysefistel niet worden waargenomen. De veneuze druk in het extracorporele systeem, tijdens dialyse en bij een konstante bloedflow gemeten, nam signifikant toe hoewel binnen het normale gebied.

Multiregressie-analyse met de veranderingen in de doorstromingsparameters van de shunt als afhankelijke variabelen toonde een signifikante prediktieve waarde van de verandering in het geïndexeerd hartminuutvolume op de $\Delta$ systolische doorstroming van de arteria brachialis. Tevens was er sprake van een signifikant negatieve prediktieve waarde van de gemiddelde arteriële bloeddruk op de $\Delta$ diastolische doorstroming van de arteria brachialis, hetgeen gerelateerd is aan de toename van de systemische vasculaire weerstand tijdens behandeling met ReHuEpo. 


\section{Hoofdstuk V}

Teneinde eventuele prothrombotische veranderingen te evalueren, werden bij chronische hemodialysepatiënten een aantal hemostatische en fibrinolytische parameters bepaald voor en na behandeling met ReHuEpo.

In een eerste patiëntengroep werd, nadat de streefhematocriet van $34 \%$ was bereikt, een verkorting van de bloedingstijd en een toename van het aantal bloedplaatjes gezien. De aanvankelijke negatieve in vivo spontane plaatjesreaktiviteit werd positief in een minderheid van de patiënten. De afname in de ADP-drempel echter daalde signifikant, hetgeen een verhoogde plaatjesreaktiviteit aangeeft na behandeling met ReHuEpo.

In een tweede groep van patiënten werden tijdens behandeling met ReHuEpo prothrombotische veranderingen waargenomen. De spiegels van het proteine-Cantigeen, de proteine-C-aktiviteit en het totale en vrije proteine-S-antigeen, allen anticoagulante eiwitten, daalden signifikant.

De plasminogeen activator inhibitor (PAI) aktiviteit veranderde niet voor de hele groep. Echter, in die patiënten, waarbij zich thrombose van de shunt ontwik'kelde, werden bij alhe meetpunten hogere PAl-aktiviteitswaarden gevonden als bij de patiënten zonder thrombose.

\section{Konklusie}

Behandeling met recombinant humaan erythropoietine (ReHuEpo) korrigeert de anemie van chronische hemodialysepatiënten en verbetert daarmee het lichamelijk welzijn als gevolg van de verbeterde perifere weefseloxygenatie. Therapie met ReHuEpo leidt tevens tot veranderingen in de macro- en microcirculatie en de vochtstatus. $\mathrm{Bij}$ een hogere hematocrietwaarde en een toegenomen bloedviscositeit daalt het geïndexeerde hartminuutvolume op basis van een daling van de hartfrequentie en van het geïndexeerde slagvolume. Dit laatste is mogelijk het gevolg van een verminderde veneuze terugstroom naar het hart.

De lange termijn studie met ReHuEpo liet een afname zien van de linker ventrikelspiermassa, met name bij die patiënten waarbij sprake was van linker ventrikelhypertrofie. Op grond hiervan zou ReHuEpo-behandeling in de predialyse-fase gunstige effekten kunnen hebben op de cardiovasculaire status.

De verhoogde perifere vasculaire weerstand als gevolg van de ReHuEpo-therapie kan in sommige patiënten leiden tot hypertensie. De oorzaak hiervan is niet geheel duidelijk, mogelijk dat de toegenomen bloedviscositeit in relatie tot de strukturele vasculaire afwijkingen hierin een rol speelt.

Tijdens behandeling met ReHuEpo was de plasma volumepreservatie tijdens dialyse bij een hogere hematocriet niet verschillend van die bij een lage hema- 
tocriet. De tegengestelde effekten van de geobserveerde veranderingen in plasma osmolaliteit en de plasma colloid-oncotische druk op de vochtverplaatsing tussen het intra- en extravasculaire compartiment zouden een verklaring kunnen zijn.

Gezien de effekten van de hoge hematocriet op de intradialytische hemodynamiek i.c., een afname van het geïndexeerde hartminuutvolume, zou hypovolemie na dialyse in dit geval een versterkte risikofaktor zijn. Tevens zou ook de hemoconcentratie, die hierbij zal ontstaan, lokaal aanleiding geven tot een verminderde weefselperfusie. Het lijkt dus van belang om met name bij hogere hematocrietwaarden hypovolemie te voorkomen.

In kombinatie met de waargenomen prothrombotische veranderingen in hemostase en/of fibrinolyse en vooral in aanwezigheid van eerder bestaande anatomische afwijkingen in de dialyseshunt, verhoogt ondervulling (hypovolemie) tijdens behandeling met ReHuEpo het risiko op dialyseshuntthrombose. 


\section{DANKWOORD}

Terugblikkend op de laatste jaren, waarin het verzamelen van onderzoeksgegevens en het uitwerken van de resultaten zijn gestalte vond in de vorm van meerdere abstracts, congresvoordrachten en artikelen, is het vanzelfsprekend dat mijn dankbare gedachten daarbij mede uitgaan naar die personen zonder wiens bijdrage de uiteindelijke totstandkoming van dit proefschrift niet mogelijk was geweest.

Op de eerste plaats denk ik aan alle dialysepatiënten bij wie de vaak belastende onderzoeken werden verricht en aan wie dit proefschrift dan ook vooral is opgedragen. Mijn respekt en grote dankbaarheid gaan uit naar het immense geduld en doorzettingsvermogen waarover zij beschikten bij het ondergaan van de vele, vaak herhaalde en tijdrovende onderzoeken, waarbij geen beperking hun motivatie en moreel kon breken om dat af te maken waaraan ze hun medewerking hadden toegezegd. De meeste patiënten werden betrokken uit de afdeling Hemodialyse van het Akademisch Ziekenhuis Maastricht.

Dr. Th. van de Wiel (Maasland ziekenhuis, Sittard) en Dr. E. Zeppenfeldt (De Wever ziekenhuis, Heerlen) waren bereid mij hun patienten voor het onderzoek toe te vertrouwen. De onderzoeksplanning kon immer zeer vlot en in harmonie worden geregeld met de verpleegkundigen van de participerende dialysecentra, waarvoor ik hen dankbaar ben.

Joost van Esser en Willy van Kuijk, destijds nog co-assistenten, dank ik voor hun belangrijke diensten verleend bij het verzamelen van gegevens, vooral in die perioden waarin opleidingsverplichtingen en klinische werkzaamheden, voortvloeiende uit mijn funktioneren als arts-assistent, voortzetting van het onderzoek dreigden te belemmeren.

De organisatie met betrekking tot agendering van de diverse onderzoeken vereisten veel inventiviteit en flexibiliteit. De positieve motivatie en betrokkenheid van allen bleken echter de sleutel tot een soepele afstemming. Van de 
diensten van het Funktie-laboratorium Cardiologie heb ik dankbaar gebruik gemaakt voor de uitvoering van het echocardiografische onderzoek door de cardiologen E.C. Cheriex en F. Pieters. Emile en Frans, veel dank voor de toewijding en nauwgezetheid waarmee jullie de niet aflatende stroom van patiënten onderwierpen aan een kundig en kritisch echocardiografisch oordeel.

Renée Penders en Edith Ermers, beiden destijds werkzaam op het Chirurgisch Vaatlaboratorium, dank ik voor het vele verrichte werk bij het Duplex Doppler onderzoek van de dialyseshunt. De steun, die Dr. J.H.M. Tordoir, chirurg, gaf bij de interpretatie van deze gegevens, was onontbeerlijk.

De plasmavolumebepalingen vonden plaats in het Nucleair Geneeskundig Laboratorium (hoofd: Dr. G.A.K. Heidendal), waarbij inspuitingen van het radioaktief gelabeld albumine en de seriële samplings werden verricht door dhr. Willems, wiens nauwkeurigheid en systematiek in verslaglegging niets te wensen overlieten.

De medewerkers van het laboratorium Hematologie en Hemostase verwerkten de afgenomen bloedmonsters en verrichtten de bloedingstijdbepalingen. Samen met Dr. Karly Hamulyak kon ik de gegevens kritisch beschouwen en interpreteren, hetgeen leerzame momenten opleverde.

Desirée van Schoubroeck en Anke Hendriks-Wijnands dank ik voor hun grondige en vooral snelle sekretariële diensten. Ondanks vele "last minute" opdrachten werden deadlines nooit overschreden!

Naar de leden van de beoordelingscommissie, Prof.Dr. R.S. Reneman, Prof.Dr. P.J.E.H.M. Kitslaar en Dr. K. Hamulyak, gaat mijn dank uit voor de kritische beoordeling van dit proefschrift.

Auch Sie, Prof.Dr. K.M. Koch, danke ich herzlich und ich bin sehr verehrt mit Threm kritischen Urteil dieser Dissertation.

Prof.Dr. Q. Maggiore, I feel very honoured and grateful concerning your willingness to review my manuscript.

Mijn promotor, Prof.Dr. J.P. van Hooff, dank ik zeer voor zijn konstruktieve bijdrage aan de afronding van het proefschrift. Hans, je intelligente kritiek en vooral je redaktionele "no nonsense" aanpak zijn voor mij zeer leerzaam geweest.

Altijd "op scherp", energiek, gemotiveerd en inspirerend, maar bij tijd en wijle ook relativerend: zo heb ik mijn co-promotor, Dr. K.M.L. Leunissen, leren kennen. 
Een speciaal woord van dank gaat naar hem uit. Beste Karel, je tomeloze inzet en je immer opbouwende kritiek bij de voortgang van dit onderzoek heeft de totstandkoming van dit proefschrift grotendeels mogelijk gemaakt. Als inventief onderzoeker, als begeleider, maar ook als mens heb ik je altijd zeer gewaardeerd.

Dat mijn prioriteiten noodzakelijkerwijze wel eens anders gesteld werden als wenselijk in mijn gezin, heeft het voor Ria, Reinier en Fleur niet altijd gemakkelijk gemaakt. Ik ben ze dankbaar voor al het geduld en het vertrouwen, waardoor de gewenste ruimte kon worden gekreëerd. 



\section{CURRICULUM VITAE}

De auteur van dit proefschrift, J.J.J.M. Wirtz, werd geboren te Heerlen op 4 juni 1954. Hij behaalde het VWO (Atheneum-B) einddiploma in 1972 aan het Sint Bernardinus College te Heerlen en begon de opleiding tot ants aan de Katholieke Universiteit van Nijmegen in hetzelfde jaar. De officiële registratie als basisarts vond plaats in mei 1981. Tussentijds onderbrak hij zijn studie gedurende een jaar voor een oriëntatiereis annex wetenschappelijke stage in India, waar hij binnen diverse projekten werkzaam was en o.a. voedingsonderzoek verrichtte bij jonge kinderen in een kleine plattelandsgemeenschap.

Als onderdeel van zijn co-assistentschappen verbleef hij vijf maanden in Indonesiê en was als zodanig 0. a. werkzaam in het ziekenhuis "Gunung Maria" te Tomohon, Sulawesi ( $\mathrm{Z}$. dr. J. Barten, gynaecologe). Gedurende anderhalf jaar na de voltooing van zijn geneeskundige basisopleiding werkte hij als wisselassistent in het Sint Anna ziekenhuis te Oss, en nadien als assistent Interne Geneeskunde (hoofd Prof.dr. P.C. Stuiver) en assistent Cardiologie (hoofd Dr. F.J. ten Cate), niet in opleiding, in het Havenziekenhuis te Rotterdam.

Vanaf 1 april 1985 volgde hij de opleiding tot intemist: gedurende de eerste drie jaar in het Sint Elisabeth ziekenhuis te Tilburg (hoofd opleiding Dr. J.H.M. Lockefeer) en nadien in het akademisch ziekenhuis te Maastricht (hoofd Prof.dr. J.A. Flendrig).

Als intemist kon hij vervolgens op 1 april 1991 worden ingeschreven in het register van erkende medische specialisten van de KNMG.

Als uitvloeisel van het gekozen aandachtsgebied Nefrologie (opleider Prof,dr. J.P. van Hooff) verkreeg hij in december 1992 de officiële erkenning als intemist-nefroloog.

Sedert januari 1992 is hij werkzaam als intemist in het Sint Laurentius ziekenhuis te Roermond. 
